INSTITUTO DE PESQUISAS ENERGÉTICAS E NUCLEARES

Autarquia associada à Universidade de São Paulo

A INFLUÊNCIA DO FERRO E DO ÓXIDO DE CÉRIO SOBRE A CONDUTIVIDADE ELÉTRICA E A RESISTÊNCIA À CORROSÃO DO ALUMÍNIO ANODIZADO

KELLIE PROVAZI DE SOUZA

Tese apresentada como parte dos requisitos para a obtenção do Grau de Doutor em Ciências na Área de Tecnologia Nuclear - Materiais

Orientadora: Dra. Elisabete Jorge Pessine

SÃo PAULO

2006 
"Aos meus pais, Ademir e Marina, ao meu marido Anderson e ao meu filho Leonardo, minhas jóias". 


\section{AGRADECIMENTOS}

À Dra. Elisabete Jorge Pessine, minha gratidão pela orientação, discussões, ensinamentos durante a realização desse trabalho e amizade.

Ao Instituto de Pesquisas Energéticas e Nucleares, à Diretoria de Engenharia de Materiais pela oportunidade de realizar esta pesquisa.

Ao CNPq e a FAPESP pelo apoio financeiro recebido.

À banca examinadora, Dra. Margarita Ballestter, Dra. Susana I. C. Torresi, Dra. Neusa Alonso Falleiros, Dr. Augusto Câmara Neiva, e às suplentes Dra. Célia M. de Alvarenga Freire e Dra. Ivone Mulako Sato.

Ao amigo Engo. Water Kenji Yoshito pelas proveitosas discussões, ajuda e pelo árduo trabalho de revisão da tese e de outros trabalhos relacionados.

À amiga Dra. Chieko Yamagata pela atenção, amizade e colaboração.

Às Dra. Ivone M. Sato, Dra. Vera Lúcia Ribeiro Salvador, e à Shimadzu do Brasil, por disponibilizar o equipamento de Fluorescência de raios X e pela ajuda com as medidas.

À Dra. Isolda Costa por disponibilizar o aparelho para análises de Espectroscopia de Impedância Eletroquímica e à Enga. Marina Menucci pelo auxílio com as medidas.

Aos Dr. Manuel R. Silva e Dr. Demétrios A. Werner Soares, da Universidade Federal de Itajubá-MG, e ao Dr. Reginaldo Muccilo do IPEN, pelo auxílio com as medidas de Impedância Elétrica.

À Dra. Clarice T. Kuniosho da EPUSP pela inestimável ajuda na caracterização microestrutural por microscopia eletrônica de varredura de alta resolução.

Ao Dr. Valter Ussui, Mariano Castagnet e Eguiberto Galego pelo constante apoio e ensinamentos de informática e consultas técnicas.

Ao Dr. Hidetoshi Takeishi por disponibilizar o equipamento Isomet para o corte das amostras.

Ao Olandir V. Correia e à Judit Cândida da Silva pela colaboração dispensada.

Aos estagiários, Edson Pereira de Souza, Marcos Molizani, Juliana Fernandes e Gerônimo Rolandi pela ajuda com a preparação das amostras e análises.

Ao Celso Viera de Morais, ao Nildemar Aparecido M. Ferreira e ao René de Oliveira, pelo 
apoio na caracterização microestrutural por microscopia eletrônica de varredura.

À Msc. Raquel de Moraes Lobo, Dileusa A. S. Galissi e ao Glausson A. F. Machado pelo apoio na caracterização microestrutural com microscópio ótico com analisador de imagens.

Ao Laboratório de Fenômeno de Superfície da EPUSP pelo empréstimo do microdurômetro e ao Leandro Justino de Paula e Jovânio de Oliveira pela ajuda nas medidas.

Aos engenheiros e técnicos do IEO/IPEN, em especial ao Engo. José Carlos Sabino pelo corte das amostras de alumínio e atenção que sempre recebi.

Aos meus pais, Ademir e Marina, ao meu marido Anderson, ao meu filho Leonardo, aos meus sogros, Carlos e Nailsa e minhas cunhadas Márcia e Adriana, pela ajuda, compreensão, torcida e incentivo.

Em especial a Deus, que me deu saúde e forças para ir aprendendo a cada dia com as experiências e desafios.

A todos que direta ou indiretamente colaboraram para a execução deste trabalho.

Muito obrigada. 
"Seja Bendito o nome de Deus para todo o sempre, porque dele é a sabedoria e a força; Ele muda os tempos e as horas; Ele remove os reis e estabelece os reis; Ele dá sabedoria aos sábios e ciência aos entendidos."

Daniel 2: 21 e 22 


\title{
A INFLUÊNCIA DO FERRO E DO ÓXIDO DE CÉRIO SOBRE A CONDUTIVIDADE ELÉTRICA E A RESISTÊNCIA À CORROSÃO DO ALUMÍNIO ANODIZADO
}

\author{
Kellie Provazi de Souza
}

\section{RESUMO}

Investiga-se a influência de diferentes tratamentos sobre o sistema alumínio com cobertura de óxido de alumínio. A anodização do alumínio em meio de ácido sulfúrico e meio misto de sulfúrico e fosfórico foi empregada para alterar a resistência à corrosão, a espessura, o grau de cobertura e a microdureza do óxido anódico; e a eletrodeposição de ferro no interior óxido anódico em meio de sulfato com tratamento químico de selagem com cério, para alterar a sua condutividade elétrica e a sua resistência à corrosão.

Para a eletrodeposição de ferro aplicou-se corrente contínua e pulsada e diversificou-se a composição do eletrólito de $\mathrm{Fe}\left(\mathrm{SO}_{4}\right)_{2}\left(\mathrm{NH}_{4}\right)_{2} \cdot 6 \mathrm{H}_{2} \mathrm{O}$, com a adição dos ácidos bórico e ascórbico e para o tratamento de selagem, variou-se a concentração do $\mathrm{CeCl}_{3}$. A espectroscopia de energia dispersiva de raios $\mathrm{X}$ (EDS), a fluorescência de raios $\mathrm{X}$ (FRX) e a análise morfológica por microscopia eletrônica de varredura (MEV) permitiram verificar que, a corrente pulsada eleva o teor de ferro na camada anódica e a presença dos aditivos inibe a oxidação do ferro. As curvas cronopotenciométricas obtidas durante a eletrodeposição de ferro indicaram que a mistura dos ácidos bórico e ascórbico aumentaram a eficiência do processo de eletrodeposição. A espectroscopia de impedância eletroquímica (EIE), medidas de microdureza Vickers (Hv) e análise morfológica evidenciaram que o tratamento de selagem melhora a resistência à corrosão do filme óxido modificado com ferro. As medidas de impedância elétrica por duas pontas permitiram comprovar o aumento da condutividade elétrica do alumínio anodizado com ferro, mesmo após o tratamento com baixas concentrações de cério.

Nanofios de ferro foram preparados utilizando os poros do óxido anódico como matriz. 


\title{
THE IRON AND CERIUM OXIDE INFLUENCE ON THE ELECTRIC CONDUCTIVITY AND THE CORROSION RESISTANCE OF ANODIZED ALUMINUM
}

\author{
Kellie Provazi de Souza
}

\begin{abstract}
The influence of different treatments on the aluminum system covered with aluminum oxide is investigated. The aluminum anodization in sulphuric media and in mixed sulphuric and phosphoric media was used to alter the corrosion resistance, thickness, coverage degree and microhardness of the anodic oxide. Iron electrodeposition inside the anodic oxide was used to change its electric conductivity and corrosion resistance.

Direct and pulsed current were used for iron electrodeposition and the $\mathrm{Fe}\left(\mathrm{SO}_{4}\right)_{2}\left(\mathrm{NH}_{4}\right)_{2} \cdot 6 \mathrm{H}_{2} \mathrm{O}$ electrolyte composition was changed with the addition of boric and ascorbic acids. To the sealing treatment the $\mathrm{CeCl}_{3}$ composition was varied. The energy dispersive $\mathrm{x}$-ray (EDS), the $\mathrm{x}$-ray fluorescence spectroscopy (FRX) and the morphologic analysis by scanning electronic microscopy (SEM) allowed to verify that, the pulsed current increase the iron content inside the anodic layer and that the use of the additives inhibits the iron oxidation. The chronopotentiometric curves obtained during iron electrodeposition indicated that the boric and ascorbic acids mixture increased the electrodeposition process efficiency. The electrochemical impedance spectroscopy (EIE), the Vickers (Hv) microhardness measurements and morphologic analysis evidenced that the sealing treatment improves the corrosion resistance of the anodic film modified with iron. The electrical impedance (EI) technique allowed to prove the electric conductivity increase of the anodized aluminum with iron electrodeposited even after the cerium low concentration treatment.
\end{abstract}

Iron nanowires were prepared by using the anodic oxide pores as template. 


\section{SUMÁRIO}

\section{PÁGINA}

1 INTRODUÇÃO 10

2 OBJETIVOS 12

3 REVISÃO DA LITERATURA

$\begin{array}{lll}3.1 & \text { Anodização do alumínio } & 13\end{array}$

3.1.2 Teorias e modelos sobre a formação do óxido anódico sobre o alumínio 14

3.1.3 Influência de alguns parâmetros experimentais sobre a qualidade do filme anódico 20

$\begin{array}{lll}3.1 .3 \text { a A solução eletrolítica } & 20\end{array}$

3.1 .3 b Técnica aplicada: anodização pulsada $\quad 21$

3.2 Matriz de óxido anódico de alumínio 22

3.3 Camada de conversão de cério sobre o alumínio e sobre o alumínio anodizado 26

4 TÉCNICAS EMPREGADAS NA INCORPORAÇÃO METÁLICA NO FILME ANÓDICO 30

$5 \quad$ TÉCNICAS E CARACTERIZAÇÕES EMPREGADAS 32

5.1 Cronopotenciometria 32

5.2 Microscopia ótica com luz polarizada e analisador de imagens 33

5.3 Microscopia eletrônica de varredura 34

5.4 Espectroscopia de impedância eletroquímica 35

5.5 Medidas de impedância elétrica (método de duas pontas) 35

$\begin{array}{lll}5.6 & \text { Fluorescência de raios X } & 36\end{array}$

5.7 Medidas de microdureza 36

6 MATERIAIS E MÉTODOS 38

$\begin{array}{lll}6.1 & \text { Substrato } & 38\end{array}$

6.2 Anodização 38

6.3 Eletrodeposição de ferro 39

6.4 Preparação dos nanofilamentos de ferro 40

6.5 Tratamento químico com $\mathrm{CeCl}_{3} \quad 40$

6.6 Caracterização das amostras 41 
7.1 Influência das condições de anodização nas características do filme anódico

7.1.1 Influência do regime de aplicação de potencial na anodização em eletrólito $\mathrm{H}_{2} \mathrm{SO}_{4}$

7.1.2 Influência da duração da anodização em eletrólito $\mathrm{H}_{2} \mathrm{SO}_{4}$. 45

7.1.3 Influência da temperatura do eletrólito $\mathrm{H}_{2} \mathrm{SO}_{4}$ na camada anódica. 48

7.1.4 Influência da anodização por controle da corrente ou do potencial no filme de óxido anódico em $\mathrm{H}_{2} \mathrm{SO}_{4}$.

7.1.5 Influência da concentração do eletrólito usado na anodização 52

7.1.6 Influência da potencial pulsado na anodização 60

7.1.7 Influência da composição do eletrólito usado na anodização 65

7.2 Influência da anodização e da composição do eletrólito de anodização na $\begin{array}{ll}\text { resistência à corrosão do alumínio } & 67\end{array}$

7.3 Eletrodeposição de ferro no alumínio anodizado 69

7.3.1 Efeito da composição do eletrólito usado na eletrodeposição de ferro 73

7.3.2 Influência do regime de eletrodeposição (por $\mathrm{CC}$ e $\mathrm{CP}$ ) no teor de ferro da $\begin{array}{ll}\text { camada anódica } & 78\end{array}$

$7.4 \quad$ Preparação dos nanofios de ferro $\quad 81$

7.5 Influência da eletrodeposição de ferro na resistência à corrosão do alumínio $\begin{array}{ll}\text { anodizado } & 83\end{array}$

7.6 Influência do tratamento químico com $\mathrm{CeCl}_{3}$

7.6.1 Influência do tratamento com $\mathrm{CeCl}_{3}$ no alumínio anodizado com ferro quanto à espessura e a microdureza do óxido anódico $\quad 85$

7.6.2 Influência do tratamento com $\mathrm{CeCl}_{3}$ no alumínio anodizado com ferro $\begin{array}{ll}\text { eletrodepositado sobre a resistência à corrosão } & 87\end{array}$

7.6.3 Influência da eletrodeposição de ferro e do tratamento com cério nas $\begin{array}{ll}\text { propriedades elétricas do alumínio anodizado } & 88\end{array}$

8 CONCLUSÕES $\quad 93$

9 SUGESTÕES PARA TRABALHOS FUTUROS 


\section{INTRODUÇÃO}

O alumínio possui diversas vantagens em relação aos demais metais: é mais leve, dúctil e trabalhável, além de ser bom condutor de calor e eletricidade. Com facilidade pode-se laminá-lo, dando-lhe a forma de folhas, ampliando sua utilização, porém esta operação diminui consideravelmente sua resistência à corrosão, à abrasão e também sua dureza. Apesar de sua aparente estabilidade, quando em contato com diversos ambientes agressivos, o alumínio é um metal reativo.

O alumínio é um metal que possui maior resistência à corrosão que a maioria dos metais, essa propriedade é proporcionada por uma fina camada de óxido, formada sobre sua superfície, pela ação do oxigênio do meio ambiente. No entanto, este óxido conhecido como camada de barreira, que possui cerca de $3 \mathrm{~nm}$ de espessura, não proporciona a devida proteção contra os agentes agressivos do meio ambiente, ocasionando, com o passar do tempo, o afinamento da superfície metálica.

É possível alterar, por exemplo, a espessura desta camada natural de óxido, e o processo de anodização do alumínio tem sido bastante estudado com foco nesta mudança [1-4], principalmente pela proteção que este tratamento pode proporcionar ao metal. Sabe-se que o óxido de alumínio formado através do processo de anodização possui propriedades de dureza e resistência à corrosão e à abrasão melhores que a do próprio alumínio, e por esta razão, este processo é muito empregado nas indústrias que fabricam peças de alumínio para equipamentos e outros objetos.

A anodização do alumínio em essência é um processo eletroquímico que visa o aumento da espessura da camada de $\mathrm{Al}_{2} \mathrm{O}_{3}$ que já existe sobre sua superfície. A camada se torna bem mais espessa, atingindo valores de 5 a $100 \mu \mathrm{m}$, dependendo das condições experimentais empregadas durante a anodização. O filme de óxido anódico, assim preparado possui em geral microdureza entre 300 e $500 \mathrm{Hv}$, ele aumenta a proteção do alumínio, pois contribui para a melhora da sua resistência à corrosão e da sua abrasão. Dependendo das condições de anodização é possível formar filmes mais ou menos porosos, como resultado da diminuição da quantidade de poros presentes na camada de óxido anódico, há maior proteção ao ataque químico causado pelo eletrólito ao substrato.

O óxido anódico apresenta resistência à passagem da corrente elétrica, fazendo com que após a anodização, haja um aumento da resistividade elétrica do alumínio, que alcança valores elevados e crescentes com o aumento da espessura do óxido anódico. Entretanto, este comportamento do filme 
anódico pode ser alterado através da incorporação de distintos materiais no interior dos seus poros, que por sua vez podem ser modificados adequadamente para atender a estes propósitos.

Neste trabalho estudamos o efeito da incorporação de ferro na condutividade elétrica do alumínio anodizado preparado em meio de ácido sulfúrico e em meio misto de sulfúrico e fosfórico. O ferro foi escolhido por ser um metal encontrado em grande abundância na natureza, o que o barateia e também por possuir condutividade elétrica elevada $\left(9,9310^{6} \mathrm{~S} / \mathrm{cm}\right)$. Além disso, a possibilidade de fabricação de nanofios de ferro utilizando o óxido anódico poroso como matriz [5], permitirá utilizar os nanofios na confecção de nanochips e de até nanomáquinas.

Entretanto, como o ferro se oxida com facilidade, foi investigado um tratamento químico simples com $\mathrm{CeCl}_{3}$ (selagem), para melhorar a resistência à corrosão do sistema alumínio anodizado após a implantação de ferro.

Apesar da selagem com cromato ter sido usada como um método padrão de proteção contra a corrosão do alumínio anodizado por muito tempo, os cromatos são altamente tóxicos e carcinogênicos e isso conduziu à pesquisa no desenvolvimento de métodos alternativos e eficazes [6] que os substituísse.

Reconhece-se como uma alternativa atrativa aos revestimentos de conversão do cromato para as proteções de ligas de alumínio, o emprego de compostos do cério que não são tóxicos e são relativamente baratos. Diversos procedimentos experimentais já foram ensaiados, visando formar um filme rico em cério sobre as distintas ligas de alumínio; entretanto, nestes processos, quase todos os revestimentos de conversão do cério eram depositados diretamente na matriz das ligas de alumínio e pouca atenção foi dada a sua aplicação em ligas de alumínio anodizadas. Isto porque a anodização já representa uma das técnicas mais extensamente usadas para a proteção contra a corrosão de ligas de alumínio. É de interesse, explorar a possibilidade de formar, em um banho de cloreto, uma camada de conversão de cério no filme poroso do alumínio anodizado. 


\section{OBJETIVOS}

Os objetivos desse estudo são investigar a mudança na condutividade elétrica do alumínio anodizado após a eletrodeposição de ferro, a preparação dos nanofios de ferro usando o óxido anódico poroso como matriz, e a influência do tratamento com cloreto de cério na resistência à corrosão do alumínio anodizado modificado com o ferro. 


\subsection{Anodização do alumínio}

O processo de anodização é constituído por três etapas, cada uma delas exercendo um impacto nas propriedades da superfície [7]. Essas três etapas são:

1. Pré-tratamento da superfície do alumínio, nesta etapa o alumínio é polido e decapado;

2. O processo de anodização num eletrólito sob parâmetros controlados e;

3. A etapa de acabamento que pode ser a selagem ou a incorporação de materiais ou compostos químicos para alterar as propriedades do filme óxido: condutividade $(\mathrm{Fe}, \mathrm{C}$, etc.), resistência à corrosão (óxidos de terras-raras), resistência à abrasão $(\mathrm{Pb})$, ou simplesmente para coloração (polímeros).

A reação global de anodização é mostrada da seguinte forma simplificada:

$$
2 \mathrm{Al}^{3+}+3 \mathrm{R}^{2-}+3 \mathrm{H}_{2} \mathrm{O} \Leftrightarrow \mathrm{Al}_{2} \mathrm{O}_{3}+3 \mathrm{H}_{2} \mathrm{R}
$$

onde $\mathrm{R}^{2-}$ é um ânion bivalente proveniente do eletrólito, por exemplo $\mathrm{SO}_{4}{ }^{2-}$, quando o eletrólito usado for $\mathrm{o}_{2} \mathrm{SO}_{4}$.

Principais reações do processo:

No ânodo:

$$
\begin{array}{cl}
\text { Reação eletroquímica: } & \mathrm{Al}_{(\mathrm{s})}^{0}+3 \mathrm{e}^{-} \Leftrightarrow \mathrm{Al}^{3+}{ }_{(\mathrm{aq})} \\
\text { Reação química: } & \mathrm{Al}^{3+}{ }_{(\mathrm{aq})}+\mathrm{O}^{2-}{ }_{(\mathrm{aq})} \Leftrightarrow \mathrm{Al}_{2} \mathrm{O}_{3(\mathrm{~s})}
\end{array}
$$

No cátodo:

$$
\text { Reação eletroquímica: } \quad 2 \mathrm{H}^{+}{ }_{(\mathrm{aq})}+2 \mathrm{e}^{-} \Leftrightarrow \mathrm{H}_{2(\mathrm{~g})}
$$


A camada de óxido formada pelo processo de anodização pode ser chamada de camada anódica, filme anódico, óxido anódico, filme de óxido, etc. Por questão de padronização nesse trabalho chamaremos de óxido anódico, ou simplesmente filme.

Para que haja a formação do óxido anódico poroso, é necessário que haja a migração por um processo de condução iônica dos íons $\mathrm{Al}^{3+} \mathrm{e}^{2-}$ através da camada de barreira. Esse processo vem sendo estudado ao longo dos tempos, por vários autores com um mecanismo não conclusivo.

Para Palibroda et. al, em publicação da última década [8,9], a camada de barreira se comporta durante o processo anódico, não como um condutor iônico, mas atuando como um semicondutor do tipo n, e o crescimento do óxido poroso de alumínio ocorre de forma descontínua, sob uma sucessão de etapas do tipo:

Etapa 1: Há a transformação da camada de barreira em um filme óxido poroso, devido a formação de lacunas na própria camada de barreira e sob a ação do campo elétrico (etapa determinante), isso ocorrendo ao mesmo tempo que a ionização do alumínio (etapa 2);

Etapa 2: Reação de ionização do alumínio;

$$
\mathrm{Al} \Leftrightarrow \mathrm{Al}^{3+}+3 \mathrm{e}^{-}
$$

Etapa 3: A formação de uma nova camada de barreira na interface alumínio/óxido poroso, que ocorre por uma reação entre os íons alumínio que estão migrando, em sentido oposto aos íons oxigênio provenientes do eletrólito.

A hipótese de que a camada de barreira se comporta como um semicondutor durante o crescimento do óxido poroso está de acordo com as etapas mencionadas.

\subsubsection{Teorias e modelos sobre a formação do óxido anódico sobre o alumínio}

Como, ao longo dos anos, vários autores vêm tentando explicar o mecanismo do processo de anodização do alumínio, isso permite ordenar as teorias associadas a ele em três grupos distintos, eles serão resumidos a seguir.

O primeiro grupo de teorias tem somente valor histórico dentro do panorama científico. Nestas teorias considera-se que o óxido anódico de alumínio se forma em duas etapas, uma eletroquímica, onde há a saída dos íons $\mathrm{Al}^{3+}$ da estrutura cristalina do metal e da etapa química de formação do óxido, nelas é considerado que o óxido anódico possui uma única fase, e que este seria continuamente produzido na superfície do eletrodo. A porosidade desta camada seria resultado da 
ação de dissolução do filme causada pelo eletrólito. Neste grupo podem ser classificadas as teorias de Setoh e Mitaya, Rummel et al., Güntherschulze et al., Mott e Schenk apud Wernick [10-16], etc.

Defensores do segundo grupo de teorias já levam em consideração que o óxido anódico possui mais de uma fase. Akimov et al. apud Wernick [17] são da opinião que o filme anódico pode ser grosseiramente dividido em duas camadas de óxido de alumínio: uma fina, compacta, aderente ao metal e levemente hidratada, e outra mais espessa fortemente hidratada. O modelo proposto para o crescimento dos filmes anódicos dessa fina camada ocorre de acordo com as equações 6 e 7:

$$
\begin{array}{lr}
\text { Etapa eletroquímica: } & \mathrm{Al}^{0}{ }_{(\mathrm{s})} \Leftrightarrow \mathrm{Al}^{3+}{ }_{(\mathrm{aq})}+3 \mathrm{e}^{-} \\
\text {Etapa química: } & 2 \mathrm{Al}^{3+}{ }_{(\mathrm{aq})}+3 \mathrm{O}^{2-}{ }_{\text {aq }} \Leftrightarrow \mathrm{Al}_{2} \mathrm{O}_{3(\mathrm{~s})}
\end{array}
$$

Além de assumirem a possibilidade dos íons $\mathrm{Al}^{3+}{ }_{(\mathrm{aq})} \mathrm{e}^{2-}{ }_{(\mathrm{aq})}$ difundirem através da camada, sendo que $\mathrm{o}^{\mathrm{Al}^{3+}}$ (aq) difunde a partir da região da camada próxima ao metal até a região mais externa, e o $\mathrm{O}_{(\text {aq) }}^{2-}$ na direção oposta. Este processo induz a formação de uma nova camada de $\mathrm{Al}_{2} \mathrm{O}_{3(\mathrm{~s})}$ sob o filme. $\mathrm{O}$ processo de interação entre o eletrólito, nesse caso o ácido sulfúrico, e o filme ocorre na superfície da camada, causando a dissolução parcial do $\mathrm{Al}_{2} \mathrm{O}_{3(\mathrm{~s})}$, através da reação 8:

$$
\mathrm{Al}_{2} \mathrm{O}_{3(\mathrm{~s})}+3 \mathrm{H}_{2} \mathrm{SO}_{4(\mathrm{aq})} \Leftrightarrow \mathrm{Al}_{2}\left(\mathrm{SO}_{4}\right)_{3(\mathrm{aq})}+3 \mathrm{H}_{2} \mathrm{O}_{(\mathrm{l})}
$$

Assim, o fino filme de óxido é transformado em um filme espesso e poroso devido à ação de dissolução causada pelo eletrólito, que facilita a penetração dos íons $\mathrm{Al}^{3+}{ }_{(\mathrm{aq})} \mathrm{e} \mathrm{O}^{2-}{ }_{\text {aq }} \mathrm{e}$, portanto, a formação de mais $\mathrm{Al}_{2} \mathrm{O}_{3 \text { (s) }}$ poroso, além do que, um novo filme compacto mais interno e próximo ao metal é simultaneamente produzido com uma espessura constante $(0,01-0,1 \mu \mathrm{m})$. Os poros são de formato cônico com a ponta direcionada para a superfície do metal, com as paredes mais hidratadas que o restante do filme.

Um pouco mais tarde, outros autores [18,19] apresentaram modelo similar ao de Akimov et al. apud Wernick [17] para estabelecer como ocorre a formação de um filme anódico poroso.

As opiniões dos autores que defendem o segundo grupo auxiliaram na resolução de vários problemas práticos importantes, como o desenvolvimento de métodos para obter filmes de óxidos 
anódico mais porosos ou acelerar o processo eletroquímico, não se detendo em estabelecer todos os fenômenos envolvidos na oxidação anódica.

No terceiro grupo, fazem parte as teorias que incluem opiniões alicerçadas nos resultados de análises como microscopia eletrônica, com a observação de átomos, e outras análises. Neste grupo [20,21], é considerado que a formação do filme também ocorre em diversas etapas; e que há dependência tanto da sua composição como também da sua estrutura celular, além de existir uma forte correlação entre as estruturas do filme e do substrato metálico. Para este grupo, também se considera no modelamento do mecanismo de formação do filme, a sua natureza coloidal.

Assim, para Müller [20] o crescimento do óxido anódico na superfície do alumínio é devido à presença de precipitados cristalizados, provenientes da solução supersaturada que se forma no interior dos poros da camada anódica. A presença desses precipitados cristalizados causaria uma diminuição na densidade de corrente. Esses precipitados de hidróxido de alumínio, na forma de um gel, formariam então uma camada aderente ao ânodo.

Para Samartisev, citado por Kawai e Ueda [21], há a hidrólise do sulfato de alumínio no óxido anódico formado em ácido sulfúrico, e a subseqüente precipitação do hidróxido de alumínio coloidal, formando uma camada uniforme na superfície do ânodo. A camada vai sofrendo desidratação, pois a temperatura se eleva localmente em decorrência da natureza exotérmica da reação de formação do óxido $\left(2 \mathrm{Al}^{3+}{ }_{(\text {aq })}+3 \mathrm{O}_{(\text {aq })}^{2-} \rightarrow \mathrm{Al}_{2} \mathrm{O}_{3(\mathrm{~s})}+\right.$ energia $)$, dando lugar ao espessamento de uma camada porosa. O processo se repete, pois o eletrólito nos poros é continuamente transferido.

Krotov apud Wernick [22] fez análises químicas e termogravimétricas dos filmes anódicos preparados em meio de ácido sulfúrico, e encontraram que eles consistem de uma mistura de $\mathrm{Al}(\mathrm{OH})_{3}$ e $\mathrm{AlOOH}$, e que este último, seria o responsável pelas partículas coloidais que se formam durante o crescimento do filme.

Shreider apud Wernick [23] propõe um modelo no qual o processo de formação da camada de óxido sobre o alumínio ocorre em estágios que estão esquematizados na TAB. 1: 
TABELA 1: Modelo proposto por Shreider (1960) [23] para o processo de oxidação do alumínio em meio de $\mathrm{H}_{2} \mathrm{SO}_{4}$.

\begin{tabular}{|c|c|c|c|c|}
\hline \multirow[t]{2}{*}{. $\mathrm{N}^{\mathrm{O}}$} & \multirow{2}{*}{$\begin{array}{c}\text { Estágios } \\
\text { Sítios }\end{array}$} & \multicolumn{3}{|r|}{ Reações } \\
\hline & & $\mathrm{N}^{\mathrm{O}}$ & Natureza & Equação \\
\hline \multirow[t]{2}{*}{ I } & \multirow{2}{*}{$\begin{array}{l}\text { Superfície } \\
\text { metálica }\end{array}$} & 1 & $\begin{array}{l}\text { Ionização e saída/difusão } \\
\text { dos íons de alumínio da } \\
\text { estrutura cristalina }\end{array}$ & $\mathrm{Al} \rightarrow \mathrm{Al}^{3+}+3 \mathrm{e}^{-}$ \\
\hline & & 2 & $\begin{array}{l}\text { Formação de hidrogênio } \\
\text { junto com a dissolução } \\
\text { do alumínio através dos } \\
\text { sítios livres da camada } \\
\text { de barreira }\end{array}$ & $2 \mathrm{Al}+3 \mathrm{H}_{2} \mathrm{SO}_{4} \rightarrow \mathrm{Al}_{2}\left(\mathrm{SO}_{4}\right)_{3}+3 \mathrm{H}_{2}$ \\
\hline II & $\begin{array}{l}\text { Interior da } \\
\text { camada de } \\
\text { barreira }\end{array}$ & 1 & $\begin{array}{l}\text { Migração dos íons } \mathrm{Al}^{3+} \mathrm{e} \\
\mathrm{O}^{2-} \text { em direções opostas } \\
\text { através da camada }\end{array}$ & \\
\hline III & $\begin{array}{l}\text { Interior da } \\
\text { camada de } \\
\text { barreira } \\
\text { próximo à } \\
\text { superfície } \\
\text { externa }\end{array}$ & 1 & $\begin{array}{l}\text { Formação do óxido } \\
\text { primário }\end{array}$ & $2 \mathrm{Al}^{3+}+3 \mathrm{O}^{2-} \rightarrow \mathrm{Al}_{2} \mathrm{O}_{3}$ \\
\hline \multirow[t]{2}{*}{ IV } & \multirow{2}{*}{$\begin{array}{c}\text { Porção } \\
\text { externa da } \\
\text { camada } \\
\text { de barreira } \\
\text { (término dos } \\
\text { poros). }\end{array}$} & 1 & $\begin{array}{l}\text { Dissolução do óxido } \\
\text { produzido }\end{array}$ & $\mathrm{Al}_{2} \mathrm{O}_{3}+3 \mathrm{H}_{2} \mathrm{SO}_{4} \rightarrow \mathrm{Al}_{2}\left(\mathrm{SO}_{4}\right)_{3}+\mathrm{H}_{2} \mathrm{O}$ \\
\hline & & 2 & $\begin{array}{l}\text { Decomposição dos } \\
\text { grupos } \mathrm{OH}^{-}\end{array}$ & $6 \mathrm{OH}^{-} \rightarrow 3 \mathrm{O}^{2-}+3 \mathrm{H}_{2} \mathrm{O}$ \\
\hline \multirow[t]{4}{*}{ V } & \multirow[t]{3}{*}{$\begin{array}{l}\text { Na parede dos } \\
\text { poros }\end{array}$} & 1 & $\begin{array}{l}\text { Hidratação do óxido } \\
\text { primário para formar a } \\
\text { boemita }\end{array}$ & $\mathrm{Al}_{2} \mathrm{O}_{3}+\mathrm{H}_{2} \mathrm{O} \rightarrow \mathrm{Al}_{2} \mathrm{O}_{3} \cdot \mathrm{H}_{2} \mathrm{O}$ \\
\hline & & 2 & $\begin{array}{l}\text { Hidratação do óxido } \\
\text { primário para formar a } \\
\text { hidralgilita }\end{array}$ & $\mathrm{Al}_{2} \mathrm{O}_{3}+3 \mathrm{H}_{2} \mathrm{O} \rightarrow \mathrm{Al}_{2} \mathrm{O}_{3} \cdot 3 \mathrm{H}_{2} \mathrm{O}$ \\
\hline & & 3 & $\begin{array}{l}\text { Dissolução dos óxidos } \\
\text { hidratados }\end{array}$ & $\begin{aligned} \mathrm{Al}_{2} \mathrm{O}_{3} \cdot \mathrm{nH}_{2} \mathrm{O} & +3 \mathrm{H}_{2} \mathrm{SO}_{4} \rightarrow \mathrm{Al}_{2}\left(\mathrm{SO}_{4}\right)_{3} \\
& +(\mathrm{n}+3) \mathrm{H}_{2} \mathrm{O}\end{aligned}$ \\
\hline & & 4 & $\begin{array}{l}\text { Adsorção dos ânions do } \\
\text { eletrólito e suas } \\
\text { conversões }\end{array}$ & \\
\hline \multirow[t]{2}{*}{ VI } & $\begin{array}{l}\text { Canais dos } \\
\text { poros }\end{array}$ & 1 & $\begin{array}{l}\text { Difusão e migração dos } \\
\text { reagentes }\end{array}$ & \\
\hline & & 2 & $\begin{array}{l}\text { Remoção dos gases e } \\
\text { produtos das reações } \\
\text { IV } 1,2 \text { e V } 3\end{array}$ & \\
\hline
\end{tabular}


De acordo com a TAB. 1, no processo de anodização, a camada de barreira é a primeira que se forma e a sua espessura aumenta com a tensão aplicada e diminui com o aumento da capacidade de dissolução que o eletrólito possui de causar ao substrato. A camada de barreira não é porosa, mas pode conduzir íons de alumínio do retículo cristalino para o banho, através dos sítios não regulares (lacunas) que expõem o substrato. A parte externa da camada, ao contrário, é microporosa devido à ação contínua de sua dissolução causada pelo eletrólito, entre outros parâmetros do processo. Além disso, esta estrutura permite uma condução elétrica restrita que está associada intimamente com a espessura desta camada de óxido. A resistência específica da camada isolante é da ordem de $10^{11}$ $\mathrm{S} / \mathrm{cm}$, e da camada condutora de $10^{7} \mathrm{~S} / \mathrm{cm}$ afetando sensivelmente a corrente elétrica que fluiu no sistema.

No modelo de Murphy e Michelson apud Wernick [24], os íons alumínio $\mathrm{Al}^{3+}$ e hidrogênio $\mathrm{H}^{+}$ difundem através da camada de barreira em direção ao eletrólito, enquanto que os íons $\mathrm{OH}^{-}, \mathrm{O}^{2-}$ e $\mathrm{SO}_{4}{ }^{2-}$ e água difundem na direção oposta. Isso estaria acontecendo na interface camada de barreira / camada porosa e resultaria na variação da espessura das camadas. Os poros seriam formados devido ao alto calor formado no local (gerado pela reação de formação do óxido que é exotérmica) e à dissolução do óxido pela ação do eletrólito sobre o mesmo.

Anteriormente aos modelos aqui apresentados, micrografias eletrônicas [25] permitiram verificar a existência de uma estrutura celular seqüencial dos filmes porosos, desenvolvida também a partir da ação conjunta da dissolução causada pelo eletrólito e da temperatura envolvida, esse modelo foi esquematizado como mostrado na FIG.1.

Assim, a dissolução do óxido de barreira, resultado da ação da temperatura e do eletrólito, seria a responsável pela formação dos poros. Como a corrente de íons flui através de um poro individual, a célula cilíndrica inicialmente cresce na direção do campo elétrico aplicado. Cada célula em particular faz uma junção linear com os outros seis cilindros em sua vizinhança e finalmente assume a forma de uma célula hexagonal. Ao mesmo tempo, os poros possuem a forma de estrela com seis pontas, onde cada ponta da estrela aponta para o vértice do hexágono (FIG. 1).

No estágio inicial da formação do filme anódico, a intensidade da corrente elétrica cai para um valor mínimo devido a formação da camada isolante densa (camada de barreira), após 4-5 segundos ela aumenta, há a formação dos poros e finalmente, após cerca de 15 segundos, a corrente começa a diminuir com o aumento da espessura da camada anódica. 


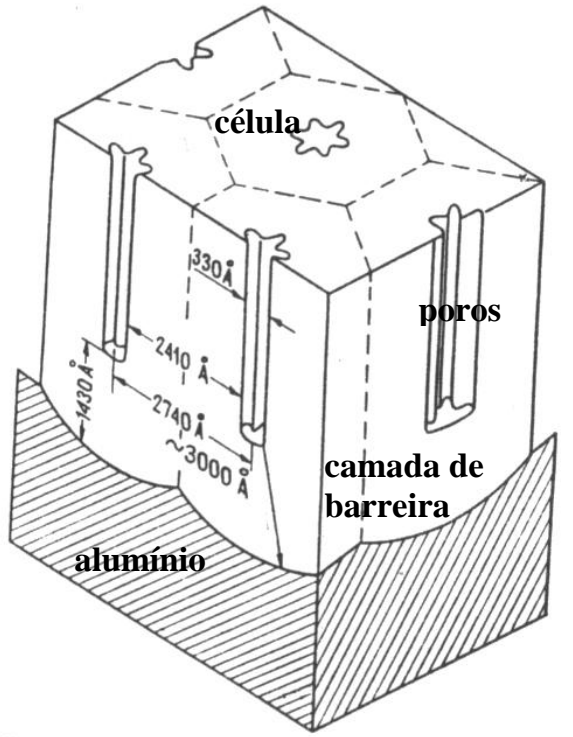

FIGURA 1: Esquema proposto [25] para a estrutura celular hexagonal do filme de óxido anódico de alumínio, com o formato e dimensões da célula e dos poros.

Os autores avaliaram as dimensões da célula do óxido com base nas medidas de porosidade e da tensão aplicada, estimando que o diâmetro dos poros seja constante, e vale aproximadamente $33 \mathrm{~nm}$. Hoje sabe-se que o diâmetro dos poros podem variam significativamente dependendo das condições de anodização (de 30 a $100 \mathrm{~nm}$ aproximadamente).

A composição das células não é uniforme; elas são compostas de variedades do $\mathrm{Al}_{2} \mathrm{O}_{3}$ quimicamente distintas: bayerita e boemita. Quando o eletrólito penetra através desses poros até o fundo deles, na fronteira com o substrato, há além da etapa eletroquímica, a hidratação do óxido das paredes externas permitindo a formação de alguma quantidade de boemita $\left(\gamma-\mathrm{Al}_{2} \mathrm{O}_{3} \cdot 3 \mathrm{H}_{2} \mathrm{O}\right)$ que é mais resistente à ação do meio ambiente. A intensidade da hidratação é maior no topo do poro do que no fundo. A camada de barreira pode conter mais de $2 \%$ de água. Juntamente com a hidratação, acontece a absorção de íons do eletrólito.

Enfim, os poros do filme anódico podem absorver grandes quantidades de eletrólito. A quantidade absorvida depende não somente da natureza do eletrólito, mas também dos parâmetros básicos da formação do filme como temperatura, tempo de anodização, composição e concentração da solução, e também da densidade de corrente.

A composição da liga também influencia não só as características do filme, como também o processo de anodização. Nas ligas Al 2024-T3, por exemplo, utilizadas na aeronáutica por causa das suas boas propriedades mecânicas; a presença do cobre como elemento de liga afeta tanto a sua resistência à corrosão como também a etapa de anodização, pois o desprendimento do oxigênio ocorre mais provavelmente em sítios contendo os intermetálicos de cobre presentes na liga que não 
foram anodizados, ou os que sofreram anodização parcial [1] comprometendo a uniformidade do filme anódico.

\subsubsection{Influência de alguns parâmetros experimentais sobre a qualidade do filme anódico}

\subsection{3 a A solução eletrolítica}

Vários trabalhos já foram publicados com o intuito de associar a composição dos filmes de óxido anódico com a natureza do eletrólito empregado na anodização do alumínio; uma vez que processo pode ser realizado tanto em meio ácido [26], como no neutro [27] e também no alcalino [28], devido ao caráter anfótero do alumínio.

O primeiro processo de anodização patenteado na Inglaterra em 1927, e também desenvolvido nos Estados Unidos, utilizou ácido sulfúrico como eletrólito. Desde então, muitas variações deste processo foram desenvolvidas e aplicadas no mundo inteiro.

Na revisão de Stevenson apud Wernick [29], foi comparada a influência de diferentes composições de eletrólito ácido sobre a dureza, espessura, resistência química, resistência à abrasão e à corrosão do óxido de alumínio formado por anodização. Os filmes de $\mathrm{Al}_{2} \mathrm{O}_{3}$ formados em ácido sulfúrico apresentam melhor resistência à corrosão que os filmes preparados em ácido crômico ou ácido oxálico, porém filmes crescidos em ácido crômico apresentam melhor resistência química que os demais estudados, além de serem mais duros e possuírem melhor resistência à abrasão que os filmes preparados com o ácido sulfúrico ou com o ácido oxálico. Quanto à espessura, os filmes mais espessos foram os obtidos em ácido oxálico (até $60 \mu \mathrm{m}$ ), seguido dos filmes obtidos em ácido sulfúrico (até $30 \mu \mathrm{m}$ ) e os filmes que apresentaram espessuras menores foram os crescidos em ácido crômico (até $7 \mu \mathrm{m}$ ), para que fosse possível esse tipo de comparação, as demais condições experimentais foram iguais nos três casos. A partir desses resultados, foi possível inferir que um dos fatores que influenciaram a variação dessas características do óxido anódico, foi a condutividade iônica de cada um dos eletrólitos.

De acordo com as propriedades desejadas do filme, em meio de ácido sulfúrico, costuma-se variar a concentração do ácido desde ao redor de $10 \%$ até $25 \%$, e isso é associado com o controle de outras condições experimentais como pré e pós-tratamento, temperatura do banho, aditivos incorporados ao eletrólito, etc. 
A contaminação do filme anódico está intimamente associada com o eletrólito de trabalho. $\mathrm{O}$ estudo do efeito do eletrólito de trabalho na composição do óxido anódico foi feito por autores desde Bengough e Sutton até Pullen apud Wernick [30,31], usando métodos distintos de medida, para os últimos radioativos, para estimar o teor de sulfato no filme. Eles detectaram que durante os primeiros segundos iniciais de anodização, aproximadamente $15 \%$ deste ânion já se incorpora no filme, e que na anodização com ácido crômico, este valor vai a 1,5\%. Anos mais tarde Raub et al. apud Wernick [32], aplicaram as mesmas técnicas radioativas no estudo detalhado da incorporação de sulfato nos revestimentos preparados em eletrólitos com um teor muito baixo de sulfato, como o ácido sulfosalicílico ou o maleico. Eles determinaram que, embora nesses eletrólitos a concentração de sulfato se situava entre 0,35 e $0,50 \%$, este era essencial para o processo e que o revestimento anódico retinha de 5 a $10 \%$ do íon sulfato.

A anodização com o ácido fosfórico, ao contrário da anodização em ácido sulfúrico, fornece filmes óxidos mais porosos [33], possibilitando a incorporação de novos materiais nos poros, tanto por deposição química [34], como eletroquímica [35].

Em soluções alcalinas, a anodização do alumínio fornece filmes óxidos em geral porosos. Existem poucos trabalhos que tem estudado eletrólitos com altos valores de $\mathrm{pH}$ na formação de filmes de óxidos porosos, devido à natureza agressiva do banho. Bogoyavlensy [36] preparou filmes anódicos em 15\% de carbonato de sódio usando corrente contínua e corrente pulsada, e verificou que os filmes formados com controle da tensão em torno de 100 volts, apesar de espessos, apresentaram propriedades protetoras inferiores aos filmes formados em ácido sulfúrico sob a mesma condição.

Neufeld e Ali [37] preparam filmes de óxidos anódicos porosos em eletrólito com pH 9-11 em liga de alumínio com $99,5 \%$ de $\mathrm{Al}$, sob temperatura elevada $\left(60-80^{\circ} \mathrm{C}\right)$, e a resistência à corrosão e à abrasão não foi mais significativa que a estabelecida quando o eletrólito empregado na anodização foi o $\mathrm{H}_{2} \mathrm{SO}_{4}$.

Novas aplicações do alumínio anodizado foram sendo estabelecidas quando preparado com filmes de óxidos porosos, pois esses permitem tratamentos posteriores, que modificam suas características [34, 35, 38, 39]. 


\subsection{3 b Técnica aplicada: anodização pulsada}

Algumas características da anodização de ligas de alumínio realizada com anodização pulsada, em relação às anodizações por corrente contínua são: economia de reagentes; diminuição do impacto ambiental em relação à produção de rejeitos; economia no tempo de processo de 20 a 25\% [40-42]; possibilidade de anodizar ligas de alumínio com elevado teor de $\mathrm{Si}$, facilidade de anodizar peças com geometria complexa; possibilidade de trabalhar com peças de grande porte, etc. Quanto ao filme de óxido anódico, há melhora tanto na sua aderência ao substrato, mesmo quando são produzidos com maiores espessuras [43], como também na sua resistência à corrosão e à abrasão, pois o óxido é mais uniforme e menos poroso.

A corrente pulsada quando comparada à corrente contínua na anodização em ácido sulfúrico, sob as mesmas condições experimentais, resulta na formação de um filme de óxido com maior dureza e espessura [43]. Isto é possível porque os parâmetros da técnica são adequadamente manipulados (ciclo de trabalho-DC e duração e/ou intervalo dos pulsos). Assim, quando o ciclo de trabalho ou DC é baixo (o tempo do pulso “off” é longo e o tempo do pulso “on" é curto), é possível a aplicação de altas correntes na anodização com curta duração, o que permite que o calor gerado na interface óxido/solução seja dissipado na solução durante o longo tempo “off”. É a produção de calor da reação de formação do filme óxido, que conduz à formação de um filme poroso e que sob circunstâncias extremas leva à sua queima e dissolução [40].

A uma baixa temperatura de anodização e alta densidade de corrente, o processo pode fornecer um filme duro e compacto, mas, devido à queima do óxido causada pela alta densidade de corrente, a formação de um revestimento espesso fica difícil de ser conseguida em condições de anodização sob corrente contínua. A queima pode ser evitada usando-se temperatura e densidade de corrente relativamente baixas, contudo, estas condições tendem a causar porosidade e impedir a formação de um filme compacto e espesso [44]. Além disso, sabe-se que na anodização a corrente de trabalho total não pode ser inicialmente aplicada, sendo necessário um aumento gradual da mesma, para que as reações eletroquímicas e químicas aconteçam satisfatoriamente. Contudo, quando se utilizam retificadores de corrente pulsados, este aumento pode ser mais rápido, permitindo uma economia de tempo, um aumento de produtividade [42] e principalmente a obtenção de filmes anódicos mais duros sobre ligas de alumínio com cobre ou silício. 


\subsection{Matriz de óxido anódico de alumínio}

Um conjunto de poros com escala nanométrica, presentes no óxido anódico preparado sob determinadas condições de anodização do alumínio, se transforma numa matriz adequada para a fabricação de nanofios metálicos. Nessa técnica é feita a eletrodeposição do metal desejado no interior dos poros do óxido anódico [33, 38, 45-47], seguido da dissolução química do óxido e do alumínio. Os nanofilamentos produzidos podem ter diversas aplicações, como em nanochips, ou outros sistemas em escala nanométrica [48].

É possível, enfim, por meio da incorporação de distintas espécies na matriz anódica, constituída por nanotubos de $\mathrm{Al}_{2} \mathrm{O}_{3}$ sobre o alumínio, alterar a sua condutividade elétrica [49] e propriedades óticas, entre outras. A dopagem do óxido anódico é então um processo que deve levar em consideração as características dos poros quanto: ao diâmetro, a quantidade, a composição e natureza do substrato levando em consideração as condições de anodização que influenciam significativamente nas características do filme.

No processo de implantação metálica por eletrodeposição no alumínio anodizado, os íons do metal presentes no eletrólito se reduzem à forma metálica, formando um depósito que preenche os poros do filme anódico desde o fundo até a parte externa, de acordo com a equação 9:

$$
\mathrm{Me}^{\mathrm{z}+}(\mathrm{aq})+\mathrm{ze}^{-} \rightarrow \mathrm{Me}^{0}(\mathrm{~s})
$$

O modelo mais aceito assume que a transferência dos íons metálicos ocorre por migração sob a influência do campo elétrico. O metal seria depositado diretamente sob o poro, adjacente ao substrato, uma região sob ação maior do campo elétrico. Nestas condições de eletrodeposição, se forma um fio do metal, que se transforma numa ponte condutora entre o alumínio e a solução eletrolítica no lado oposto do poro [39,50]. Resumidamente o processo admite as seguintes hipóteses, para explicar a transferência de carga na camada de barreira no fundo dos poros do óxido anódico pela ação do campo elétrico [39]:

1. A condutividade eletrônica do óxido anódico da camada de barreira se comporta como um semicondutor do tipo n; 
2. A difusão dos íons metálicos, $\mathrm{Me}^{\mathrm{z+}}(\mathrm{aq})$, ocorre no interior do óxido anódico poroso, que é hidratado e contém cerca de $60 \%$ de água;

3. A migração dos íons metálicos de $\mathrm{Me}^{\mathrm{z}+}$ (aq) no interior do óxido anódico ocorre pela influência do campo elétrico;

4. Pode ocorrer formação de hidrogênio, ocasionando um excesso de íons $\mathrm{OH}^{-}$, que pode dissolver a camada de óxido nesses sítios, de acordo com as equações:

$$
\begin{aligned}
& \mathrm{H}_{2} \mathrm{O}_{(\mathrm{l})}+\mathrm{e}^{-} \rightarrow \quad 1 / 2 \mathrm{H}_{2(\mathrm{~g})}+\mathrm{OH}_{(\mathrm{aq})}^{-} \\
& \mathrm{AlOOH}_{(\mathrm{s})}+\mathrm{OH}_{(\mathrm{aq})}^{-} \rightarrow \mathrm{AlO}_{2}^{-}(\mathrm{aq}) \\
& \mathrm{AlOOH}_{(\mathrm{s})}+\mathrm{e}_{(\mathrm{l})}^{-} \rightarrow \mathrm{AlO}_{2}^{-}{ }_{(\mathrm{aq})}+1 / 2 \mathrm{H}_{2(\mathrm{~g})}
\end{aligned}
$$

Nesse processo, o óxido de alumínio, a boemita $(\mathrm{AlOOH})$ é transformada em uma espécie solúvel sem modificar a concentração local de água, permitindo que a reação prossiga até que um buraco seja formado na camada de óxido, e a solução alcance a superfície externa do alumínio [51].

Além disso, como a concentração de água no interior dos poros diminui com o aumento da proximidade do substrato de alumínio e a resistividade do óxido aumenta de forma correspondente, não é viável que a deposição metálica venha ocorrer no topo dos poros do óxido anódico, como assume alguns autores [51].

Outros autores também assumem que o transporte das cargas no processo de eletrodeposição ocorre pela mobilidade dos íons metálicos no interior dos poros do óxido anódico e da camada de barreira $[52,53]$, Palibroda et al. [8,9] também assume a natureza semicondutora da camada de barreira.

A eletrodeposição de metais como o $\mathrm{Ni}, \mathrm{Ag}, \mathrm{Sn}, \mathrm{Au}, \mathrm{Fe}$ e Co tem sido usada para alterar as propriedades dos filmes porosos de óxido de alumínio [54,55], visando não só colorir o alumínio como também para produzir artefatos como dispositivos de gravação e de memória magnética [21] ou até placas para absorver seletivamente a radiação solar (eletrodeposição de $\mathrm{SnO}_{2}$ ) [56]. Polímeros também podem ser empregados na modificação da composição do filme de alumina para alterar a sua propriedade ótica [33].

Outro aspecto relevante quando se compara o alumínio a outros metais é a melhora da sua resistência à corrosão que também pode ser alcançada, através do mesmo processo de implantação metálica/intermetálica ao filme anódico [57]. 
No trabalho de N. R. de Tacconi et al. [49], para a fabricação de uma nova geração de diodos, a eletrodeposição de semicondutores no alumínio anodizado modificou a condutividade do óxido anódico, isso foi verificado por experimentos foto-eletroquímicos.

A eletrodeposição de ferro na matriz de alumínio anodizado pode, além de modificar as suas propriedades elétricas e magnéticas [5,21], produzir nanofios de ferro [5]. Pontifex et al. [58] após a implantação de ferro no óxido anódico de alumínio obteve os nanofilamentos de ferro com $60 \mathrm{~nm}$ de diâmetro e $700 \mathrm{~nm}$ de comprimento. A partir destes valores, propôs que estas seriam as dimensões internas dos poros presentes no filme de óxido anódico, preparado sob as condições apresentadas no trabalho.

Sabe-se, todavia, que ainda não há um mecanismo conclusivo [47,59] que descreva adequadamente a influência de metais na camada de óxido anódico, alterando as características condutoras do filme.

As técnicas eletroquímicas empregadas na incorporação de metais no interior da matriz de óxido anódico são as com corrente contínua e corrente pulsada. Esta última detém algumas vantagens, que vêem não só por produzir melhores eletrodepósitos do ponto de vista físico-químico, mas também sobre aspectos econômicos do processo global [60-65].

O fato da corrente aplicada ser pulsada, melhora a distribuição dessa corrente, diminuindo as regiões de alta densidade de corrente que provocam a "queima" dos revestimentos. Há melhora também do poder de penetração do banho, e os metais depositados possuem menor quantidade de hidrogênio adsorvido à superfície, diminuindo a tensão dos revestimentos quando comparados aos obtidos por corrente contínua [62-64]. A aderência dos revestimentos obtidos por corrente pulsada sobre metais passivantes como aço inox é bastante satisfatória. [64].

Além das vantagens citadas, eletrodeposições por corrente pulsada $[63,65]$ também aumentam a velocidade de deposição, reduzem a presença de impurezas e de microporosidade nos depósitos, e melhoram satisfatoriamente algumas propriedades como: ductilidade, dureza, resistência ao desgaste e à corrosão.

Independente da técnica empregada na incorporação metálica ao filme anódico é a reatividade do eletrodepósito que afetará a sua vida útil e o desempenho do artefato a que se destinará.

Entretanto, há procedimentos experimentais que permitem alterar ou atenuar este comportamento e no caso específico do alumínio anodizado, isso será abordado no próximo item. 


\subsection{Camada de conversão de cério sobre o alumínio e sobre o alumínio anodizado}

Há trabalhos que estudam tratamentos para a formação de camada de conversão de cromato no alumínio anodizado [66-68] para aumentar sua resistência à corrosão, com resultados satisfatórios. Porém, é bastante conhecido que o cromato é tóxico e carcinogênico. Uma alternativa ambientalmente amigável tem sido o tratamento com compostos de cério, que conhecidamente possui capacidade inibidora de corrosão.

A idéia de revestimentos de conversão de cério como um revestimento protetor nas ligas de alumínio foi proposta por Hinton et al. [69] em meados dos anos 1980. Eles verificaram que as adições de íons do cério à solução do cloreto de sódio (utilizada nos ensaios de corrosão) reduziam significativamente a taxa da corrosão da liga 7075 de alumínio. O resultado inspirou um grande interesse para eles e outros peritos em investigar os processos de formação, o mecanismo de formação e a caracterização de revestimentos de conversão de cério para as ligas de alumínio. Estes estudos preliminares revelaram que a proteção à corrosão foi atribuída à formação de um filme de óxido de cério hidratado na superfície da liga. Assim, os processos de revestimentos de conversão de cério foram desenvolvidos para encontrar-se com a demanda de processos não tóxicos de revestimentos de conversão [70-72].

Deve-se notar, entretanto, que entre estes processos, quase todos os revestimentos de conversão de cério eram diretamente depositados na matriz das ligas de alumínio, e poucos estudos dão atenção a sua aplicação em ligas de alumínio anodizadas. A anodização é uma das técnicas mais extensamente usadas para a proteção à corrosão das ligas de alumínio e é de interesse explorar a possibilidade de usar a técnica de conversão de cério para selar o óxido anódico de alumínio e contribuir para elevar ainda mais a sua vida útil.

Para o tratamento, tanto do alumínio como do alumínio anodizado com cério foram desenvolvidos processos químicos $[34,73,74]$ e eletroquímicos $[75,76]$ em soluções de $\mathrm{Ce}\left(\mathrm{NO}_{3}\right)_{3}$ [77] e $\mathrm{CeCl}_{3}$ [78-82] na presença da $\mathrm{H}_{2} \mathrm{O}_{2}$. Quando se adiciona o $\mathrm{H}_{2} \mathrm{O}_{2}$, ele atua como agente acelerador da reação de formação da camada de óxido de cério sobre o substrato, sua presença é fundamental quando a solução usada é de $\mathrm{Ce}\left(\mathrm{NO}_{3}\right)_{3}$ pois nesse caso o $\mathrm{H}_{2} \mathrm{O}_{2}$ é o único responsável pelo ataque químico que gera elétrons que serão usados nas reações de formação da camada de óxido de cério, e pela formação de mais $\mathrm{OH}^{-}$, favorecendo a precipitação do filme de óxido de cério. (reações 26 e 30, respectivamente). 
Yu et al. [6] verificaram por EDS acoplado ao MEV, no processo de selagem com terras raras do óxido anódico poroso sobre Al-6061/SiC, que já no início da imersão na solução, há a precipitação de uma mistura de óxido/hidróxido de cério nos poros do óxido anódico. Há a formação sobre a superfície do revestimento anódico, de uma barreira impermeável no topo dos poros constituída por essa mistura e caracterizada como depósitos esféricos. Revelou-se que o revestimento consiste predominantemente no composto de cério III, e parte dele é oxidado a cério IV no revestimento exterior da camada. O grau de cobertura do filme de cério sobre o substrato depende das condições de tratamento, como duração, temperatura e composição da solução.

O mesmo grupo publicou outros resultados sob o mesmo tema e com outras ligas utilizandose de curvas de polarização e da espectroscopia de impedância eletroquímica, se centrando na proposição de um mecanismo e testes de resistência à corrosão [83,84]. Os resultados mostraram que o revestimento permanece passivo em circuito aberto $-780 \mathrm{mV}$ até $-250 \mathrm{mV}$, e que só após 6 dias de imersão em solução de $\mathrm{NaCl}$, o revestimento externo da camada de conversão de cério começa a diminuir sua propriedade anticorrosiva. Entretanto, a parte mais interna do filme anódico selado com cério interno não sofre corrosão em até 60 dias imersão.

Há alguns trabalhos que procuram explicar o processo de formação da camada de conversão de cério sobre o alumínio, as principais etapas serão comparadas a seguir.

A formação da camada de conversão de cério é um processo ativado eletroquimicamente pelo aumento local do pH ocasionado pelas reações de oxidação nos sítios anódicos da superfície do substrato, mas não envolve reações de oxirredução, sendo portanto, um processo puramente químico [85]. Em pH's alcalinos, acima de 8, pode ocorrer a precipitação tanto do $\mathrm{Ce}(\mathrm{OH})_{3}$ quanto do $\mathrm{CeO}_{2}$, dependendo do potencial (verificado no diagrama de Pourbaix do cério), sendo os dois processos ativados simplesmente pelo $\mathrm{pH}$.

De acordo com o mecanismo proposto mais aceito para a precipitação da camada, seria de que a oxidação do $\mathrm{Ce}(\mathrm{III})$ a $\mathrm{Ce}(\mathrm{IV})$ ocorreria na própria solução de conversão devido à ação dos íons $\mathrm{OH}^{-}$resultantes da redução do $\mathrm{O}_{2}$ (reações 13 e 14). Segundo a literatura, nas condições investigadas a reação de redução do $\mathrm{O}_{2}$ poderia ocorrer por dois mecanismos diferentes: pelo caminho proposto por Arnott et al. (1985) [86]:

$$
\mathrm{O}_{2}+2 \mathrm{H}_{2} \mathrm{O}+4 \mathrm{e}^{-} \rightarrow 4 \mathrm{OH}^{-}
$$

Ou então pelo caminho de dois elétrons proposto por Aldykiewicz et al. (1996)[87]: 


$$
\mathrm{O}_{2}+2 \mathrm{H}_{2} \mathrm{O}+2 \mathrm{e}^{-} \rightarrow \mathrm{H}_{2} \mathrm{O}_{2}+2 \mathrm{OH}^{-}
$$

Nos dois casos, os íons $\mathrm{OH}^{-}$gerados provocariam a formação de complexos $\mathrm{Ce}(\mathrm{IV})$ através das reações de oxidação do $\mathrm{Ce}(\mathrm{III})$ na solução [88]:

$$
\begin{aligned}
& 4 \mathrm{Ce}^{3+}+\mathrm{O}_{2}+2 \mathrm{H}_{2} \mathrm{O}+4 \mathrm{OH}^{-} \rightarrow 4 \mathrm{Ce}(\mathrm{OH})_{2}{ }^{2+} \\
& 2 \mathrm{Ce}^{3+}+2 \mathrm{H}_{2} \mathrm{O}+2 \mathrm{OH}^{-} \rightarrow 2 \mathrm{Ce}(\mathrm{OH})_{2}{ }^{2+}+\mathrm{H}_{2}
\end{aligned}
$$

Os quais, posteriormente, precipitariam sob a forma de $\mathrm{CeO}_{2}$, de acordo com a seguinte reação:

$$
\mathrm{Ce}(\mathrm{OH})_{2}{ }^{2+}+2 \mathrm{OH}^{-} \rightarrow \mathrm{CeO}_{2}+2 \mathrm{H}_{2} \mathrm{O}
$$

A transformação do Ce(III) a Ce(IV) em solução diretamente pela ação da água também foi proposta por Aldyukiewicz (1996) [87]:

$$
\mathrm{Ce}^{3+}+2 \mathrm{H}_{2} \mathrm{O} \rightarrow \mathrm{Ce}(\mathrm{OH})_{2}{ }^{2+}+2 \mathrm{H}^{+}+\mathrm{e}^{-}
$$

$\mathrm{Na}$ presença do oxidante $\mathrm{H}_{2} \mathrm{O}_{2}$ Hugues et al. (2000) propuseram um caminho alternativo para a precipitação do $\mathrm{CeO}_{2}$ contituído das seguintes etapas:

$$
\begin{gathered}
\mathrm{Ce}^{3+}+\mathrm{H}_{2} \mathrm{O}_{2} \rightarrow \mathrm{Ce}\left(\mathrm{H}_{2} \mathrm{O}_{2}\right)^{3+} \\
\mathrm{Ce}\left(\mathrm{H}_{2} \mathrm{O}_{2}\right)^{3+} \rightarrow \mathrm{Ce}\left(\mathrm{H}_{2} \mathrm{O}_{2}\right)^{2+}+\mathrm{H}^{+} \\
\mathrm{Ce}\left(\mathrm{H}_{2} \mathrm{O}_{2}\right)^{2+}+1 / 2 \mathrm{H}_{2} \mathrm{O}_{2} \rightarrow \mathrm{Ce}\left(\mathrm{O}_{2}\right)^{2+}+\mathrm{H}_{2} \mathrm{O} \\
\mathrm{Ce}\left(\mathrm{O}_{2}\right)^{2+}+2 \mathrm{e}^{-} \rightarrow \mathrm{CeO}_{2}
\end{gathered}
$$

$\mathrm{O}$ pH em que o $\mathrm{CeO}_{2}$ e o $\mathrm{Ce}(\mathrm{OH})_{3}$ se precipitam é alto, nessas condições o óxido é instável. Ao mesmo tempo que se precipita a camada, parte do óxido se dissolve. As reações responsáveis pelo aumento do pH necessário à precipitação da camada são:

$$
\begin{gathered}
2 \mathrm{H}^{+}+2 \mathrm{e}^{-} \rightarrow \mathrm{H}_{2} \\
\mathrm{O}_{2}+2 \mathrm{H}_{2} \mathrm{O}+4 \mathrm{e}^{-} \rightarrow 4 \mathrm{OH}^{-}
\end{gathered}
$$


Os elétrons mostrados nas equações 13 e 14 são gerados nas seguintes reações:

$$
\begin{gathered}
\mathrm{Al} \rightarrow \mathrm{Al}^{3+}+3 \mathrm{e}^{-} \\
\mathrm{H}_{2} \mathrm{O}_{2} \rightarrow 2 \mathrm{H}^{+}+\mathrm{O}_{2}+2 \mathrm{e}^{-}
\end{gathered}
$$

Assim, a formação da camada de conversão seria provocada pelos íons hidroxila gerados na reação 24 (Hughes et al, 2000) [88]:

$$
\begin{gathered}
4 \mathrm{Ce}^{3+}+\mathrm{O}_{2}+2 \mathrm{H}_{2} \mathrm{O}+4 \mathrm{OH}^{-} \rightarrow 4 \mathrm{Ce}(\mathrm{OH})_{2}{ }^{2+} \\
2 \mathrm{Ce}^{3+}+2 \mathrm{H}_{2} \mathrm{O}+2 \mathrm{OH}^{-} \rightarrow 2 \mathrm{Ce}(\mathrm{OH})_{2}{ }^{2+}+\mathrm{H}_{2}
\end{gathered}
$$

e precipita sob a forma de $\mathrm{CeO}_{2}$ :

$$
\mathrm{Ce}(\mathrm{OH})_{2}{ }^{2+}+2 \mathrm{OH}^{-} \rightarrow \mathrm{CeO}_{2}+2 \mathrm{H}_{2} \mathrm{O}
$$

A partir da introdução do $\mathrm{H}_{2} \mathrm{O}_{2}$ nas soluções de conversão, Hughes (2000) [88] tem sugerido uma outra reação de redução, responsável pela elevação local do $\mathrm{pH}$, originando a precipitação da camada de óxido de cério:

$$
\mathrm{H}_{2} \mathrm{O}_{2}+2 \mathrm{e}^{-} \rightarrow 2 \mathrm{OH}^{-}
$$

O aumento da resistência à corrosão alcançada após esse tratamento, é explicada pela formação de um filme fino de óxido de cério que protege a superfície do substrato dificultando o acesso das espécies do meio à superfície do substrato [89]. 


\section{TÉCNICAS EMPREGADAS NA INCORPORAÇÃO METÁLICA NO FILME} ANÓDICO

Neste trabalho a incorporação de metais ao filme anódico foi realizada aplicando as técnicas de eletrodeposição por corrente contínua e pulsada.

$\mathrm{Na}$ eletrodeposição com corrente contínua é possível controlar a velocidade do processo e a qualidade dos eletrodepósitos, que é função principalmente da densidade de corrente adotada e da duração do pulso. Além disso, no regime com corrente contínua, apenas um parâmetro elétrico é variável (densidade de corrente ou potencial), ao passo que em sistemas regidos por corrente pulsada, quatro parâmetros podem ser variados de forma independente: densidade de corrente de pulso catódico $\left(\mathrm{i}_{\mathrm{c}}\right)$, densidade de corrente de pulso anódico $\left(\mathrm{i}_{\mathrm{a}}\right)$, duração do pulso catódico $\left(\mathrm{t}_{\mathrm{c}}\right.$ ou $\left.\mathrm{t}_{\mathrm{on}}\right)$ e duração do pulso anódico ou nulo ( $\mathrm{t}_{\mathrm{a}}$ ou $\left.\mathrm{t}_{\text {off }}\right)$. A soma dos tempos "on" e "off" constituem um período.

A variação desses parâmetros altera as propriedades do filme eletrodepositado e a influência de cada um deles será citada a seguir.

O tempo de pulso catódico, ou tempo "on", é o tempo durante o qual o pulso de corrente catódica é aplicado. Nesse período há a formação da camada cristalina, onde será influenciada a estrutura e a rugosidade do eletrodepósito.

O tempo de pulso nulo, ou tempo "off”, é o intervalo sem a passagem de corrente entre dois pulsos consecutivos. Neste período há o relaxamento da camada pulsante e a regeneração da interface: a concentração de cátions na dupla camada diminui e há a desativação dos centros de crescimento.

A intensidade de corrente catódica ou intensidade de corrente de pulso é a intensidade máxima de corrente aplicada durante o tempo de pulso. Na eletrodeposição pulsada, esse parâmetro assume valores muito altos que muitas vezes não podem ser alcançados em corrente contínua.

$\mathrm{O}$ ciclo de trabalho (duty cicle-DC) é a razão entre o $\mathrm{t}_{\text {on }}$ e a soma $\left(\mathrm{t}_{\mathrm{on}}+\mathrm{t}_{\mathrm{off}}\right)$. $\mathrm{O}$ ciclo de trabalho pode variar de 1 a $100 \%$, sendo que $100 \%$ corresponde à corrente contínua, onde o tempo “off” é igual a zero. Os tempos "on" e "off” podem variar de microsegundos a segundos, o ciclo de trabalho pode ser calculado por:

$$
\mathrm{DC}=\left[\left(\mathrm{t}_{\mathrm{on}}\right)\left(\mathrm{t}_{\mathrm{on}}+\mathrm{t}_{\mathrm{off}}\right)^{-1}\right] \times 100
$$


onde: $\mathrm{DC}=$ ciclo de trabalho

$\mathrm{t}_{\mathrm{on}}=$ duração do pulso de corrente catódica

$\mathrm{t}_{\mathrm{off}}=$ duração do pulso de corrente zero

A densidade de corrente média ( $i_{\mathrm{m}}$ ) define a velocidade de eletrodeposição do metal e é equivalente a densidade de corrente aplicada na eletrodeposição por corrente contínua, e depende do ciclo de trabalho através da seguinte relação [90]:

$$
\mathrm{i}_{\mathrm{m}}=\mathrm{i}_{\mathrm{c}} \times \mathrm{DC}
$$

onde:

$$
\begin{aligned}
& \mathrm{i}_{\mathrm{c}}=\text { densidade de corrente catódica } \\
& \mathrm{DC}=\text { ciclo de trabalho }
\end{aligned}
$$

A corrente pulsada pode gerar mudanças significativas na morfologia, nas propriedades mecânicas e na resistência à corrosão dos depósitos o que torna a técnica de alto interesse industrial quando comparada à convencional contínua. 


\section{TÉCNICAS E CARACTERIZAÇÕES EMPREGADAS}

As técnicas empregadas na caracterização dos filmes obtidos neste trabalho foram: microscopia, incluindo microscopia ótica (MO) com a utilização de luz polarizada e analisador de imagens (AI) e microscopia eletrônica de varredura (MEV) com espectroscopia de energia dispersiva de raios $\mathrm{X}$ (EDS); fluorescência de raios X (FRX); técnicas eletroquímicas como cronopotenciometria e espectroscopia de impedância eletroquímica (EIE); e físicas como medidas de impedância elétrica por duas pontas e medidas de microdureza com o uso de um microdurômetro.

\subsection{Cronopotenciometria}

Este método consiste em manter uma corrente constante e medir o potencial resultante em função do tempo num sistema eletroquímico.

À medida que a eletrólise progride, a concentração das espécies eletroativas adjacentes ao eletrodo decresce, isso ocorre lentamente, fazendo com que o potencial do eletrodo mude na mesma proporção. O potencial do eletrodo de trabalho depende da razão de concentração na superfície do eletrodo que é determinado pela equação de Nernst.

Se a intensidade de corrente mantida for muito alta, será atingida uma situação em que a concentração próxima ao eletrodo será reduzida virtualmente a zero e com isso o potencial tenderia a infinito. Na realidade isto não acontece, pois normalmente há alguma outra espécie na solução que tenha potenciais mais negativos (por exemplo: eletrólito suporte, solvente...). Desta forma, o potencial muda rapidamente até um certo valor, que seja possível uma nova reação do eletrodo.

O tempo desde o começo da eletrólise até a rápida mudança de potencial é chamado de tempo de transição $\tau$ e está relacionado com a concentração da espécie eletroativa [91].

Após o tempo de transição, o potencial cai então para um valor mais negativo no qual possa começar um novo processo de redução. Portanto, cada reação de transferência de elétrons tem um tempo de transição característico. Assim, cada tempo de transição indica a ocorrência de mais de uma reação eletroquímica.

Na FIG. 2 pode-se observar um cronopotenciograma típico, cujo segmento (AB) indica o tempo de transição. O potencial correspondente a este segmento pode ser relacionado ao potencial 
de redução das espécies eletroativas. De (B) a (C) o potencial atinge valores mais negativos, até que em (C) começa um novo processo de redução [91].

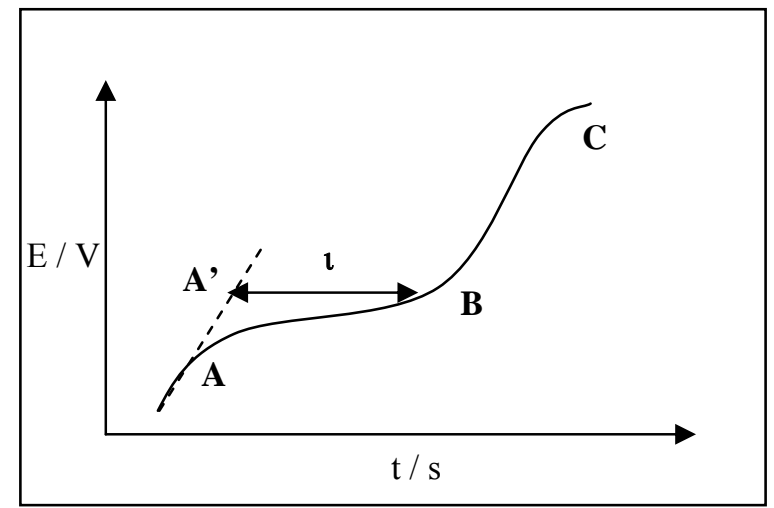

FIGURA 2: Cronopotenciograma padrão

Neste trabalho, a cronopotenciometria é utilizada para avaliar a influência dos aditivos ácido bórico e ácido ascórbico presentes no eletrólito sobre a eletrodeposição de ferro, ou seja: como evolui a oxidação do $\mathrm{Fe}^{2+}{ }_{\text {aq }} \mathrm{a} \mathrm{Fe}^{3+}$ aq em solução.

\subsection{Microscopia ótica com luz polarizada e analisador de imagens}

A microscopia ótica consiste num conjunto de técnicas que visam não só a observação do que está sendo analisado por meio do microscópio ótico, mas também a preparação prévia desses materiais, e ainda a captura de imagens para posterior observação.

O microscópio de luz polarizada é um microscópio ótico comum, no qual a luz que provém da fonte luminosa, atravessa um sistema polarizador colocado junto do condensador, que polariza as ondas luminosas num só plano. O emprego de um feixe de luz polarizada permite estudar certos aspectos da morfologia da amostra, que não são visíveis com a microscopia ótica comum.

Para observar as modificações que o objeto observado produz no trajeto da luz polarizada, interpõe-se junto da ocular, um segundo sistema de polarização, denominado sistema analisador. Quando o eixo do analisador se encontra paralelo ao do polarizador, obtém-se o máximo de luz. Pelo contrário, quando os eixos do analisador e do polarizador estiverem cruzados, não se verifica transmissão de luz, isto é, ocorre extinção. 
Quando se emprega o microscópio de luz polarizada em posição de extinção, pode-se observar se nestas condições, o objeto interposto é capaz de restituir uma parte ou toda a luminosidade. Nestas condições, só as estruturas birrefringentes podem ser vistas. Isto ocorre porque elas dividem o feixe polarizado em dois; um deles é absorvido pelo analisador, mas o outro, perpendicular ao primeiro, atravessa o analisador e vai formar a imagem.

$\mathrm{O}$ analisador de imagens é um equipamento que permite produzir imagens de cortes transversais de lâminas com alta luminosidade. Ele foi desenvolvido com base na dificuldade em se visualizar lâminas através de microscópios convencionais, que geralmente possui um campo restrito de visão, dificultando desta forma a identificação das características macroscópicas de uma imagem. O software suplanta este problema ao digitalizar a lâmina microscópica com boa resolução, produzindo uma imagem que pode ser visualizada, medida, manipulada e analisada posteriormente.

\subsection{Microscopia eletrônica de varredura}

O uso desta técnica vem se tornando mais freqüente por fornecer informações de detalhe, com aumentos de até 300.000 vezes. A imagem eletrônica de varredura é formada pela incidência de um feixe de elétrons no material a ser estudado, sob condições de vácuo. A incidência do feixe de elétrons no material promove a emissão de elétrons secundários, retroespalhados, auger e absorvidos, assim como de raios $\mathrm{X}$ característicos e de catodo luminescência. A imagem eletrônica de varredura representa em tons de cinza o mapeamento e a contagem de elétrons secundários (SE secondary electrons) e retroespalhados (BSE - backscattering electrons) emitidos pelo material analisado.

Ao MEV pode ser acoplado o sistema para a espectroscopia de energia dispersiva-EDS, que possibilita a determinação da composição qualitativa e semi-quantitativa das amostras, a partir da emissão de raios X característicos, com limite de detecção da ordem de $1 \%$.

Os materiais não condutores de corrente elétrica para serem analisados no MEV/EDS devem ser previamente metalizados. A metalização consiste na deposição, a vácuo, de uma película micrométrica de material condutor (ouro ou carbono) sobre a superfície do material, possibilitando a condução da corrente elétrica [92]. 


\subsection{Espectroscopia de impedância eletroquímica}

A análise de espectroscopia de impedância eletroquímica-EIE envolve a aplicação de uma perturbação de potencial ou de corrente no sistema sob investigação. A perturbação do sistema é feita mediante a aplicação de um potencial sobre a qual é superimposta uma variação senoidal de potencial com pequena amplitude. Este método de aplicação do potencial possibilita que o sistema seja perturbado empregando poucos milivolts, e torna possível a investigação de fenômenos eletroquímicos próximos ao estado de equilíbrio.

Como resultado surge uma corrente de natureza senoidal que mediante um monitoramento das relações entre o potencial aplicado e esta corrente são obtidos o módulo da impedância do sistema e o ângulo de fase (defasagem da corrente em relação ao potencial aplicado).

O conceito de impedância, originalmente introduzido para descrever a resposta de sistemas compostos por capacitâncias, resistências e indutâncias, estendeu-se aos sistemas eletroquímicos, uma vez que inúmeros processos podem contribuir para a relação entre a corrente e o potencial do sistema. Assim, a partir das medidas da impedância e ângulo de fase é possível avaliar processos como transporte de carga (incluindo estimativa de velocidade de transferência), condutividade de filmes, capacitância redox e de dupla camada, coeficientes de difusão de portadores de carga, entre outros [93].

\subsection{Medidas de impedância elétrica (método duas pontas)}

Pode-se fazer uma medida direta da resistividade elétrica de um material, conhecendo-se com precisão as suas dimensões, medindo-se a diferença de potencial e a corrente elétrica que flui através do mesmo, sob a ação de um campo elétrico $a c$ aplicado. A FIG. 3 esboça o arranjo experimental para este tipo de medida. O circuito elétrico contido no retângulo pontilhado equivale ao tocarmos os pontos A e B do material com os terminais de um multímetro comum. A leitura, em ohms (V/i), e as dimensões da amostra são usados no cálculo e, para materiais de alta resistividade elétrica é necessário usar fonte de alimentação e amperímetro, separadamente [94]. 


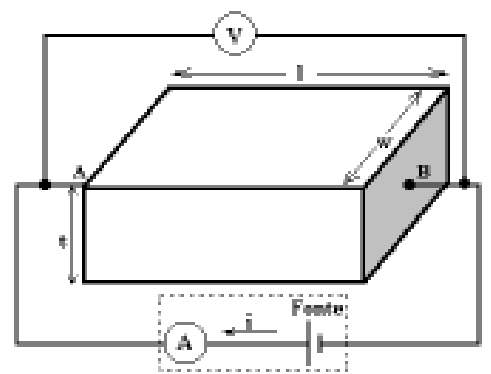

FIGURA 3: Arranjo experimental para o método duas pontas

Este método é válido somente se a quantidade de portadores de carga no material a ser analisado for alta; ou se sob pequenas variações de temperatura, a densidade desses portadores não for muito afetada, como no caso de materiais ôhmicos, isolantes ou semicondutores de baixa condutividade.

\subsection{Fluorescência de raios $X$}

A fluorescência de raios $\mathrm{X}$ é um método analítico quali-quantitativo, multielementar, baseado nas medidas das intensidades dos raios $\mathrm{X}$ característicos emitidos por elementos que constituem a amostra após uma excitação adequada [80]. Os raios $\mathrm{X}$ incidentes que excitam os átomos constituintes da amostra emitem por sua vez linhas espectrais com energias características do elemento, que são medidas em sistemas de detectores e cujas intensidades estão relacionadas com a concentração.

Os sistemas de detecção permitem análises químicas multielementares, rápidas, não destrutivas, sem o uso de curvas de calibração individuais realizadas por meio do método de parâmetros fundamentais, preparação simplificada de amostra e bons limites de detecção.

\subsection{Medidas de microdureza}

O microdurômetro é um equipamento que permite medir a dureza de filmes na escala de micrômetros. Seu mecanismo é simples, nele, um identador penetra a amostra com uma determinada carga em um local preestabelecido após a observação do operador utilizando um microscópio (acoplado ao microdurômetro), após a identação, a resposta é dada através de uma relação entre a carga aplicada e o tamanho da marca feita pela penetração, levando-se em 
consideração a carga aplicada. Para uma mesma carga aplicada e mesmo tempo de aplicação da carga, quanto menor a penetração, mais dura é a substância analisada. No presente trabalho as identações foram realizadas transversalmente à amostra, de forma que a identação atingiu somente o filme anódico, sem alcançar o alumínio.

Existem os nanodurômetros que permitem medir a ultra-microdureza, ou seja, determinar a dureza de filmes finos na escala de nanômetros. 


\section{MATERIAIS E MÉTODOS}

\subsection{Substrato}

A liga de alumínio 6063 com $1 \mathrm{~mm}$ de espessura, cuja composição dada por Fluorescência de Raios-X (FRX) é mostrada na TAB. 2, foi utilizado nesse estudo. A área anodizada corresponde a 1 $\mathrm{cm}^{2}$, conforme mostrado na FIG. 4:

TABELA 2: Composição da liga de alumínio dada por FRX:

\begin{tabular}{|l|l|l|l|l|l|l|l|l|l|}
\hline Elemento & $\mathrm{Al}$ & $\mathrm{Mg}$ & $\mathrm{Fe}$ & $\mathrm{Cr}$ & $\mathrm{Cu}$ & $\mathrm{Si}$ & $\mathrm{Zn}$ & $\mathrm{Ti}$ & $\mathrm{Mn}$ \\
\hline Teor (\%) & 97,934 & 1,415 & 0,332 & 0,133 & 0,112 & 0,038 & 0,022 & 0,011 & 0,003 \\
\hline
\end{tabular}

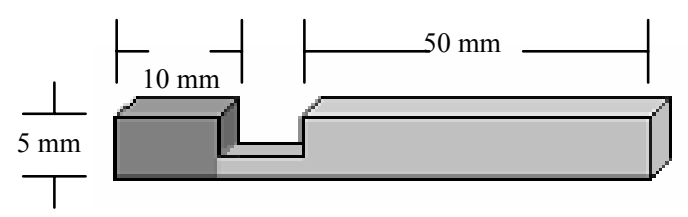

FIGURA 4: Amostra de alumínio como usada no presente trabalho. A área mais escura corresnonde à área tratada.

Após o corte, as amostras foram lixadas em lixa de carbeto-silício com granulações 200, 400, 600 e 1500 , decapadas em NaOH $2 \mathrm{~mol} \mathrm{~L}^{-1}$ por 1 min e posteriormente neutralizadas em $\mathrm{HNO}_{3} 8$ mol L ${ }^{-1}$ por $1 \mathrm{~min}$, entre uma etapa e outra, as amostras foram lavadas em água corrente.

\subsection{Anodização}

As anodizações por controle de corrente e do potencial foram feitas em um retificador de corrente, com corrente contínua e pulsada. Foram estudadas duas composições de eletrólito: $\mathrm{H}_{2} \mathrm{SO}_{4}$ 0,9; 1,7 e 2,6 mol L ${ }^{-1}$ e $\mathrm{H}_{2} \mathrm{SO}_{4} 0,85 \mathrm{~mol} \mathrm{~L}^{-1}+\mathrm{H}_{3} \mathrm{PO}_{4} 0,65 \mathrm{~mol} \mathrm{~L}^{-1}$, o último foi chamado nesse trabalho de "eletrólito misto". 
As temperaturas de eletrólito estudadas foram 10,15 e $20^{\circ} \mathrm{C}$, com tempos de anodização de 25 , 40 e 55 minutos.

As anodizações foram feitas controlando-se o potencial (nesse caso o potencial aplicado foi aumentado até atingir um potencial final de $23 \mathrm{~V}$, e esse foi mantido até o final da anodização) ou por controle da corrente (no qual após atingir a corrente densidade de $83 \mathrm{~mA} \mathrm{~cm}^{-2}$, essa foi mantida até o final da anodização).

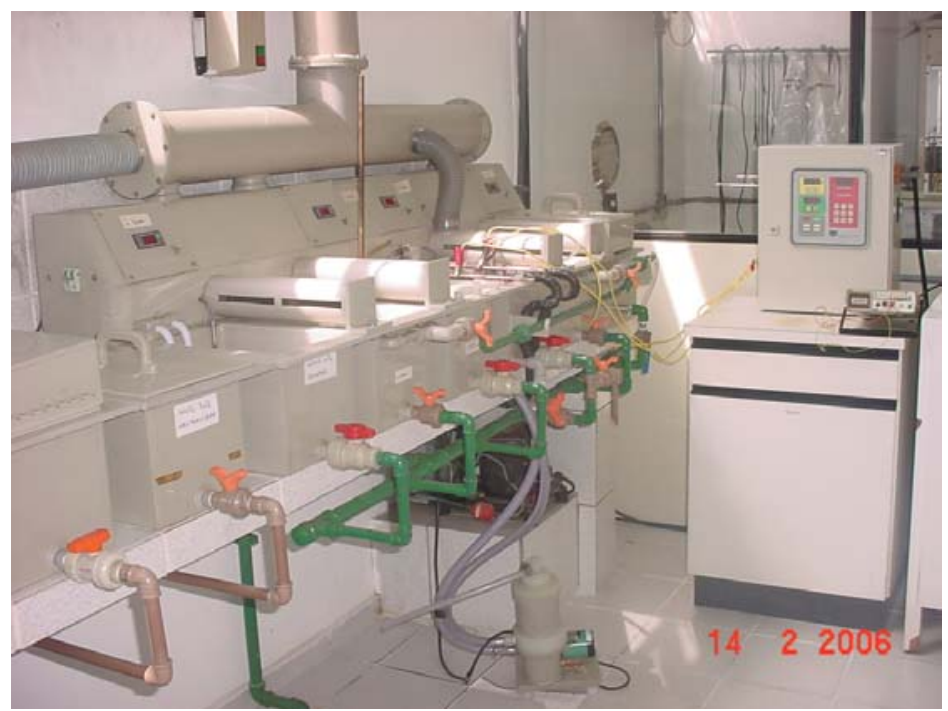

FIGURA 5: Mini linha para anodização com os tanques, o retificador e multímetro para monitorar a corrente.

Na FIG. 5 é mostrado o arranjo da mini linha de anodização utilizada nesse trabalho, onde um retificador de corrente contínua e pulsada tem saída para alimentação dos barramentos para o tanque de anodização, que possui um sistema de refrigeração e um duto em PVC para a circulação do eletrólito no filtro para a remoção de particulados e para a homogeneização da temperatura ao longo da área útil do tanque. A temperatura nos banhos é mantida com sensores acoplados a controlador digital-termostato com diferencial de $0,5^{\circ} \mathrm{C}$.

\subsection{Eletrodeposição de ferro}

As eletrodeposições galvanostáticas foram realizadas em um retificador de corrente, com corrente contínua e pulsada. O eletrólito utilizado foi $\mathrm{o}$ sulfato ferroso amoniacal 
$\left[\mathrm{FeSO}_{4}\left(\mathrm{NH}_{4}\right)_{2} \mathrm{SO}_{4} \cdot \mathrm{H}_{2} \mathrm{O}\right] \quad 0,31 \mathrm{~mol} \mathrm{~L}^{-1}$ e a influência dos aditivos ácido bórico $\left(\mathrm{H}_{3} \mathrm{BO}_{4}\right)$ 0,65 mol L $\mathrm{m}^{-1}$ e ácido ascórbico $\left(\mathrm{C}_{6} \mathrm{H}_{8} \mathrm{O}_{6}\right)$ 0,06 $\mathrm{mol} \mathrm{L}^{-1}$ na qualidade do depósito e na eficiência da eletrodeposição foi investigada. A duração das eletrodeposições a temperatura ambiente foram 20,40 e 60 segundos, aplicando-se uma densidade de corrente média de $30 \mathrm{~mA} / \mathrm{cm}^{2}$ e foram estudados os ciclos de trabalho: 80,90 e 100\%, sendo que $100 \%$ corresponde à corrente contínua.

\subsection{Preparação dos nanofilamentos de ferro}

Após anodização por controle de potencial, por $40 \mathrm{~min}$ a $20^{\circ} \mathrm{C}$ em "eletrólito misto", e eletrodeposição galvanostática de ferro por corrente pulsada por 60 segundos, as amostras foram dissolvidas em NaOH $2 \mathrm{~mol} \mathrm{~L}^{-1}$ e os nanofios foram coletados com o auxílio de um imã revestido com uma fita adesiva, e posicionado próximo à solução, de modo que os nanofios foram atraídos pelo imã. A superfície da fita adesiva com os nanofios foi recoberta com uma fina camada de ouro e observada em MEV (Cambridge Steroscan 240 com sistema de análise de imagem Kontron KS300) com EDS.

\subsection{Tratamento químico com $\mathrm{CeCl}_{3}$}

As amostras de alumínio anodizado com ferro incorporado foram mergulhadas em solução de $\mathrm{CeCl}_{3}$ a $50^{\circ} \mathrm{C}$ por 30 minutos (tempos maiores foram testados, mas foi observado um ataque químico excessivo ao alumínio anodizado). Foram estudadas três concentrações de $\mathrm{CeCl}_{3}, 10^{-3} \mathrm{~mol}$ $\mathrm{L}^{-1} ; 5 \times 10^{-3} \mathrm{~mol} \mathrm{~L}^{-1}$ e $8,6 \times 10^{-2} \mathrm{~mol} \mathrm{~L}^{-1}$.

A solução de cloreto de cério foi preparada dissolvendo-se o sal de óxido de cério em $\mathrm{HCl}$ concentrado, sob agitação e aquecimento. Após esse procedimento, o óxido em excesso é filtrado, e a concentração da solução de $\mathrm{CeCl}_{3}$ é obtida através de ensaio de óxidos totais. A partir daí a solução de $\mathrm{CeCl}_{3}$ é diluída até a concentração desejada.

No ensaio de óxidos totais, todo o cério presente na solução analisada é precipitado na forma de óxido adicionando-se $\mathrm{NH}_{3} \mathrm{OH}$ concentrado a essa solução, sob agitação e aquecimento, o óxido gerado é filtrado e, após secagem em mufla a $800^{\circ} \mathrm{C}$ por 1 hora, os óxidos são pesados e calcula-se a concentração de cério na solução analisada, a partir da massa dos óxidos obtida. 


\subsection{Caracterização das amostras}

A caracterização microestrutural das amostras foi feita com microscópio ótico Olympus AHMT com analisador de imagens (AI) Quantimet 600 Leica e em microscópio eletrônico de varredura (MEV) Philips modelo XL 30 com espectroscópio de energia dispersiva de raios X (EDS) (operadores Nildemar A.M. Ferreira e Celso V. Moraes ambos do CCTM-IPEN), e em MEV Cambridge Steroscan 240 com sistema de análise de imagem Kontron KS-300 (operadora Dra. Clarice T. Kuniosho da Escola Politécnica-USP), sendo que essas imagens foram da superfície e da seção transversal das amostras. Para a obtenção das imagens de perfil, as amostras foram cortadas em Isomet, embutidas em resina epóxi a frio, lixadas e polidas, esse mesmo tipo de tratamento foi feito para as medidas de microdureza Vickers $(\mathrm{Hv})$, onde as identações foram feitas transversalmente de modo que atingiram apenas o óxido anódico.

Para as medidas de microdureza Vickers $(\mathrm{Hv})$, foi estabelecida uma distância de $10 \mu \mathrm{m}$ entre a interface metal/óxido e a identação para todas as medidas, para evitar erros decorrentes da diferença de microdureza que pode existir em diferentes regiões do óxido anódico de uma mesma amostra.

As análises de impedância eletroquímica foram realizadas em um analisador de resposta de freqüências Solartron aplicando $10 \mathrm{mV}$ e a faixa de freqüências estudada foi de $20 \mathrm{KHz}$ a $2 \mathrm{MHz}$, a temperatura ambiente foi mantida em torno de $20 \pm 2^{\circ} \mathrm{C}$.

Para as análises por fluorescência de raios X (FRX) - 900 Shimadzu, não foi necessário nenhum tipo de pré-tratamento das amostras.

As curvas cronopotenciométricas foram obtidas em potenciostato/galvanostato G\&G Princeton Applied Research 273a, simultaneamente às eletrodeposições de ferro.

A análise de impedância elétrica por duas pontas foi feita em Impedancímetro ac HP 4192 A de $5 \mathrm{~Hz}$ a $13 \mathrm{MHz}$ e também não exigiram pré-tratamento das amostras. Nessa análise foi feito um sanduíche da amostra de alumínio anodizado com e sem os tratamentos entre duas placas de platina ligadas ao impedancímetro, onde um potencial de $200 \mathrm{mV}$ foi aplicado e medida a corrente que atravessou a amostra, permitindo avaliar a resistência oferecida pela amostra à passagem da corrente. 


\section{RESULTADOS E DISCUSSÕES}

\subsection{Influência das condições de anodização nas características do filme anódico}

A anodização do alumínio forma dois tipos de filmes de óxido: filmes pouco porosos e filmes porosos. Os filmes pouco porosos possuem microdureza superior, e são preparados em soluções quase neutras em que o óxido não é solúvel. Os filmes porosos são formados em soluções ácidas de pH baixo. As características do filme anódico como espessura da camada de barreira e porosa, porosidade, grau de cobertura, etc., são determinadas pelos parâmetros empregados na anodização como composição, concentração e temperatura do eletrólito, duração da anodização e regimes como corrente contínua (CC)/corrente pulsada (CP), controle de potencial ou de corrente, etc.

A fim de estudar a formação de um filme de óxido de alumínio com espessura desejável para a proteção do alumínio e ao mesmo tempo, porosidade e morfologia favoráveis para abrigar o ferro no interior dos seus poros, foi estudada a influência de diversas condições de anodização, como o regime de aplicação do potencial, anodização por controle de potencial ou da corrente, por potencial contínuo e pulsado variando as freqüência dos pulsos e os ciclos de trabalho, além da composição, temperatura do eletrólito e duração da anodização.

Inicialmente foram feitos estudos em eletrólito $\mathrm{H}_{2} \mathrm{SO}_{4}$. Após as primeiras conclusões foi estudada uma composição de eletrólito de uma mistura de $\mathrm{H}_{3} \mathrm{PO}_{4}$ com $\mathrm{H}_{2} \mathrm{SO}_{4}$ para garantir as propriedades protetoras obtidas em $\mathrm{H}_{2} \mathrm{SO}_{4}$ com uma certa porosidade alcançada em eletrólito $\mathrm{H}_{3} \mathrm{PO}_{4}$.

\subsubsection{Influência do programa de aplicação de potencial na anodização em eletrólito $\mathrm{H}_{2} \mathrm{SO}_{4}$}

Este estudo foi necessário, pois foi verificado experimentalmente que se fosse aplicado o potencial máximo (23 V) logo no início da anodização, o filme não se formaria. Este fenômeno já era esperado, pois quando se aplica um potencial muito alto no alumínio sem a proteção da camada anódica, há a saída dos íons da estrutura cristalina do metal muito rápida havendo, portanto, a corrosão total do metal antes da formação da camada de $\mathrm{Al}_{2} \mathrm{O}_{3}$. 
Em primeiro lugar, foram estudadas amostras anodizadas no regime de anodização por controle do potencial, e se fez necessário o estudo do programa de aplicação de potencial que favorecesse a formação de um filme de boa qualidade.

Verificou-se através de imagens obtidas em microscópio ótico utilizando um analisador de imagens que, aumentando-se o potencial gradativamente forma-se uma camada mais homogênea, com espessura mais uniforme, conforme é mostrado nas FIG. 6-A e 6-B.

Na FIG. 6-A pode-se observar que a camada é bem homogênea, possuindo poucas falhas ou crateras, protegendo o substrato, verificado por um teste simples de medida da condutividade elétrica utilizando-se um multímetro, além disso, nela não foram encontradas regiões com exposição do substrato. Diferentemente do observado no caso da FIG. 6-B.
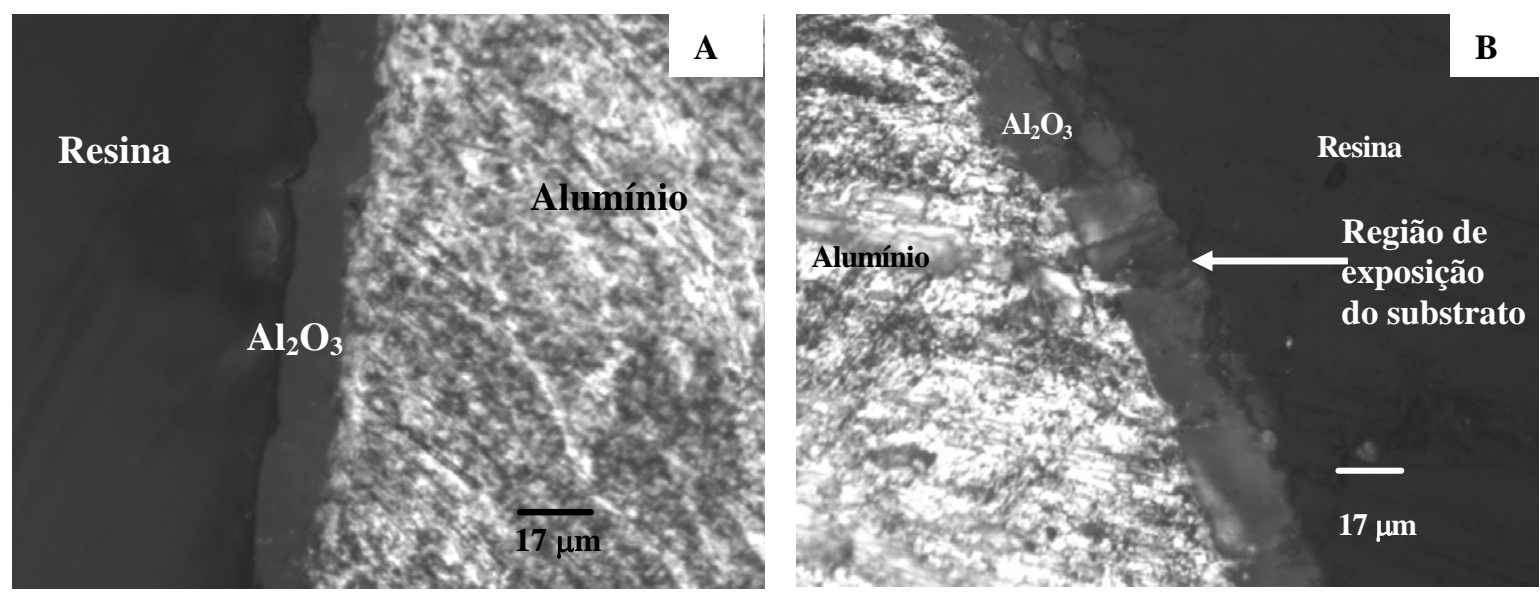

FIGURA 6: Micrografia obtida em microscópio ótico com analisador de imagem do corte transversal do alumínio anodizado por 40 minutos, aplicando-se um potencial final de $23 \mathrm{~V}$ :

(A) aumentando $1 \mathrm{~V}$ a cada minuto e (B) aumentando $5 \mathrm{~V}$ a cada 5 minutos.

A FIG. 6-B mostra as condições do filme formado com uma aplicação abrupta do potencial. O filme possui falhas e crateras em toda sua extensão, sendo que algumas falhas fazem com que a superfície do alumínio fique exposta ao meio, portanto, esta não é uma condição experimental favorável para a formação de um filme com boas propriedades protetoras ao alumínio. Com o objetivo de avaliar se as falhas na camada eram provenientes de algum dano causado no processo de lixamento e polimento, as mesmas amostras foram novamente preparadas e visualizadas no analisador de imagens, e os resultados foram confirmados. 
A não-uniformidade da espessura do óxido observada na FIG. 6-B pode ser explicada porque no momento em que é aplicado um potencial de $5 \mathrm{~V}$ logo no início da anodização, quando o alumínio ainda está sem a proteção da camada anódica, a corrosão intensa sobre o alumínio pode alterar a morfologia da sua superfície, porém como o potencial não é tão intenso quanto os $23 \mathrm{~V}$, em algumas regiões pode estar se formando a camada anódica. Ao se aplicar mais $5 \mathrm{~V}$, a camada anódica continua crescendo e seguindo a morfologia do alumínio, que já foi modificada no início da anodização, causando a não uniformidade da espessura do óxido, com regiões cobertas e regiões expostas do metal.

TABELA 3: Espessuras da camada de $\mathrm{Al}_{2} \mathrm{O}_{3}$ obtidas por anodização por controle de potencial com diferentes programas de aplicação de potencial durante 20 minutos.

\begin{tabular}{|c|c|}
\hline Programa de aplicação de potencial & Espessuras (mícrons) \\
\hline 1 V a cada minuto & 16,0 \\
\hline 5 V a cada 5 minutos & 16,0 \\
\hline 0,5 V a cada 1 minuto & 15,5 \\
\hline
\end{tabular}

Comparando os resultados mostrados na TAB. 3 e nas FIG. 6-A e 6-B, pode-se observar que a espessura da camada não sofre influência significativa do programa de aplicação de potencial no processo de anodização, porém o grau de cobertura do óxido anódico sobre o alumínio é muito superior quando o potencial é aumentado gradativamente, e por esse motivo as anodizações por controle de potencial à partir destes resultados serão feitas dessa maneira. Porém, se no programa de aplicação de potencial fosse aumentado $1 \mathrm{~V}$ por minuto, o potencial final de $23 \mathrm{~V}$ só seria atingido após 23 minutos de anodização. Por isso estudou-se um programa de aumento de potencial gradativo no qual o potencial final foi atingido em 14 minutos após o início, e esse foi mantido até 40 minutos de anodização por controle do potencial. Em anodizações por controle da corrente foi seguido o mesmo regime nos primeiros 14 minutos de anodização e a partir daí uma densidade de corrente de $83 \mathrm{~mA} \mathrm{~cm}^{-2}$ foi mantida até o final da anodização.

No processo de anodização ocorrem duas reações principais, a formação química da camada de óxido, representada pela reação 33.

$$
2 \mathrm{Al}^{3+}{ }_{(\mathrm{aq})}+3 \mathrm{O}^{2-}{ }_{(\mathrm{aq})} \rightarrow \mathrm{Al}_{2} \mathrm{O}_{3(\mathrm{~s})}
$$


e a dissolução química desta ocasionada pela ação do eletrólito (reação 34):

$$
\mathrm{Al}_{2} \mathrm{O}_{3(\mathrm{~s})}+3 \mathrm{H}_{2} \mathrm{SO}_{4(\mathrm{aq})} \rightarrow \mathrm{Al}_{2}\left(\mathrm{SO}_{4}\right)_{3(\mathrm{aq})}+3 \mathrm{H}_{2} \mathrm{O}_{(\mathrm{l})}
$$

Para que a velocidade da reação de formação da camada de óxido seja maior que a velocidade de dissolução do filme é necessário que o potencial seja aplicado gradativamente, ou seja, uma velocidade de varredura menor, pois quanto mais abruptamente o potencial é aplicado, maior a velocidade de dissolução química do eletrólito sobre o filme anódico e sobre o alumínio (pois não há tempo suficiente para a formação de satisfatória de um filme homogêneo), alterando sua morfologia, e conseqüentemente alterando a morfologia do óxido. Portanto, quando o potencial é aplicado abruptamente o óxido formado é mais poroso e, portanto, menos duro cerca de $70 \mathrm{Hv}$ a menos, e se essa dissolução for muito intensa pode ocasionar uma camada com espessura não homogênea.

\subsubsection{Influência da duração da anodização em eletrólito $\mathrm{H}_{2} \mathrm{SO}_{4}$.}

Determinado o melhor programa de aplicação de potencial na anodização, a próxima etapa foi avaliar a influência da duração da anodização na qualidade do filme formado. Para isso foram feitas anodizações, fixando as mesmas condições experimentais e variando apenas a duração 25; 40 e 55 minutos. Para a caracterização desses filmes foram obtidas imagens em microscópio ótico com analisador de imagens e medidas as microdurezas dos filmes.

As medidas de microdureza dos filmes foram uma forma indireta de avaliar a porosidade do óxido anódico. Esse tipo de análise foi necessária, porque como os poros do óxido anódico possuem diâmetro muito pequeno, na escala de nanômetros, não foi possível obter dados de porosidade com testes convencionais, com o uso de porosímetro, por exemplo.

Outra forma possível de avaliar a porosidade do óxido seria através de imagens de microscopia eletrônica de transmissão, porém para esse tipo de análise seria necessário um prétratamento das amostras no qual o óxido anódico deveria ser cortado em fatias de no máximo $50 \mathrm{~nm}$ de espessura, e para esses cortes seria necessário o uso de um ultramicrótomo com lâmina de diamante. O laboratório adquiriu um ultramicrótomo, mas infelizmente não tivemos acesso à lâmina apropriada para o corte do óxido anódico. 
A TAB. 4 mostra a influência da duração da anodização na espessura e na microdureza dos filmes estudados.

TABELA 4: Influência da duração da anodização na espessura e na microdureza dos filmes anodizados por controle do potencial.

\begin{tabular}{|c|c|c|}
\hline Duração da anodização (min) & Espessura $(\mu \mathrm{m})$ & Microdureza $(\mathrm{Hv})$ \\
\hline 25 & 14,5 & 475 \\
\hline 40 & 40,0 & 358 \\
\hline 55 & 35,0 & 284 \\
\hline
\end{tabular}

Conforme é mostrado na TAB. 4, nas condições de anodização ensaiadas, conforme aumenta-se o tempo de anodização, a camada de $\mathrm{Al}_{2} \mathrm{O}_{3}$ vai aumentando sua espessura até um determinado ponto, conforme ilustram as imagens obtidas através de microscopia ótica com analisador de imagens (FIG. 7).
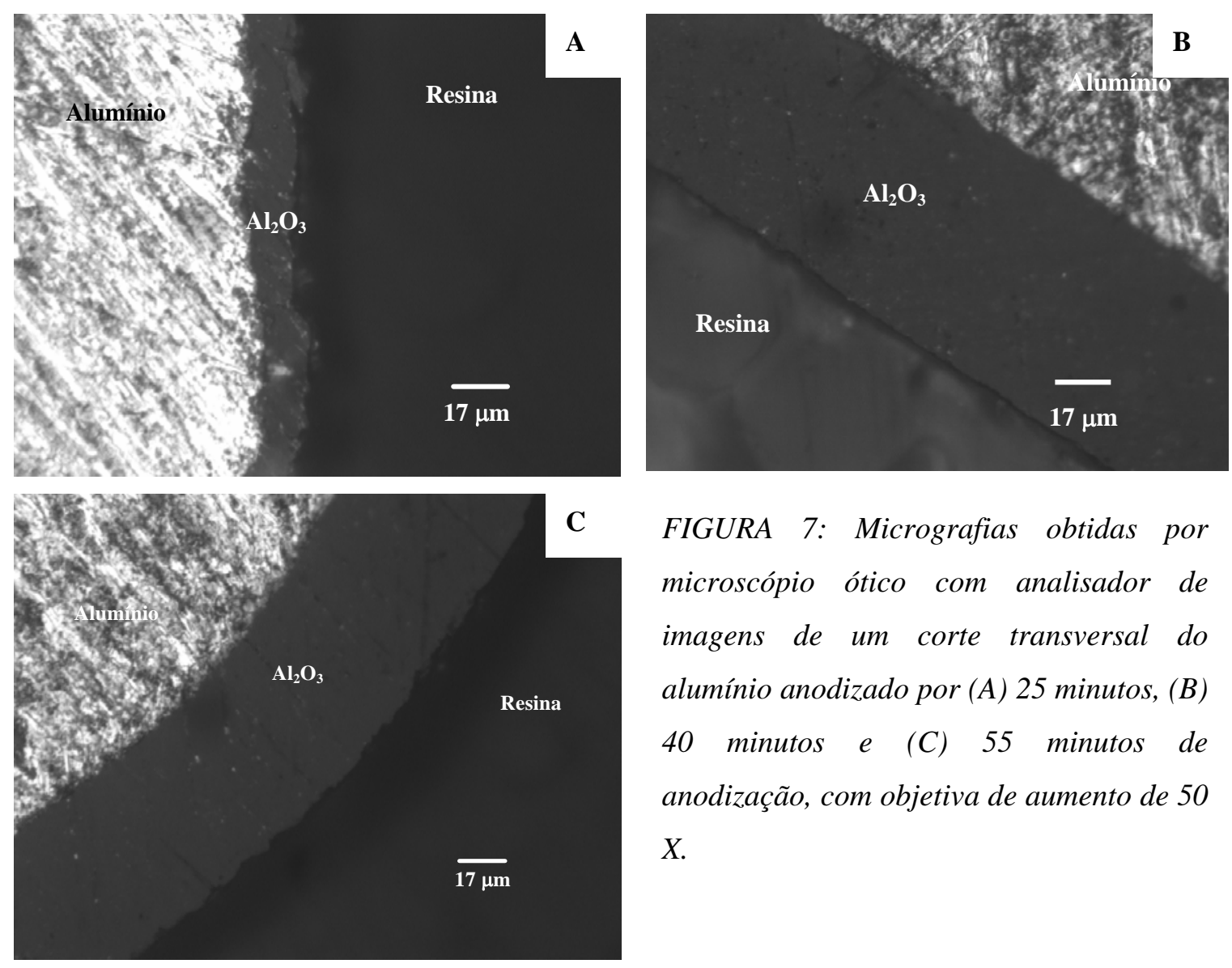

FIGURA 7: Micrografias obtidas por microscópio ótico com analisador de imagens de um corte transversal do alumínio anodizado por (A) 25 minutos, (B) 40 minutos e (C) 55 minutos de anodização, com objetiva de aumento de 50 $X$. 
Foi observado que as microdurezas dos filmes diminuíram com o aumento do tempo de anodização (TAB. 4), isso indica que quando o potencial é mantido constante, prevalece a dissolução do óxido causada pelo eletrólito, tornando o filme mais poroso, isso é favorável ao esperado neste trabalho.

As anodizações com tempos maiores (40 e 55 minutos) proporcionaram filmes com melhor cobertura ao metal, com camadas de espessuras maiores e sem grandes rachaduras, porém sabe-se que quanto maior o tempo gasto na anodização maior o consumo de energia. Por esta razão foram estudados mais dois tempos de anodização menores, 15 e 20 minutos, mantendo o potencial máximo de $23 \mathrm{~V}$, por tempos menores. Os resultados encontrados são mostrados na TAB. 5.

TABELA 5: Influência do tempo de anodização na espessura e microdureza dos filmes de $\mathrm{Al}_{2} \mathrm{O}_{3}$ formados por anodização potenciostática.

\begin{tabular}{|c|c|c|}
\hline Condições experimentais & Espessura (mícrons) & Microdureza (Vickers) \\
\hline $\begin{array}{l}\text { Tempo de anodização: 15 minutos } \\
\text { Mantendo 23 V durante 2 minutos }\end{array}$ & 10,8 & 352,7 \\
\hline $\begin{array}{l}\text { Tempo de anodização: 20 minutos } \\
\text { Mantendo 23 V durante 7 minutos }\end{array}$ & 20,0 & 330,0 \\
\hline
\end{tabular}

O filme formado em 15 minutos de anodização apresentou grau de cobertura comprometido e espessura muito pequena. Já o filme formado em 20 minutos se mostrou com uma morfologia mais uniforme com espessura e microdureza razoáveis. Imagens obtidas por microscopia ótica com analisador de imagens desses filmes comparadas com as obtidas do filme anodizado por 40 minutos indicaram maior proteção ao alumínio (maior grau de cobertura e espessura maior) no último caso.

Com relação à comparação da influência do tempo de anodização na espessura do óxido anódico (TAB. 4), pode ser observado nas imagens obtidas pelo microscópio eletrônico de varredura e por microscópio ótico com analisador de imagens, que a espessura da camada de $\mathrm{Al}_{2} \mathrm{O}_{3}$ formada em 40 minutos de anodização é muito maior que a espessura do filme formado em 25 
minutos. Isto se deve à etapa de formação do filme de $\mathrm{Al}_{2} \mathrm{O}_{3}$ que predomina em relação à etapa de dissolução do óxido anódico pelo eletrólito.

Porém, a espessura do filme formado em 55 minutos de anodização é menor que a espessura do filme formado em 40 minutos, isto provavelmente acontece devido à velocidade de dissolução do filme anódico causada pelo eletrólito que deve ser maior que a velocidade de formação do filme quando o potencial é mantido constante na anodização. Isto porque quando a anodizaçao é feita em 55 minutos o potencial máximo é mantido durante mais tempo, e durante esse período, prevalece a dissolução química do filme, já que o filme anódico com uma espessura considerável fornece uma resistência à passagem da corrente, que vai diminuindo com o tempo, esse processo dificulta um maior crescimento do filme pela ação da corrente aplicada. Essa diminuição da corrente com o tempo foi observada com a ajuda de um multímetro ligado em série com o sistema.

Os testes de microdureza mostraram que o filme formado com menor tempo de anodização (25 minutos) possui maior microdureza que o formado em 40 minutos que, por sua vez, possui maior microdureza que filmes anodizados por $55 \mathrm{~min}$ (TAB. 4). Isto pode ser explicado devido ao fato de que com o passar do tempo de anodização (mantendo o potencial constante) a corrente vai diminuindo devido ao aumento da espessura do óxido anódico (que oferece maior resistência à sua passagem) vai prevalecendo a velocidade de dissolução do filme em relação à velocidade de sua formação.

Nesta etapa do trabalho, concluímos que as melhores condições experimentais para a obtenção de um filme com características protetoras ao alumínio e, ao mesmo tempo com porosidade suficiente para receber a implantação do ferro, são aquelas em que o programa de aplicação de potencial na anodização foi gradativo e cujo tempo de anodização foi de 40 minutos.

\subsubsection{Influência da temperatura do eletrólito $\mathrm{H}_{2} \mathrm{SO}_{4}$ na camada anódica.}

A temperatura do eletrólito também influencia de maneira significativa na qualidade do filme de $\mathrm{Al}_{2} \mathrm{O}_{3}$ formado por anodização. No presente trabalho foram estudadas três temperaturas diferentes, e obtidos os resultados mostrados nos gráficos mostrados na FIG. 8.

Fica claro nos resultados obtidos que quanto menor a temperatura do eletrólito, menor a espessura do filme anódico, e maior sua microdureza (FIG. 8-A e 8-B, respectivamente), isto também foi observado em anodizações por controle da corrente. Para o objetivo deste trabalho, a 
melhor condição experimental quanto à temperatura do eletrólito é de $20^{\circ} \mathrm{C}$, já que o filme formado nesta condição possui espessura favorável a uma boa proteção do alumínio e menor microdureza, indicando maior porosidade que os demais, favorecendo a implantação de metais em etapas posteriores deste trabalho.
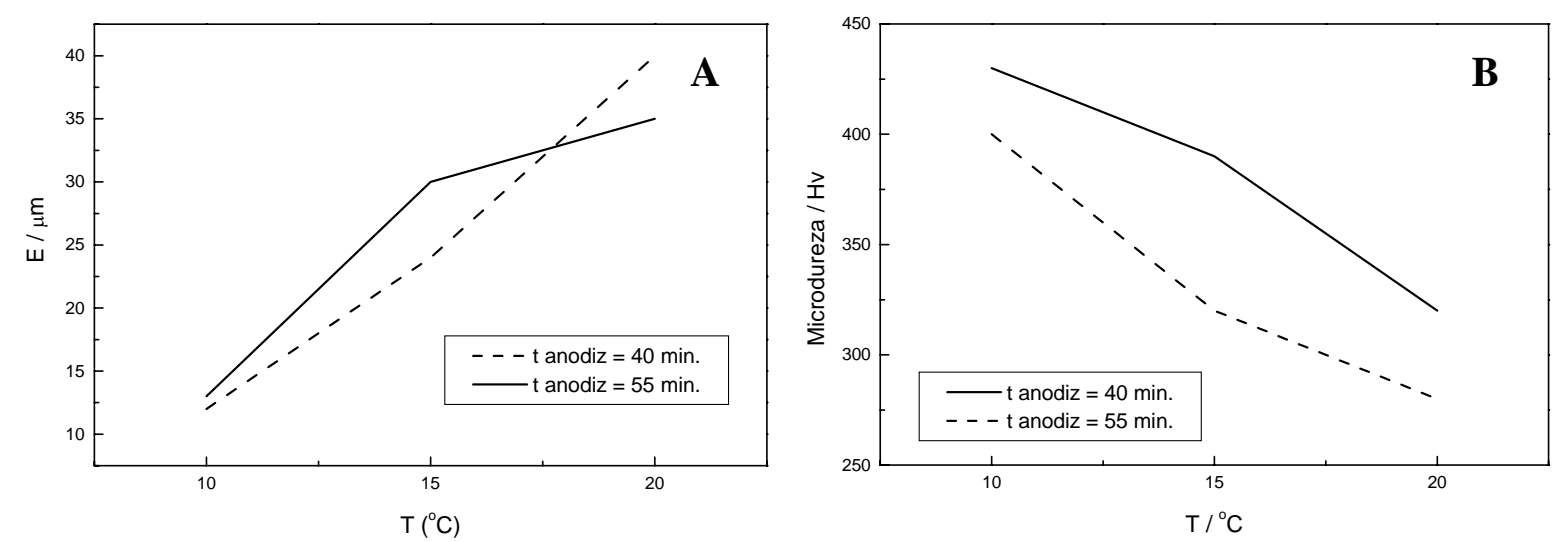

FIGURA 8: Influência da temperatura do eletrólito (A) na espessura (dada em mícrons) e (B) na microdureza Vickers do filme anódico de alumínio por anodização por controle do potencial em 40 minutos e 55 minutos.

Quanto menor a temperatura do eletrólito, menor a dissolução do filme pela ação do eletrólito e, portanto, menos poroso será o filme, mais duro. Quanto à diminuição da espessura do filme com a diminuição da temperatura, isto poderia ser explicado porque de acordo com a equação de Arrhenius (equação 35), se o mecanismo é mantido, a energia de ativação é a mesma e a diminuição da temperatura diminui a constante de velocidade $\mathrm{k}$ da reação (FIG. 9). Portanto, a velocidade da reação de formação do óxido diminui, a espessura é menor nesse caso. O aumento da espessura com a temperatura observado está de acordo com o trabalho de R-L Chiu e et al. [96] que observou o mesmo efeito a 8 e $25^{\circ} \mathrm{C}$.

$$
\ln (\mathrm{k})=\ln (\mathrm{A})-(\mathrm{Ea} / \mathrm{R} . \mathrm{T})
$$

Onde:

$\mathrm{k}=$ constante de velocidade;

$\mathrm{A}=$ constante (depende, dentre outros, da área de contato); 
$\mathrm{Ea}=$ Energia de ativação;

$\mathrm{R}=$ constante dos gases;

$\mathrm{T}=$ Temperatura;

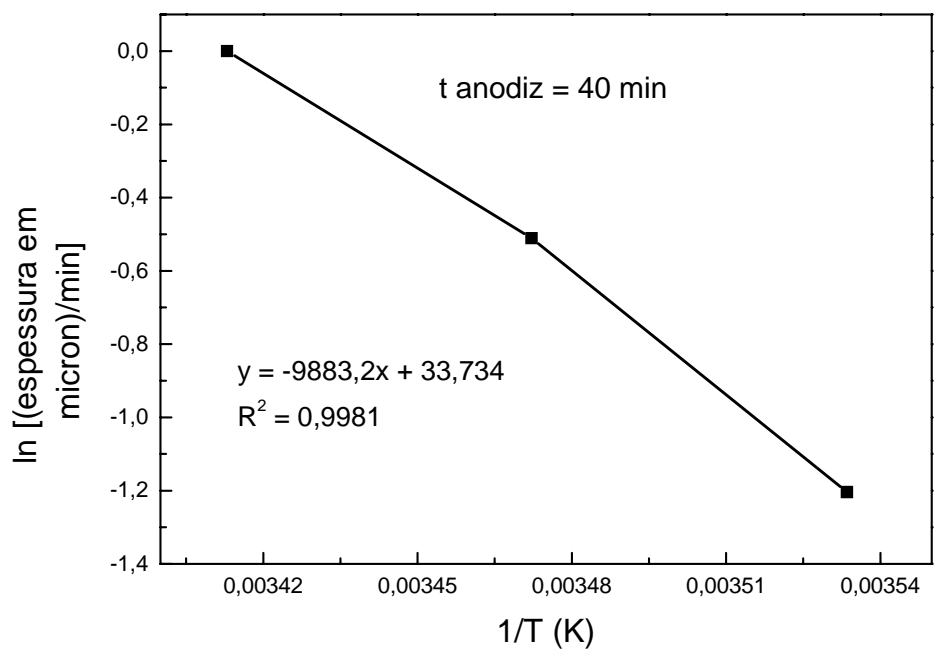

FIGURA 9: Gráfico de Arrhenius para a relação da espessura do óxido anódico com a temperatura do eletrólito, obtido a partir dos resultados experimentais de uma anodização por 40 minutos.

\subsubsection{Influência da anodização por controle da corrente ou do potencial no filme de óxido anódico em $\mathrm{H}_{2} \mathrm{SO}_{4}$.}

O objetivo desta etapa é comparar as características dos filmes formados controlando-se o potencial ou a corrente, e avaliar em quais dessas situações forma-se um filme mais favorável aos os objetivos desse trabalho. Para isso as amostras de alumínio foram anodizadas nas melhores condições encontradas, variando-se apenas os regimes de anodização.

Para o controle da corrente e do potencial, foram utilizados dois multímetros conectados ao retificador de corrente, um ligado em série, no qual a corrente era monitorada, e outro em paralelo, no qual o potencial aplicado era monitorado para ser ajustado de forma a manter a corrente constante.

Foi observado que a anodização por controle da corrente produz filmes com espessuras similares aos filmes formados por anodização com controle do potencial quando a temperatura do eletrólito é de $20^{\circ} \mathrm{C}$, porém, a $15^{\circ}$ e $10^{\circ} \mathrm{C}$, a espessura do filme anodizado por controle da corrente diminui com muito menor intensidade, como mostram as curvas mostradas no gráfico da FIG. 10. 
Portanto, em relação à espessura do filme, a anodização por controle da corrente sofre menor influência da temperatura do eletrólito, e produz filmes com maiores espessuras à 10 e $15^{\circ} \mathrm{C}$ do que a anodização por controle do potencial.

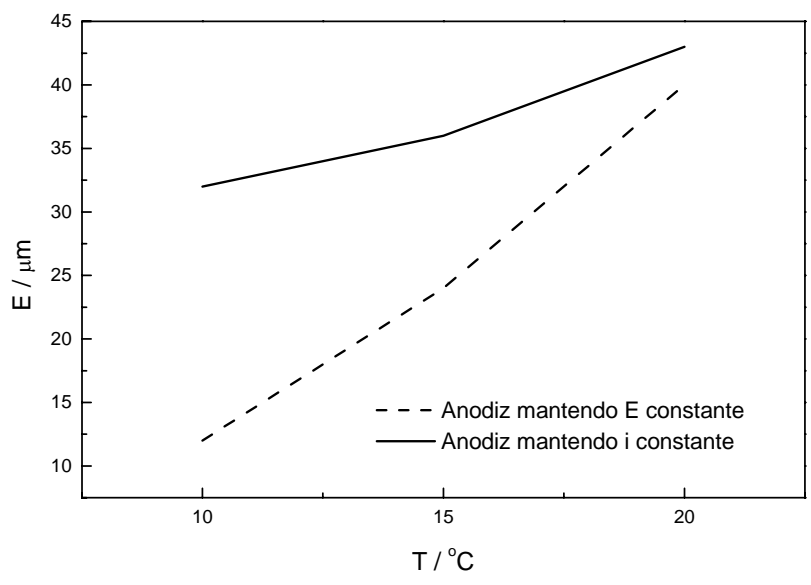

FIGURA 10: Influência do regime de anodização (por controle do potencial ou da corrente) na espessura da camada de $\mathrm{Al}_{2} \mathrm{O}_{3}$, de acordo com a variação da temperatura do eletrólito, em anodizações cujas demais condições experimentais foram as mesmas.

As microdurezas de filmes formados por anodização por controle de potencial e da corrente foram comparadas em três temperaturas diferentes (FIG. 11), e foi observado que o sistema de anodização por controle da corrente produz filmes com microdurezas superiores aos filmes formados por anodização por controle do potencial, porém em ambos os casos, conforme a temperatura do eletrólito diminui, essas microdurezas vão aumentando em proporções parecidas como mostram as curvas do gráfico da FIG. 11.

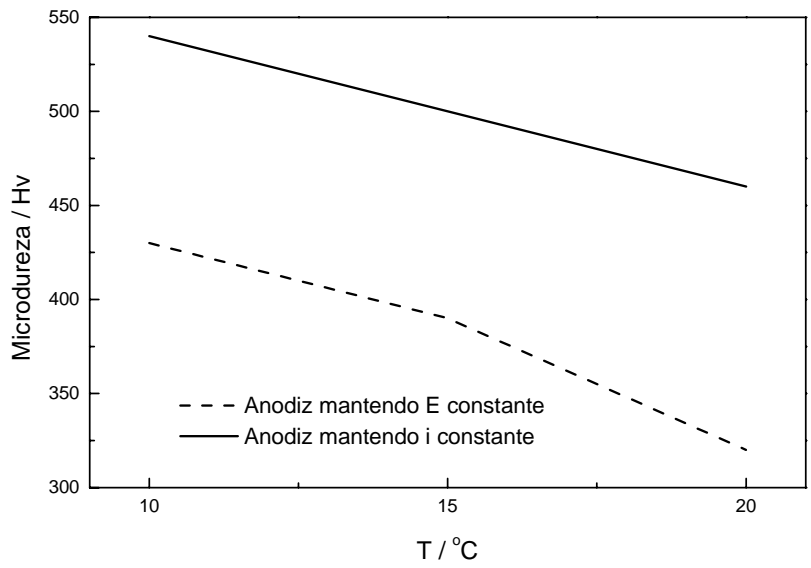

FIGURA 11: Influência do regime de anodização (por controle do potencial ou da corrente) na microdureza da camada de $\mathrm{Al}_{2} \mathrm{O}_{3}$ de acordo com a variação da temperatura do eletrólito, em anodizações com eletrólito $\mathrm{H}_{2} \mathrm{SO}_{4} 1,7 \mathrm{~mol} \mathrm{~L} \mathrm{~L}^{-1}$ durante 40 minutos. 
A camada anódica oferece resistência à passagem da corrente elétrica, por esse motivo quando se controla o potencial e o mantém constante no processo de anodização, a espessura da camada vai crescendo juntamente com a resistência à passagem da corrente, isso acarreta na diminuição da corrente, conferida com uma leitura no multímetro ligado em série, assim prevalece a velocidade de dissolução química da camada anódica em relação à velocidade de formação da camada, fazendo com que a camada fique mais porosa e, portanto, com microdureza inferior.

$\mathrm{Na}$ anodização por controle da corrente, esta é mantida, mesmo com o aumento da espessura da camada, fazendo com que a velocidade de crescimento do filme prevaleça em relação à dissolução química deste, isso explicaria a maior microdureza observada. Como o interesse do trabalho é a eletrodeposição de ferro no interior dos poros do óxido anódico, a anodização por controle do potencial é mais favorável nesse caso.

\subsubsection{Influência da concentração do eletrólito usado na anodização}

A influência da concentração do eletrólito $\mathrm{H}_{2} \mathrm{SO}_{4}$ nas características do filme anódico foi investigada. Para isso foram mantidas as demais condições de anodização, variando-se apenas a concentração do eletrólito, sendo ora $0,9 \mathrm{~mol} \mathrm{~L}^{-1}$, ora $2,7 \mathrm{~mol} \mathrm{~L}^{-1}$, e os resultados foram comparados

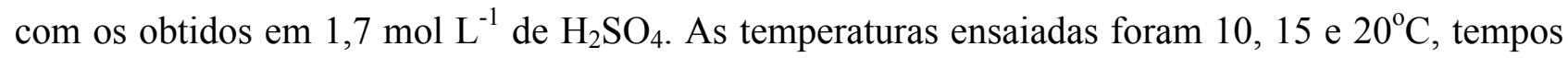
de anodização de 20 e 40 minutos e os regimes, por controle de potencial e da corrente.

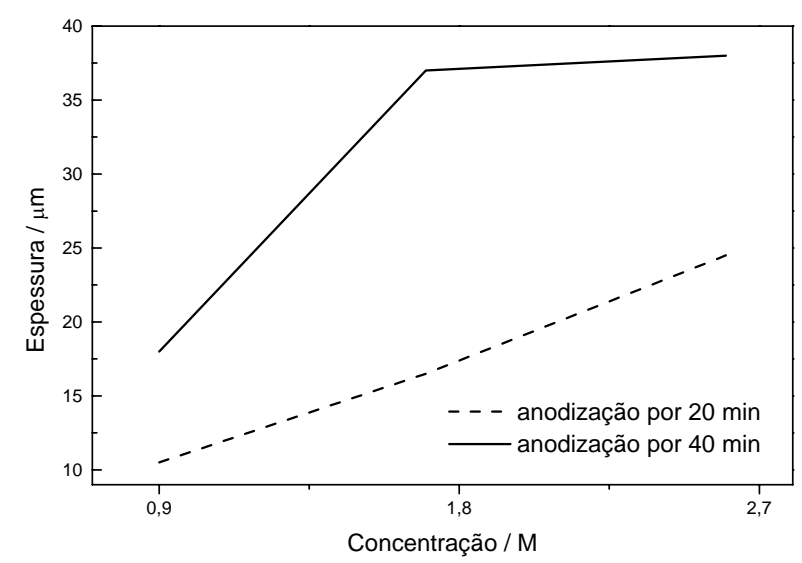

$$
\begin{aligned}
& \text { FIGURA 12: Influência da } \\
& \text { concentração do eletrólito, } \mathrm{H}_{2} \mathrm{SO}_{4} \text {, na } \\
& \text { espessura do filme de } \mathrm{Al}_{2} \mathrm{O}_{3} \text { para } \\
& \text { anodizações de } 20 \text { e } 40 \text { minutos, a } \\
& 20^{\circ} \mathrm{C} \text {, anodização por controle do } \\
& \text { potencial, nas três concentrações do } \\
& \text { eletrólito: 0,9; } 1,7 \text { e 2,6 mol } \mathrm{L}^{-1} \text {. }
\end{aligned}
$$

A condutividade iônica da solução de $\mathrm{H}_{2} \mathrm{SO}_{4}$ a $20^{\circ} \mathrm{C}$ nas três concentrações estudadas foi medida, e os valores mostrados na TAB. 6 indicam a baixa condutividade da solução menos 
concentrada, que pode ter influenciado na dimunuição da velocidade de formação da camada anódica, ocasionando menores espessuras do filme anódico nessas condições (FIG. 12).
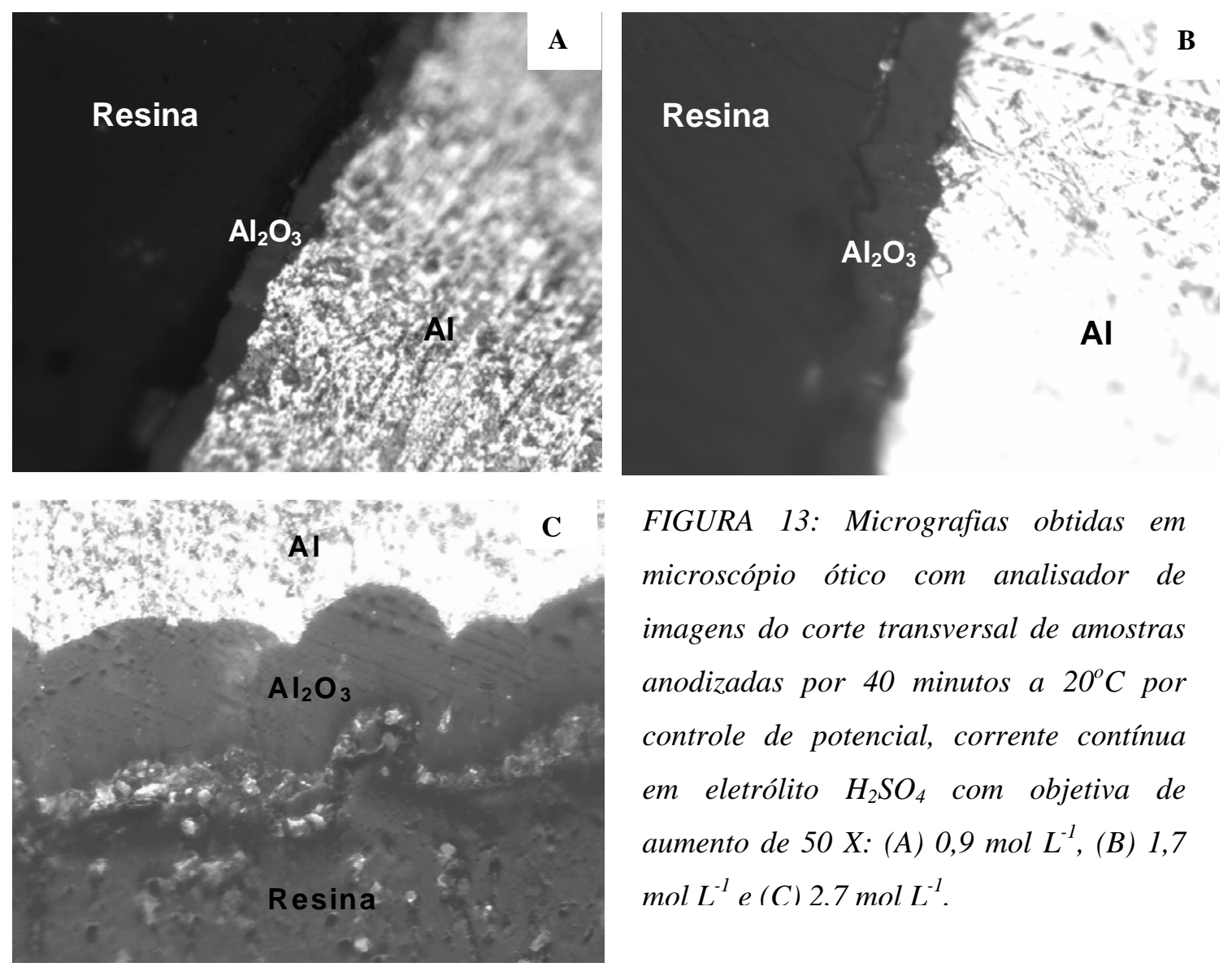

FIGURA 13: Micrografias obtidas em microscópio ótico com analisador de imagens do corte transversal de amostras anodizadas por 40 minutos a $20^{\circ} \mathrm{C}$ por controle de potencial, corrente contínua em eletrólito $\mathrm{H}_{2} \mathrm{SO}_{4}$ com objetiva de aumento de $50 \mathrm{X}$ : (A) $0,9 \mathrm{~mol} \mathrm{~L}^{-1}$, (B) 1,7 mol L-1 e (C) $2.7 \mathrm{~mol} \mathrm{~L}^{-1}$.

TABELA 6: Condutividade iônica a $20^{\circ} \mathrm{C}$ da solução de $\mathrm{H}_{2} \mathrm{SO}_{4}$ nas três concentrações estudadas.

\begin{tabular}{|l|l|}
\hline Solução & Condutividade $\Omega^{-1}$ \\
\hline $\mathrm{H}_{2} \mathrm{SO}_{4} 0,9 \mathrm{~mol} \mathrm{~L}^{-1}$ & 0,3436 \\
\hline $\mathrm{H}_{2} \mathrm{SO}_{4} 1,7 \mathrm{~mol} \mathrm{~L}^{-1}$ & 0,4965 \\
\hline $\mathrm{H}_{2} \mathrm{SO}_{4} 2,6 \mathrm{~mol} \mathrm{~L}^{-1}$ & 0,5355 \\
\hline
\end{tabular}

Como pode ser observado nas FIG. 12 e 13, a espessura do óxido anódico aumenta com a concentração do eletrólito. Este efeito ocorre nos dois tempos de anodização estudados, 20 e 40 
minutos, sendo que as anodizações feitas em 40 minutos produzem filmes com espessura maior que nas anodizações feitas em 20 minutos (FIG. 12).

Como já tinha sido observado no estudo do alumínio anodizado em $\mathrm{H}_{2} \mathrm{SO}_{4} 1,7$ mol L $\mathrm{L}^{-1}$, o tempo de anodização tem grande influência na espessura do filme de $\mathrm{Al}_{2} \mathrm{O}_{3}$, porém conforme observado nas FIG. 12 e 13 a concentração do eletrólito também influencia na espessura e no grau de cobertura da camada anódica.
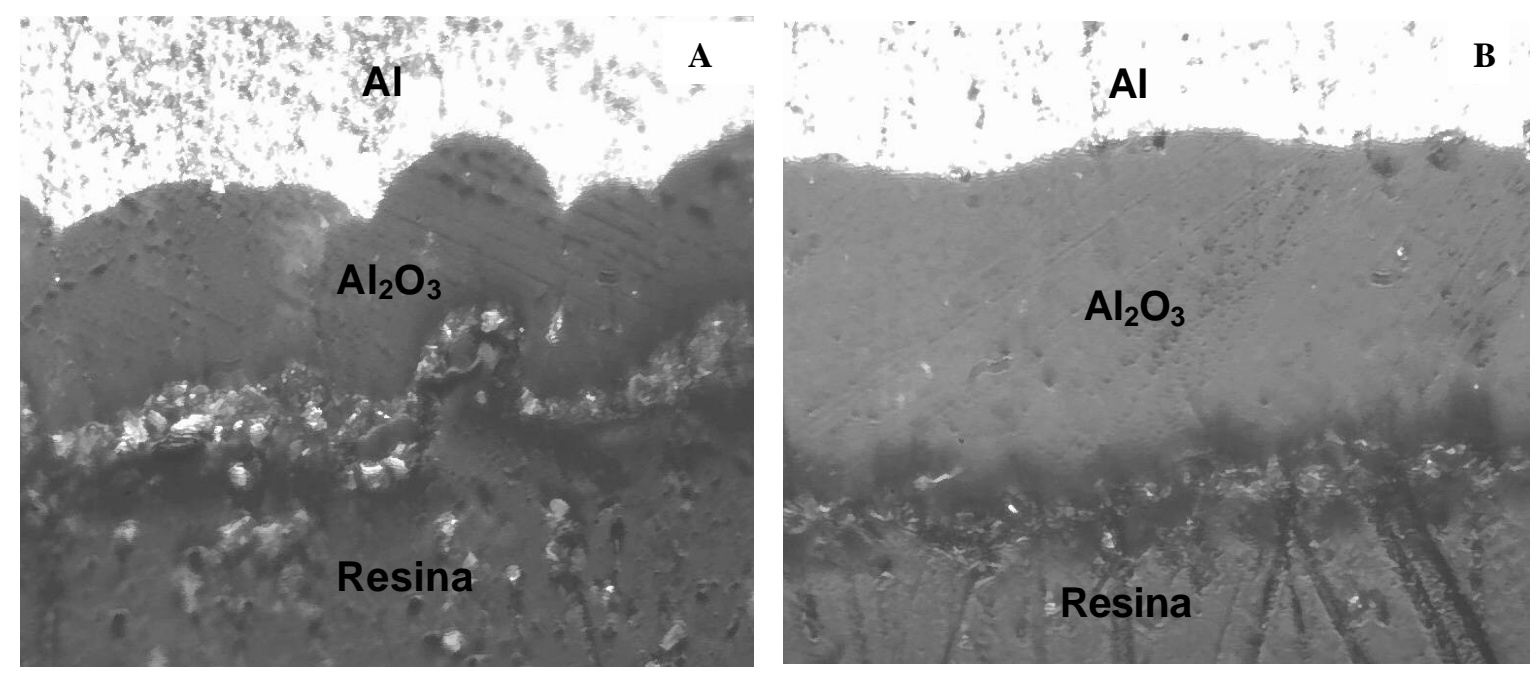

FIGURA 14: Micrografias obtidas em analisador de imagens do corte transversal de amostras anodizadas com eletrólito $\mathrm{H}_{2} \mathrm{SO}_{4}$ 2,6 mol L-1, 20ㅇ, em anodização de: (A) 20 e (B) 40 minutos; por corrente contínua, anodização por controle do potencial, com objetiva de aumento de $50 \mathrm{X}$.

Foi observado por microscópio ótico com analisador de imagens (FIG. 13-A) e também por microscópio ótico com luz polarizada que, em todos os casos estudados, camadas formadas com baixa concentração do eletrólito, $0,9 \mathrm{~mol} \mathrm{~L}^{-1}$, possuem espessuras menores e com grau de cobertura comprometidos, já que em muitas regiões foi visualizada parte do alumínio sem a presença de camada. Nos filmes crescidos em anodização com eletrólitos muito concentrados, 2,6 mol L-1, as camadas eram mais espessas, porém com espessura não uniforme, sendo que nestes casos também foram encontradas regiões de metal sem camada, principalmente nos cantos da amostra. As melhores camadas, com melhor grau de cobertura, foram as formadas em anodização utilizando $\mathrm{H}_{2} \mathrm{SO}_{4} 1,7 \mathrm{~mol} \mathrm{~L}^{-1}$.

Como pode ser observado na FIG. 14-A, mesmo que a espessura do filme de $\mathrm{Al}_{2} \mathrm{O}_{3}$ seja considerável, a topografia do filme de $\mathrm{Al}_{2} \mathrm{O}_{3}$ segue a topografia do alumínio. Se a espessura for 
pequena, qualquer desnível na topografia do substrato pode deixar parte do metal exposta ao meio, prejudicando sua proteção.
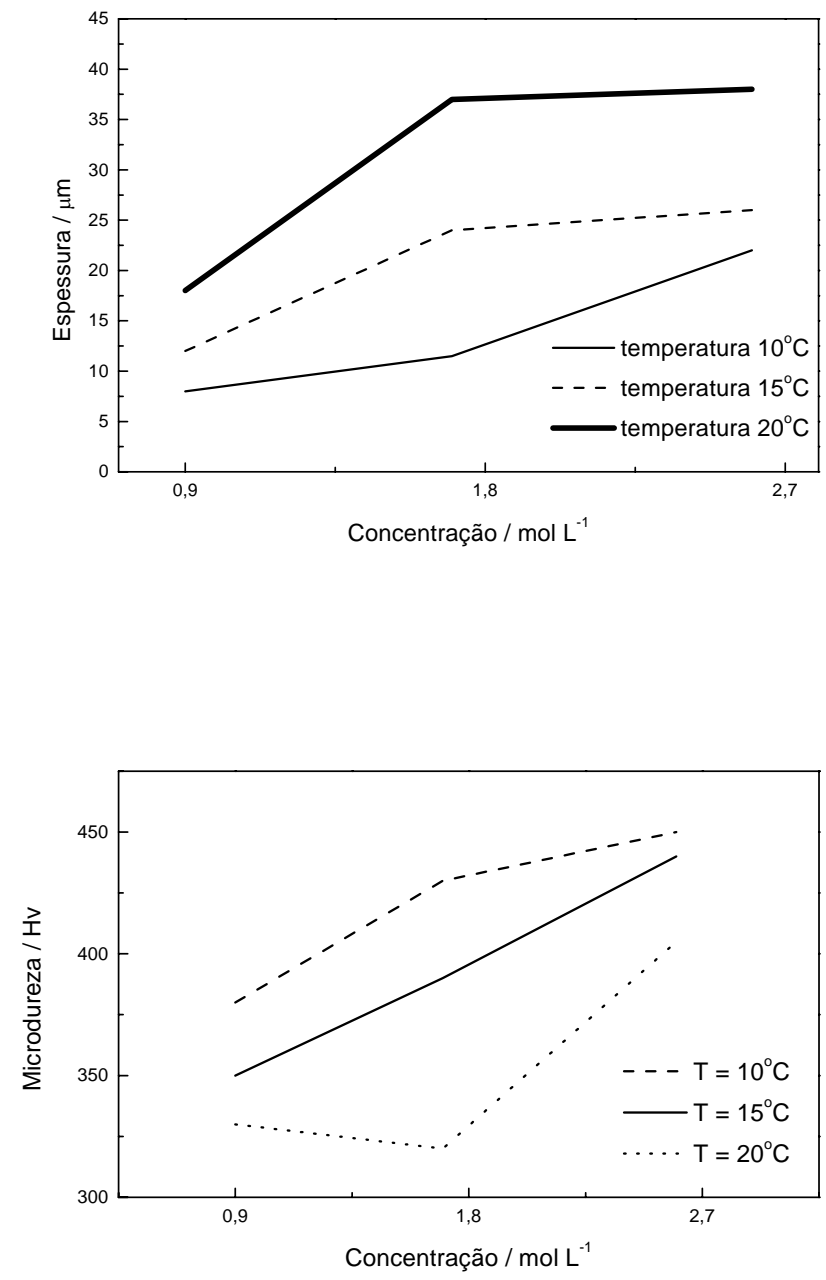

FIGURA 15: Influência da concentração do eletrólito, $\mathrm{H}_{2} \mathrm{SO}_{4}$, na espessura do filme em diferentes temperaturas 20, 15 e $10^{\circ} \mathrm{C}$, anodização por controle do potencial por 40 minutos, corrente contínua, nas três concentrações do eletrólito, 0,9; 1,7 e 2,6 mol $L^{-1}$.

FIGURA 16: Influência da concentração do eletrólito, $\mathrm{H}_{2} \mathrm{SO}_{4}$, na microdureza do filme para diferentes temperaturas de eletrólito, 20, 15 e $10^{\circ} \mathrm{C}$, anodização por controle do potencial em 40 minutos.

Comparando a influência da concentração do eletrólito na espessura do óxido anódico em relação à temperatura do banho, pode ser observado na FIG. 15 que nas três temperaturas estudadas o efeito da concentração do eletrólito é o mesmo, ou seja, o aumento da espessura com o aumento da concentração do eletrólito. Como já havia sido obtido anteriormente, quanto maior a temperatura do banho, maior a espessura do filme.

Na FIG. 16 é mostrado o mesmo efeito da concentração do eletrólito em relação à microdureza da camada anódica nas três temperaturas estudadas, ou seja, a sua microdureza aumenta com o aumento da concentração do eletrólito. 

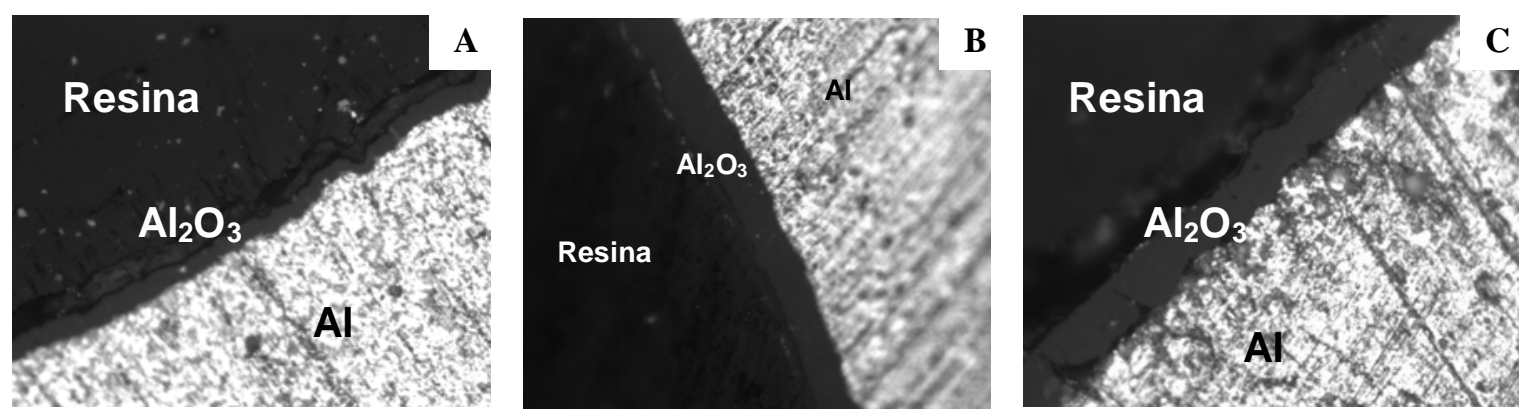

FIGURA 17: Micrografias obtidas em microscópio ótico com analisador de imagens do corte transversal de amostras anodizadas por 40 minutos potenciostaticaticamente por corrente contínua com eletrólito $\mathrm{H}_{2} \mathrm{SO}_{4} 0,9 \mathrm{~mol} \mathrm{~L} \mathrm{~L}^{-1}$ a: (A) $10^{\circ} \mathrm{C}$, (B) $15^{\circ} \mathrm{C}$ e (C) $20^{\circ} \mathrm{C}$.
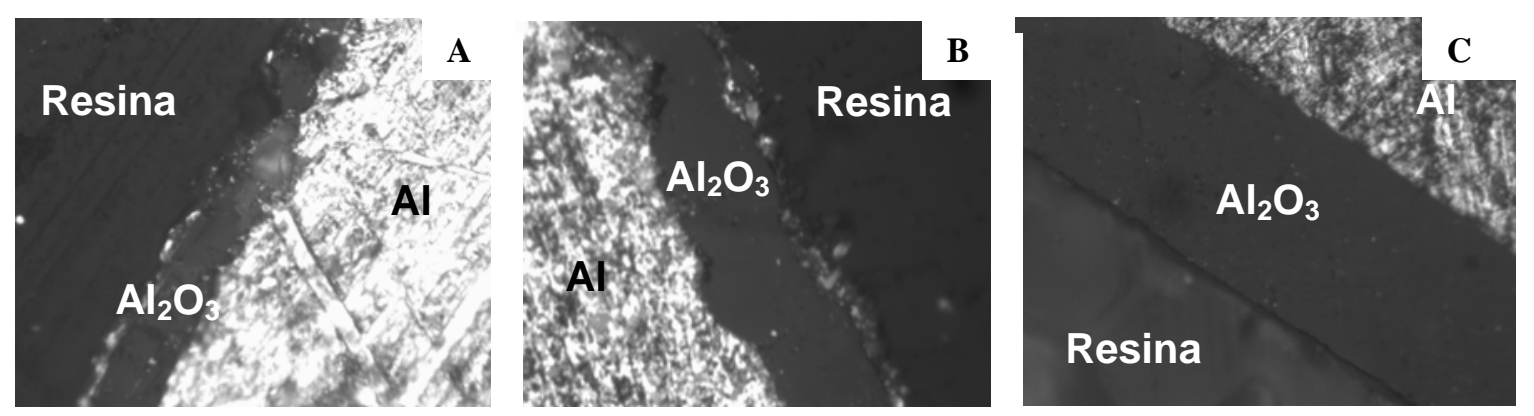

FIGURA 18: Micrografia obtida em microscópio ótico com analisador de imagens do corte transversal de amostras anodizadas potenciostaticamente por 40 minutos por corrente contínua com eletrólito $\mathrm{H}_{2} \mathrm{SO}_{4} 1,7 \mathrm{~mol} \mathrm{~L}^{-1}$ a: (A) $10^{\circ} \mathrm{C}$, (B) $15^{\circ} \mathrm{C}$ e (C) $20^{\circ} \mathrm{C}$.

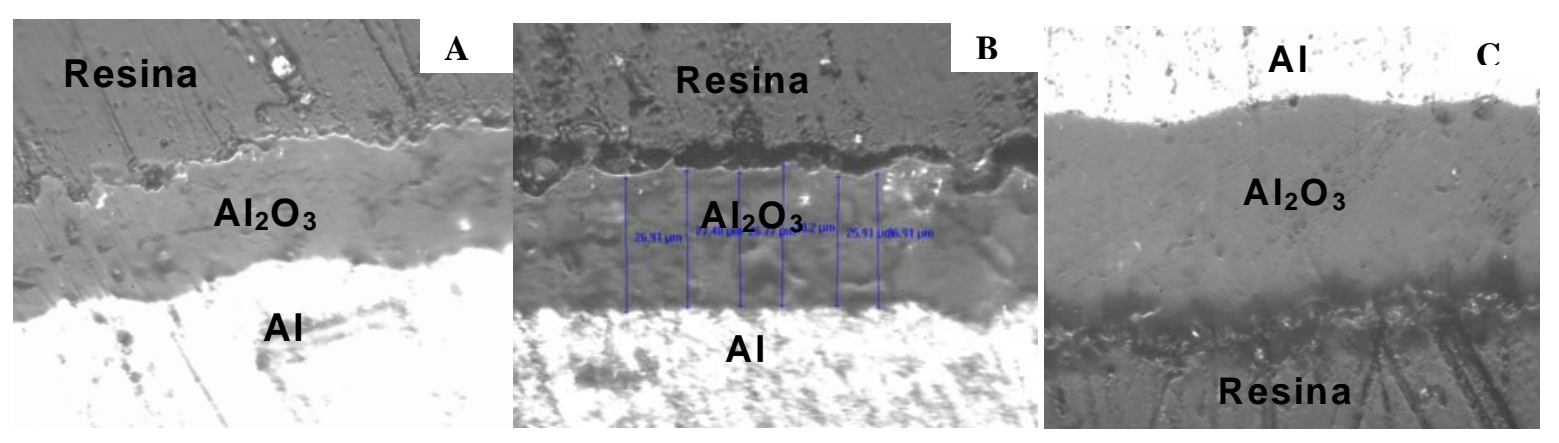

FIGURA 19: Micrografias obtidas em microscópio ótico com analisador de imagens do corte transversal de amostras anodizadas potenciostaticamente por 40 minutos por corrente contínua com eletrólito $\mathrm{H}_{2} \mathrm{SO}_{4} 2,6 \mathrm{~mol} \mathrm{~L} \mathrm{~L}^{-1}$ a: (A) $10^{\circ} \mathrm{C}$, (B) $15^{\circ} \mathrm{C}$ e (C) $20^{\circ} \mathrm{C}$. 
Comparando o efeito da concentração do eletrólito na uniformidade da espessura do filme, agora com relação à temperatura, fica claro nas FIG. 17,18 e 19, que filmes formados a $20^{\circ} \mathrm{C}$ são mais espessos e possuem espessura mais uniforme, os melhores filmes encontrados nesta parte do estudo foram os crescidos a $20^{\circ} \mathrm{C}$, com concentração do eletrólito de $1,7 \mathrm{~mol} \mathrm{~L}^{-1}$ e $2,6 \mathrm{~mol} \mathrm{~L}^{-1}$, sendo que o grau de cobertura foi superior em todas as regiões observadas nos filmes anodizados em $\mathrm{H}_{2} \mathrm{SO}_{4} 1,7 \mathrm{~mol} \mathrm{~L}^{-1}$.

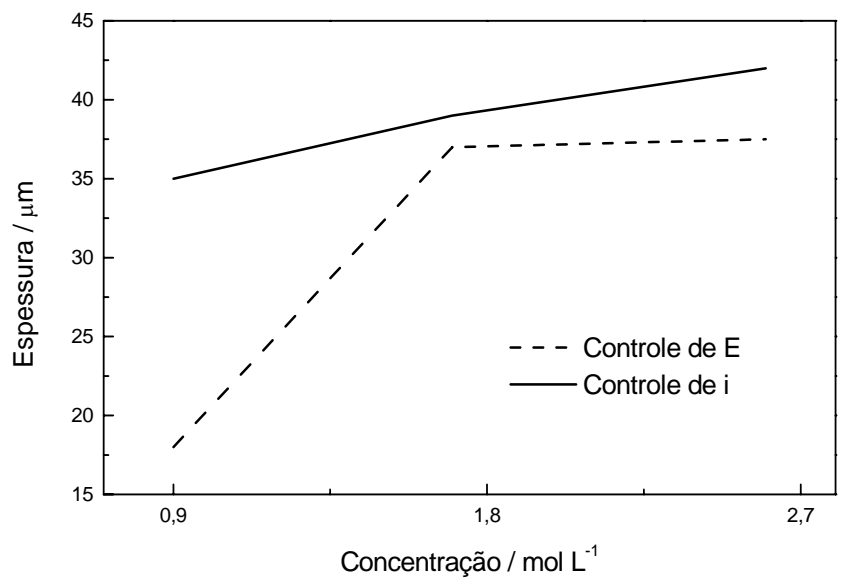

FIGURA 20: Influência da concentração do eletrólito, $\mathrm{H}_{2} \mathrm{SO}_{4}$, na espessura do filme nos diferentes regimes, em temperatura de eletrólito de $20^{\circ} \mathrm{C}$ por 40 minutos, por corrente contínua.

As espessuras dos filmes formados em anodizações com $\mathrm{T}=10^{\circ} \mathrm{C}$ e concentração do eletrólito $0,9 \mathrm{~mol} \mathrm{~L}^{-1}$ foram inferiores a $10 \mu \mathrm{m}$ e o grau de cobertura do óxido anódico foi comprometido nesse caso, assim estas condições são desfavoráveis para a boa proteção ao metal.

Como é mostrado na FIG. 20, tanto na anodização por controle do potencial como da corrente, a espessura do filme aumenta com o aumento da concentração do eletrólito, porém na anodização por controle do potencial esse efeito a baixas concentrações é mais efetivo.

O efeito da concentração do eletrólito nos dois regimes é comparado na FIG. 21, e foi observado que filmes formados em anodização por controle da corrente possuem microdurezas superiores aos formados em anodização por controle do potencial, em todas as concentrações de eletrólito estudadas. 


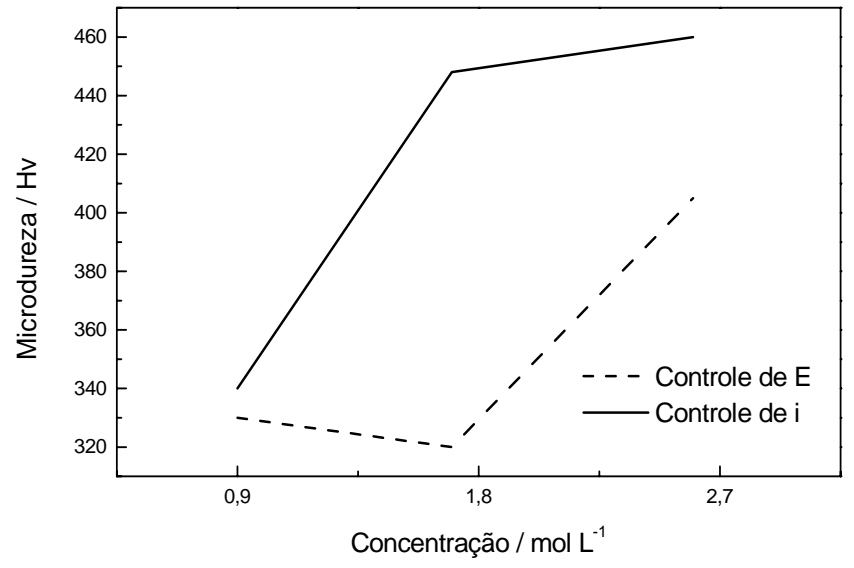

FIGURA 21: Influência da concentração do eletrólito, $\mathrm{H}_{2} \mathrm{SO}_{4}$, na microdureza do filme para diferentes regimes, por controle do potencial ou da corrente à temperatura de eletrólito de $20^{\circ} \mathrm{C}$, em 40 minutos por corrente contínua.
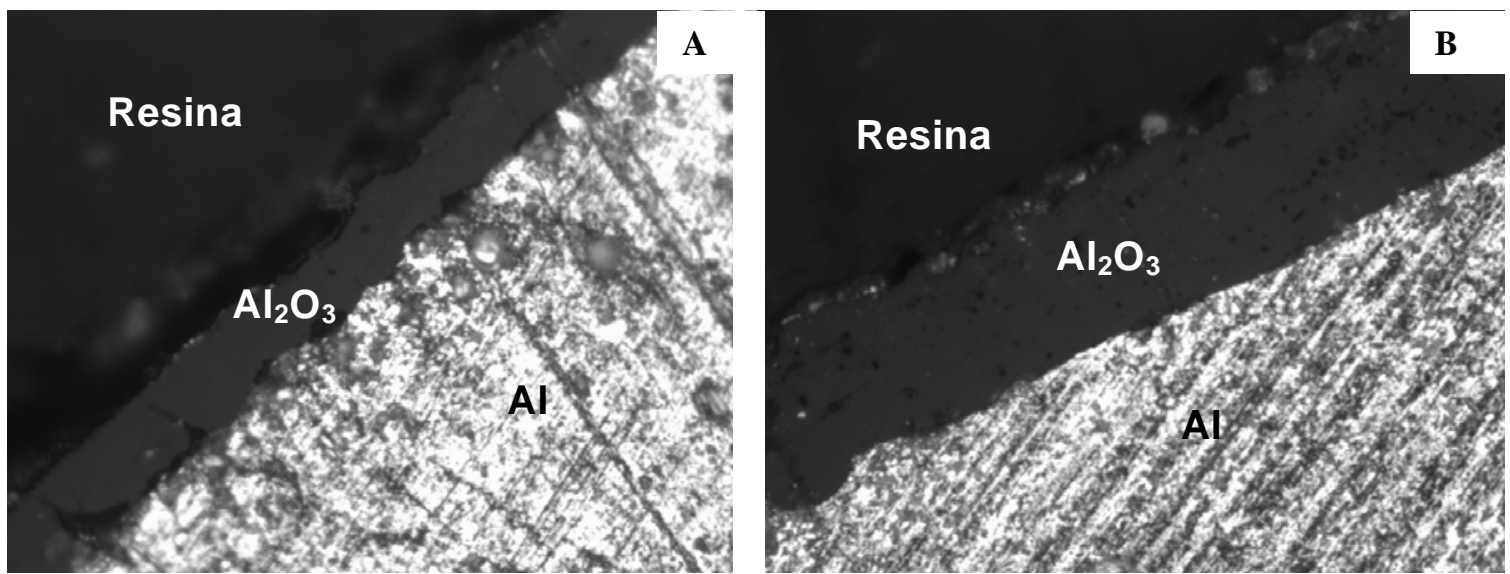

FIGURA 22: Micrografias obtidas em microscópio ótico com analisador de imagens do corte transversal de amostras anodizadas com eletrólito $\mathrm{H}_{2} \mathrm{SO}_{4} 0,9 \mathrm{~mol} \mathrm{~L}^{-1}$, a $20^{\circ} \mathrm{C}$ em anodização de 40 minutos por corrente contínua, anodização por: (A) controle do potencial e (B) controle da corrente, com objetiva de aumento de $50 \mathrm{X}$..

Nas três concentrações de $\mathrm{H}_{2} \mathrm{SO}_{4}$ estudadas a anodização por controle da corrente produziu filmes mais espessos que a anodização por controle do potencial (FIG. 22, 23 e 24). 

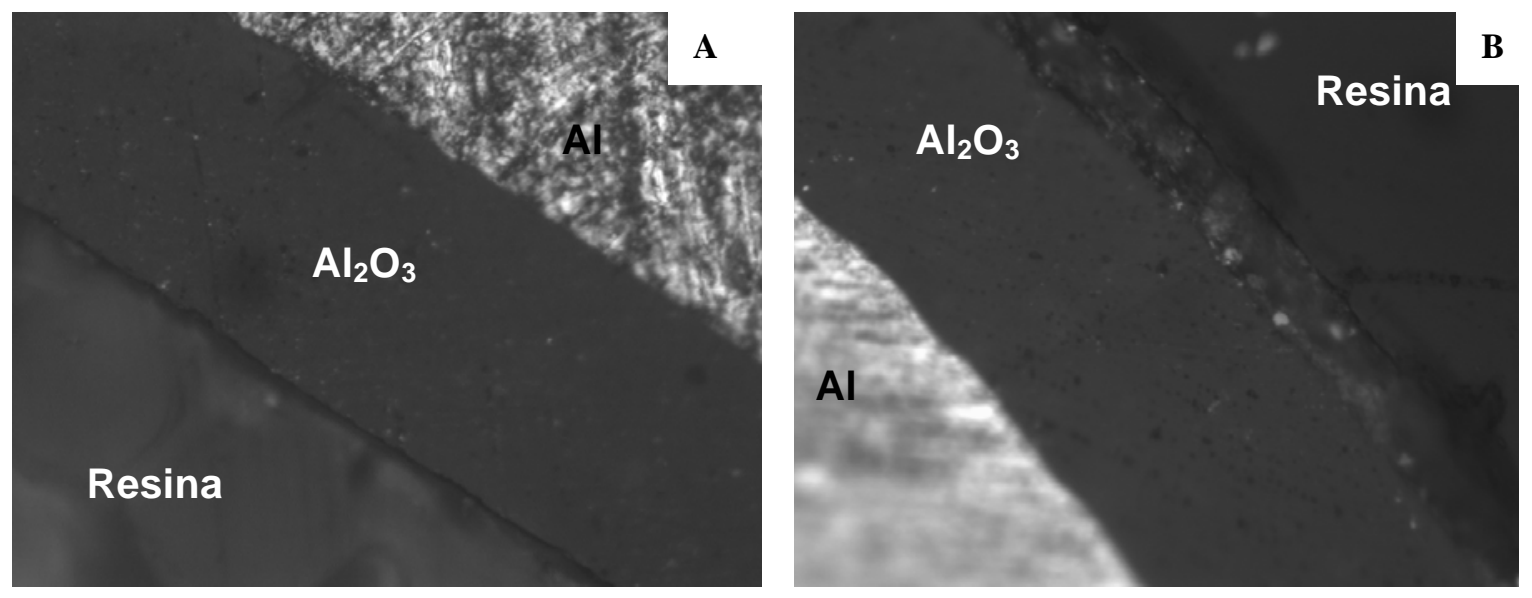

FIGURA 23: Micrografias obtidas em microscópio ótico com analisador de imagens de corte transversal de amostras anodizadas com eletrólito $\mathrm{H}_{2} \mathrm{SO}_{4} 1,7 \mathrm{~mol} \mathrm{~L} \mathrm{~L}^{-1}$, a $20^{\circ} \mathrm{C}$, em anodização de 40 minutos por corrente contínua, anodização por: (A) controle do potencial e (B) controle da corrente (B), com objetiva de aumento de $50 \mathrm{X}$.
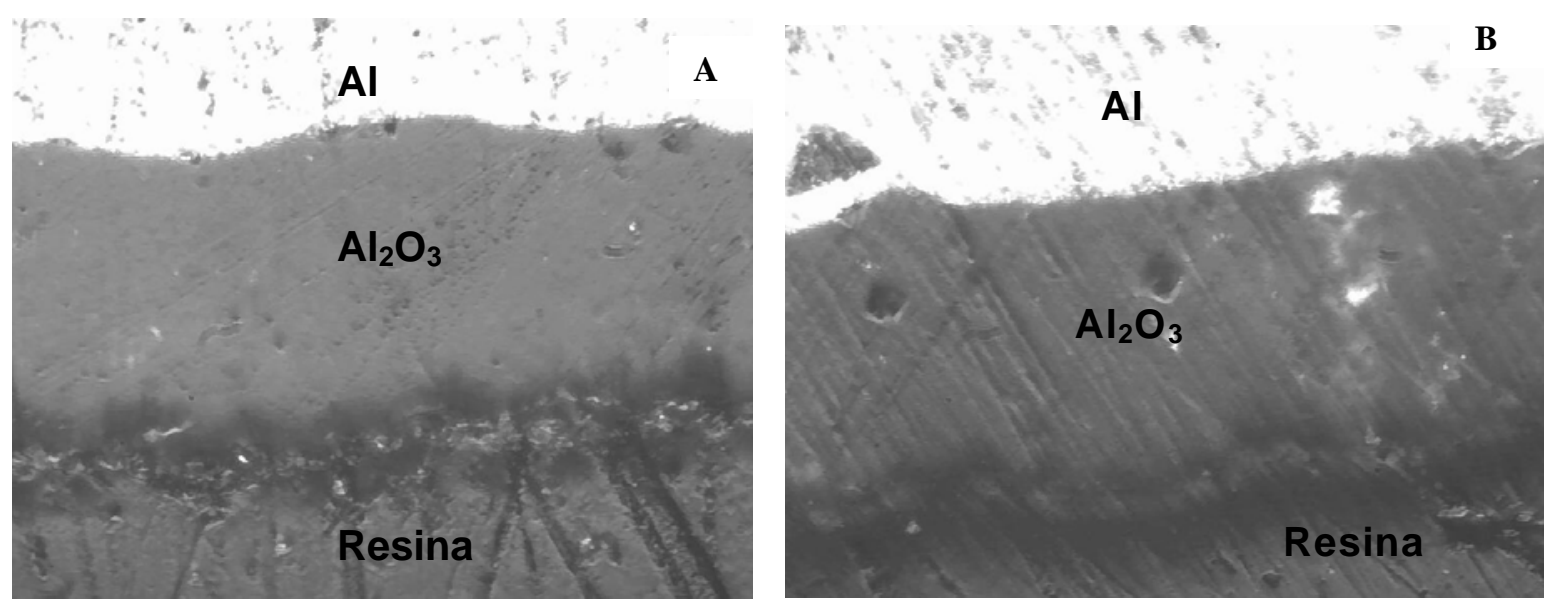

FIGURA 24: Micrografias obtidas em microscópio ótico com analisador de imagens do corte transversal de amostras anodizadas com eletrólito $\mathrm{H}_{2} \mathrm{SO}_{4} 2,6 \mathrm{~mol} \mathrm{~L}^{-1}$, a $20^{\circ} \mathrm{C}$, em anodização de 40 minutos por corrente contínua, por (A) controle do potencial e (B) controle da corrente com objetiva de aumento de $50 \mathrm{X}$.

O aumento da concentração do eletrólito utilizado na anodização causa um aumento na espessura do filme anódico. $\mathrm{O}$ aumento na espessura indica maior velocidade de formação do filme, que pode ser explicado pelo aumento da condutividade iônica do eletrólito, além de disso, o 
eletrólito mais concentrado possui maior capacidade de dissolução do filme, fazendo com que a camada de barreira (que quase não conduz corrente) possua espessura menor. A camada de barreira tem a propriedade de ser pouco porosa e oferecer certa resistência à passagem da corrente, quanto menor a espessura da camada de barreira, maior a corrente que passa na amostra, acelerando a velocidade de formação do óxido, aumentando sua espessura.

A dissolução causada pelo eletrólito sobre o filme de $\mathrm{Al}_{2} \mathrm{O}_{3}$, que ocorre simultaneamente ao crescimento acelerado do filme, torna-o mais poroso e isso pode acarretar na formação de um filme com espessura não uniforme, ou grau de cobertura comprometido, devido à forte dissolução do filme causada pelo eletrólito que acarreta em um crescimento desordenado formando lacunas, ao mesmo tempo que vai crescendo mais óxido, causando falhas na uniformidade da espessura do filme.

O preenchimento das lacunas formadas no momento da anodização desordenada explicaria a maior microdureza observada nesse tipo de filme.

No trabalho de Villanova e Dick [97], foi observado que a porosidade do óxido anódico foi superior em concentrações menores de $\mathrm{H}_{2} \mathrm{SO}_{4}$, esse dado está de acordo com o observado no presente trabalho.

\subsubsection{Influência do potencial pulsado na anodização}

No estudo do efeito da anodização por potencial pulsado, foram estudados ciclos de trabalho de 80 e $90 \%$, ciclos menores causaram a "queima" do filme no momento da anodização. Essa “queima", ou dissolução violenta do filme e do alumínio no momento da anodização pode ser explicada porque quanto menor o ciclo de trabalho, maior é o tempo "off”, ou o tempo de corrente nula [90], na etapa em que a corrente é nula, o crescimento do filme cessa, e somente há a sua dissolução pela ação do eletrólito, assim, se o tempo "off” for grande, o filme não consegue crescer a ponto de proteger o alumínio do ataque da dissolução que será intensa, devido à ação da alta corrente que está sendo aplicada ao sistema, havendo, portanto, a "queima" do filme.

As anodizações foram feitas sob as melhores condições experimentais encontradas até essa parte do estudo, ou seja: temperatura do eletrólito $20^{\circ} \mathrm{C}$, pois foi a temperatura estudada que proporcionou filmes mais espessos e porosos, tempo de anodização 40 minutos, pois foram obtidos filmes mais espessos, uniformes e porosos nesta condição e anodização por controle do potencial, 
que permitiu a formação de filmes com microdurezas menores que a anodização por corrente da corrente.

Os resultados foram comparados com os obtidos nas anodizações por corrente contínua, e serão mostrados nas FIG. 25, 26, 27 e 28.

$\mathrm{Na}$ TAB. 7, é possível observar que filmes anodizados com ciclo de trabalho de $80 \%$ apresentaram maiores espessuras que os anodizados com ciclo de trabalho de $90 \%$, nas três freqüências de pulso ensaiadas, e que quanto menor a freqüência dos pulsos, maior a espessura da camada anódica, esses resultados estão de acordo com o observado no trabalho de A. D. Juhl [98] K. Yokoyama [44] e de D. Kanagaraj [99].

De acordo com o mostrado na TAB. 8, filmes anódicos crescidos com potencial contínuo (ciclo de trabalho de 100\%) apresentaram espessuras maiores que os filmes crescidos a 90\% de ciclo de trabalho, porém menores que filmes formados com $80 \%$. Anodizações pulsadas são conhecidas por formar filmes mais espessos $[44,98,99]$. No presente trabalho, isso foi observado $\operatorname{com} \mathrm{DC}=80 \%$.

TABELA 7: Influência do ciclo de trabalho na espessura do filme anódico, variando a freqüência dos pulsos em 100, 200 e $400 \mathrm{~Hz}$ para 40 minutos de anodização em $\mathrm{H}_{2} \mathrm{SO}_{4} 1,7 \mathrm{~mol} \mathrm{~L}^{-1}, \mathrm{~T}=20^{\circ} \mathrm{C}, i_{\mathrm{m}}=83 \mathrm{~mA}$

\begin{tabular}{|c|c|c|}
\hline Freqüência (Hz) & DC $=\mathbf{8 0} \%$ & DC $=\mathbf{9 0} \%$ \\
\hline 100 & $33 \mu \mathrm{m}$ & $22 \mu \mathrm{m}$ \\
\hline 200 & $23 \mu \mathrm{m}$ & $19 \mu \mathrm{m}$ \\
\hline 400 & $17 \mu \mathrm{m}$ & $16 \mu \mathrm{m}$ \\
\hline
\end{tabular}

TABELA 8: Influência do ciclo de trabalho na espessura do $\mathrm{Al}_{2} \mathrm{O}_{3}$, em anodização com eletrólito $\mathrm{H}_{2} \mathrm{SO}_{4} 1,7 \mathrm{~mol} \mathrm{~L}^{-1}, \mathrm{~T}=20^{\circ} \mathrm{C}, 40$ minutos, freqüência $200 \mathrm{~Hz}, i_{m}=83 \mathrm{~mA} \mathrm{~cm}^{-2}$.

\begin{tabular}{|c|c|c|c|}
\hline Ciclo de Trabalho & $\mathbf{8 0 \%}$ & $\mathbf{9 0 \%}$ & $\mathbf{1 0 0 \%}$ \\
\hline Espessura $(\mu \mathrm{m})$ & 44 & 36 & 40 \\
\hline
\end{tabular}


Nas TAB. 9 e 10 é possível observar que os filmes anodizados por 40 minutos possuem maior microdureza quando formados com ciclo de trabalho de $90 \%$ que os formados em ciclo de trabalho $80 \%$. Esse fato pode ser explicado devido à maior dissolução causada pelo eletrólito em ciclos de trabalho inferiores, quando o maior o $t_{\text {off }}$ é maior, havendo maior a dissolução do filme, tornando-o mais poroso, e consequentemente menos duro.

TABELA 9: Influência do Ciclo de Trabalho na microdureza do filme de $\mathrm{Al}_{2} \mathrm{O}_{3}$, variando a freqüência dos pulsos em 100, 200 e $400 \mathrm{~Hz}$, para 40 minutos de anodização em $\mathrm{H}_{2} \mathrm{SO}_{4} 1,7$ mol L $\mathrm{L}^{-1}, T=20^{\circ} \mathrm{C}, i_{\mathrm{m}}=$ $83 \mathrm{~mA} \mathrm{~cm}^{-2}$.

\begin{tabular}{|c|c|c|}
\hline Freqüências (Hz) & DC $=\mathbf{8 0} \%$ & DC $=\mathbf{9 0 \%}$ \\
\hline 100 & $375 \mathrm{Hv}$ & $395 \mathrm{Hv}$ \\
\hline 200 & $350 \mathrm{Hv}$ & $380 \mathrm{Hv}$ \\
\hline 400 & $330 \mathrm{Hv}$ & $340 \mathrm{Hv}$ \\
\hline
\end{tabular}

TABELA 10: Influência do ciclo de trabalho na microdureza dos filmes de $\mathrm{Al}_{2} \mathrm{O}_{3}$ formados por anodização, com eletrólito $\mathrm{H}_{2} \mathrm{SO}_{4} 1,7 \mathrm{~mol} \mathrm{~L}{ }^{-1}, T=20^{\circ} \mathrm{C}$, com 40 minutos de anodização, freqüência dos pulsos $200 \mathrm{~Hz} i_{m}=83 \mathrm{~mA} \mathrm{~cm}^{-2}$.

\begin{tabular}{|l|c|c|c|}
\hline Ciclo de Trabalho & $\mathbf{8 0 \%}$ & $\mathbf{9 0 \%}$ & $\mathbf{1 0 0 \%}$ \\
\hline Microdureza (Hv) & 365 & 385 & 375 \\
\hline
\end{tabular}

Anodização pulsada é conhecida por formar filmes com maior microdureza [84], esse resultado foi alcançado no presente trabalho com $\mathrm{DC}=90 \%$.

Para cada ciclo de trabalho foram estudadas três freqüências: 100, 200 e $400 \mathrm{~Hz}$, e os resultados foram comparados, como mostrado a seguir. De acordo com o mostrado na FIG. 24, quanto maior a freqüência dos pulsos, menor a microdureza do $\mathrm{Al}_{2} \mathrm{O}_{3}$, isto está de acordo com o observado por A.D. Juhl [98] em anodizações em ácido sulfúrico. 


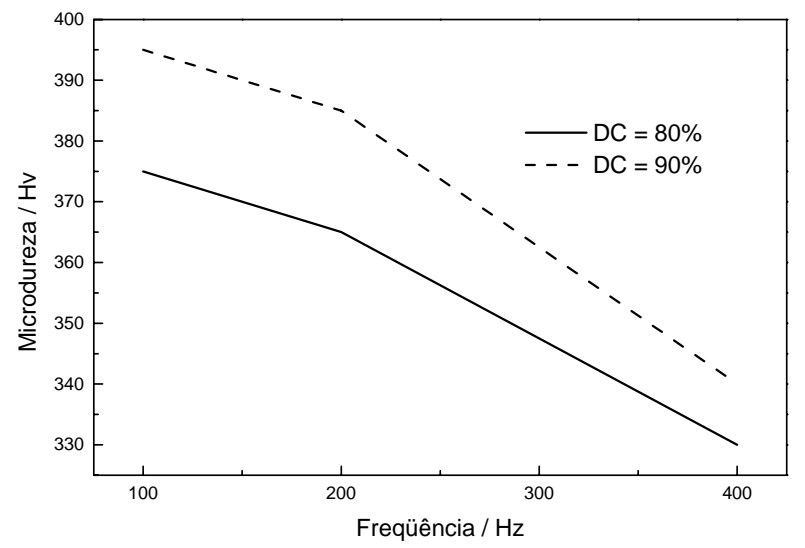

FIGURA 25: Influência da freqüência dos pulsos na microdureza dos filmes de $\mathrm{Al}_{2} \mathrm{O}_{3}$ formados em anodização por corrente pulsada, eletrólito $\mathrm{H}_{2} \mathrm{SO}_{4} 1,7 \mathrm{~mol} \mathrm{~L} L^{-1}, \mathrm{~T}=$ $20^{\circ} \mathrm{C}$ tempo de anodização 40 minutos, em dois ciclos de trabalho diferentes, 80 e 90 $\%, i_{m}=83 \mathrm{~mA} \mathrm{~cm}^{-2}$.

Foi observado em todos os casos estudados, que quanto maior a freqüência dos pulsos menor a espessura e a microdureza dos filmes de $\mathrm{Al}_{2} \mathrm{O}_{3}$. A diminuição da espessura com a microdureza indica uma dissolução muito intensa, predominante em relação à formação do filme, produzindo um filme bastante poroso e pouco espesso.
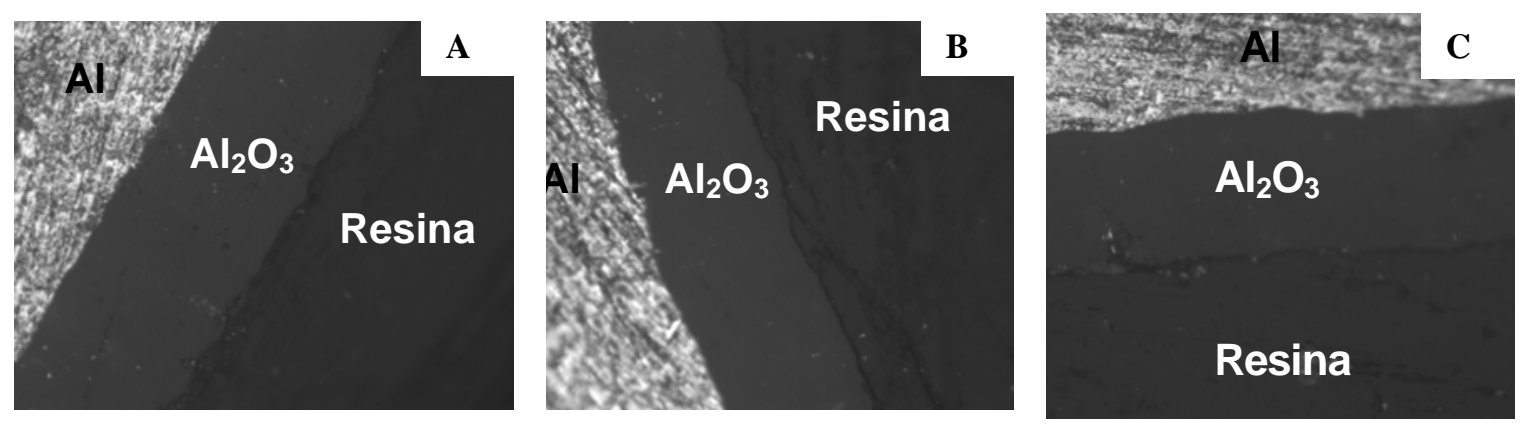

FIGURA 26: Micrografias obtidas em microscópio ótico com analisador de imagens do corte transversal de amostras de alumínio anodizadas em corrente pulsada em eletrólito $\mathrm{H}_{2} \mathrm{SO}_{4}, 1,7$ mol $L^{-1} T=20^{\circ} \mathrm{C}$, tempo de anodização 40 min., DC $80 \%$ a freqüências de pulso de (A) 100 $\mathrm{Hz}$; (B) $200 \mathrm{~Hz}$ e (C) $400 \mathrm{~Hz}$, com objetiva de aumento de $50 \mathrm{X}$.

As micrografias das FIG. 26 e 27 indicam que quanto maior a freqüência dos pulsos, menor a espessura dos filmes, isto é mais evidente nas anodizações com DC $=80 \%$ com maior freqüência dos pulsos. Análises mais detalhadas no microscópio ótico com luz polarizada indicaram que entre as três freqüências de pulsos estudadas neste trabalho, as anodizações feitas sob freqüências de 200 $\mathrm{Hz}$ proporcionaram filmes com melhor grau de cobertura e menor quantidade de rachaduras, 
proporcionando, portanto, maior proteção ao alumínio, esses resultados estão de acordo com a literatura [98].
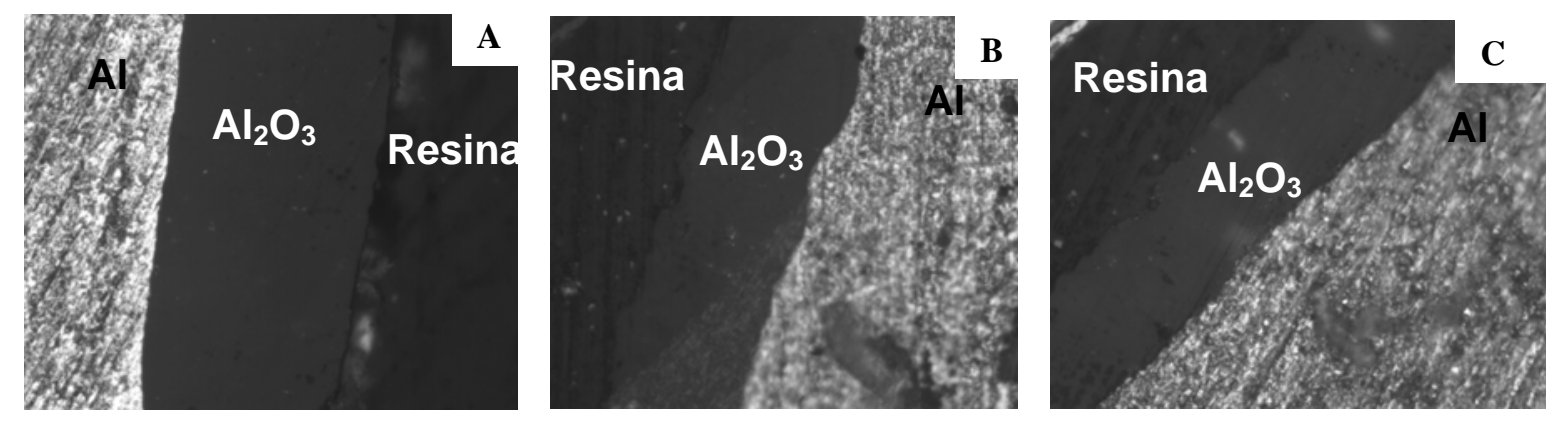

FIGURA 27: Micrografias obtidas em microscópio ótico com unalisador de imagens do corte transversal de amostras de alumínio anodizadas em corrente pulsada em eletrólito $\mathrm{H}_{2} \mathrm{SO}_{4}, 1,7$ mol $L^{-1} T=20^{\circ} \mathrm{C}$, tempo de anodização 40 min., DC $90 \%$ a freqüências de pulso de (A) $100 \mathrm{~Hz}$; (B) $200 \mathrm{~Hz}$ e (C) $400 \mathrm{~Hz}$ com objetiva de aumento de $50 \mathrm{X}$.

A falta de uniformidade da espessura do filme do óxido anódico a $400 \mathrm{~Hz}$ pode ser explicada pela forte ação de dissolução do filme devido à ação do eletrólito no momento da anodização, que poderia estar desfavorecendo a formação de um filme uniforme.

O ciclo de trabalho menor significa $t_{\text {off }}$ maior, ou seja, houve tempo maior para a dissolução do filme durante o processo de anodização, a dissolução do filme acarreta em menor espessura da camada de barreira e, portanto, o favorecimento de crescimento do filme devido à maior passagem de corrente, além disso, o potencial pulsado permite correntes mais elevadas nos tempos de pulso "on", que favorece a maior velocidade de formação do filme, esses fatores explicariam um filme mais espesso. Porém aqueles filmes crescidos com corrente contínua (ciclo de trabalho de 100\%) apresentaram espessuras maiores que os filmes crescidos a $90 \%$ de ciclo de trabalho, porém menores que filmes formados com $80 \%$. É importante considerar que no processo de anodização estão ocorrendo várias reações simultâneas e que a interpretação dos resultados não pode somente considerar um fenômeno isolado, portanto deve ser considerado neste ponto, que a dissolução do filme de $\mathrm{Al}_{2} \mathrm{O}_{3}$ também pode diminuir sua espessura.

A diminuição da microdureza com o ciclo de trabalho pode ser explicada levando em consideração que quanto maior a dissolução do filme, maior sua porosidade. 


\subsubsection{Influência da composição do eletrólito usado na anodização}

$\mathrm{O}$ eletrólito $\mathrm{H}_{3} \mathrm{PO}_{4}$ é conhecido por formar filmes mais porosos, favoráveis à implantação metálica. Assim, foram feitos diversos testes com o objetivo de avaliar qual a melhor concentração de $\mathrm{H}_{3} \mathrm{PO}_{4}$ utilizado como eletrólito para anodizar as amostras de alumínio, e foi observado que para se obter uma anodização em solução de $\mathrm{H}_{3} \mathrm{PO}_{4}$ seria necessária à aplicação de um potencial superior ao que estava sendo aplicado na anodização em solução de $\mathrm{H}_{2} \mathrm{SO}_{4}$, analisando em termos práticos, $\mathrm{o}$ uso de mais energia não seria economicamente viável. Uma alternativa encontrada para contornar esse problema seria aumentar excessivamente a concentração de $\mathrm{H}_{3} \mathrm{PO}_{4}$, o que também não seria prático e nem economicamente viável. Devido a isso, foi estudado um "eletrólito misto", cuja composição é de $\mathrm{H}_{2} \mathrm{SO}_{4} 0,85 \mathrm{~mol} \mathrm{~L}^{-1}+\mathrm{H}_{3} \mathrm{PO}_{4}$ 0,65 mol L ${ }^{-1}$. Com este eletrólito misto, nestas concentrações, e mantidas as melhores condições de anodização encontradas nesse estudo, foi obtida uma anodização com características protetoras muito parecidas com as das amostras anodizadas $\mathrm{em}_{2} \mathrm{SO}_{4}$ puro.

A seguir serão mostrados os estudos comparativos das propriedades dos filmes crescidos nas duas composições de eletrólito.
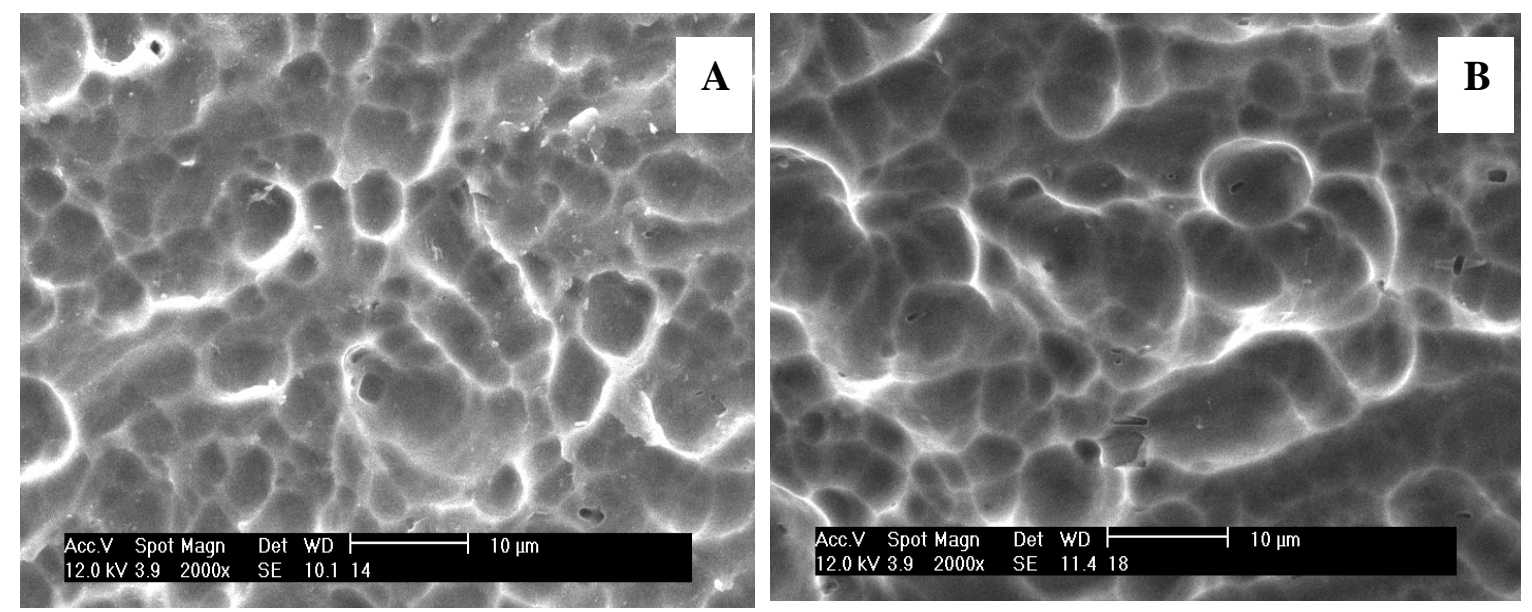

FIGURA 28: Micrografias obtidas por MEV da superfície de amostras de alumínio anodizado por controle do potencial por corrente contínua, $t=40 \mathrm{~min}, \mathrm{~T}=20^{\circ} \mathrm{C}, \mathrm{V}=23 \mathrm{~V}$ em: (A) $\mathrm{H}_{2} \mathrm{SO}_{4}$ $1,7 \mathrm{~mol} \mathrm{~L}^{-1}$ e (B) $\mathrm{H}_{3} \mathrm{PO}_{4} 0,65 \mathrm{~mol} \mathrm{~L}^{-1}+\mathrm{H}_{2} \mathrm{SO}_{4} 0,85 \mathrm{~mol} \mathrm{~L}^{-1}$.

Na FIG. 28 é mostrada a micrografia obtida por MEV da superfície de um filme anodizado em eletrólito (A) $\mathrm{H}_{2} \mathrm{SO}_{4} 1,7 \mathrm{~mol} \mathrm{~L}^{-1}$ e (B) $\mathrm{H}_{2} \mathrm{SO}_{4} 0,85 \mathrm{~mol} \mathrm{~L}^{-1}+\mathrm{H}_{3} \mathrm{PO}_{4} 0,65 \mathrm{~mol} \mathrm{~L}^{-1}$. Nesta figura é possível observar que não ocorreram diferenças significativas na morfologia do filme, permitindo 
concluir que o eletrólito misto não alterou a morfologia do filme, este resultado foi positivo. Outra evidência da capacidade protetora conservada dos filmes anodizados em eletrólito misto, foram os resultados obtidos nas análises por espectroscopia de impedância eletroquímica, que serão mostrados no próximo ítem.

Para avaliar melhor qual eletrólito é mais favorável para a implantação metálica e proteção do alumínio foram realizadas análises por FRX para verificar a quantidade de ferro presente em cada filme após a implantação metálica. Estes resultados serão comentados posteriormente.

A condutividade do eletrólito $\mathrm{H}_{3} \mathrm{PO}_{4} 0,65 \mathrm{~mol} \mathrm{~L}{ }^{-1}+\mathrm{H}_{2} \mathrm{SO}_{4} 0,85 \mathrm{~mol} \mathrm{~L}{ }^{-1}$ foi medida e comparada com a do eletrólito $\mathrm{H}_{2} \mathrm{SO}_{4} 1,7 \mathrm{~mol} \mathrm{~L}^{-1}$, os valores mostrados na TAB. 11 indicam que a condutividade não varia significativamente nas duas soluções.

TABELA 11: Condutividade iônica a $20^{\circ} \mathrm{C}$ das soluções de $\mathrm{H}_{2} \mathrm{SO}_{4} \quad 1,7 \mathrm{~mol} \mathrm{~L}^{-1}$ e $\mathrm{H}_{3} \mathrm{PO}_{4}$ 0,65 mol L $\mathrm{L}^{-1}+\mathrm{H}_{2} \mathrm{SO}_{4}$ $0,85 \mathrm{~mol} \mathrm{~L}^{-1}$.

\begin{tabular}{|c|c|}
\hline Solução & Condutividade $\left(\boldsymbol{\Omega}^{-\mathbf{1}}\right)$ \\
\hline $\mathrm{H}_{2} \mathrm{SO}_{4} 1,7 \mathrm{~mol} \mathrm{~L}^{-1}$ & 0,4965 \\
\hline $\mathrm{H}_{3} \mathrm{PO}_{4} 0,65 \mathrm{~mol} \mathrm{~L}^{-1}+\mathrm{H}_{2} \mathrm{SO}_{4} 0,85 \mathrm{~mol} \mathrm{~L}^{-1}$ & $0,4717 \mathrm{~S}$ \\
\hline
\end{tabular}
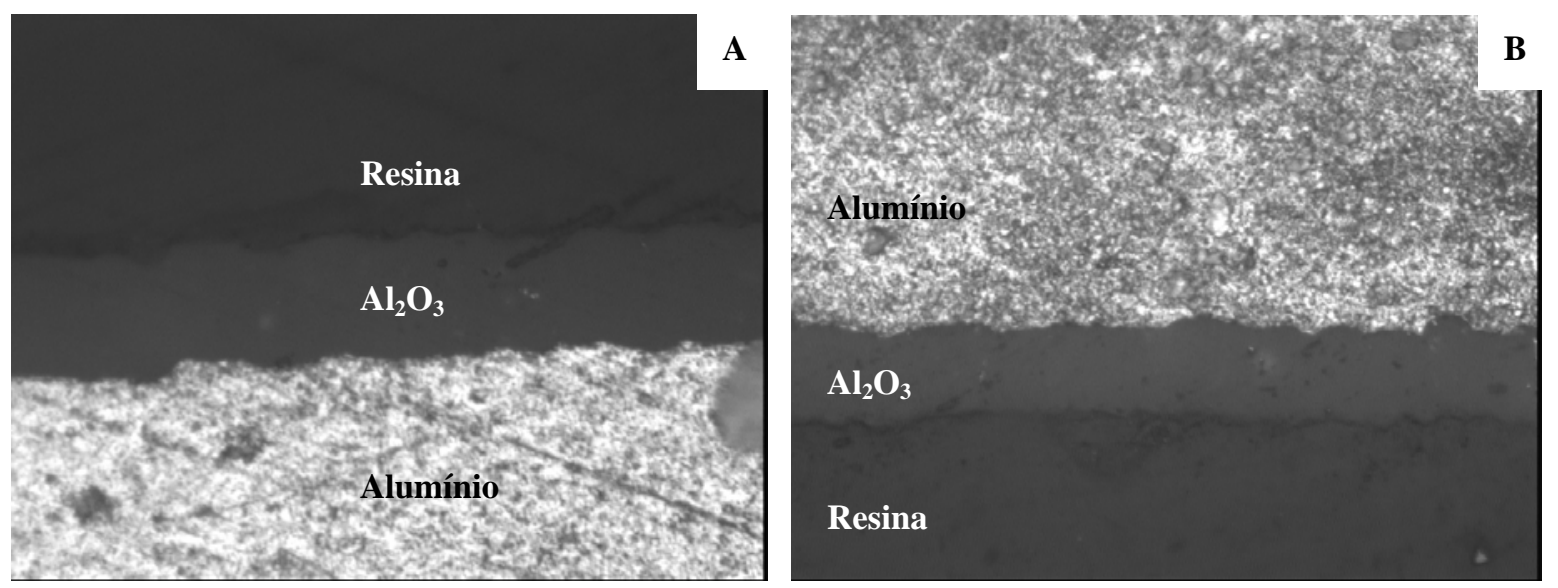

FIGURA 29: Micrografias obtidas em microscópio ótico com analisador de imagens do corte transversal de um filme de $\mathrm{Al}_{2} \mathrm{O}_{3}$ crescido em anodização por controle do potencial por corrente contínua, $t=40 \mathrm{~min}$., $T=20^{\circ} \mathrm{C}, E=23 \mathrm{~V}$ em (A) $\mathrm{H}_{2} \mathrm{SO}_{4} 1,7 \mathrm{~mol} \mathrm{~L}^{-1}$ e (B) $\mathrm{H}_{2} \mathrm{SO}_{4} 0,85 \mathrm{~mol} \mathrm{~L}^{-1}+$ $\mathrm{H}_{3} \mathrm{PO}_{4} 0,65 \mathrm{~mol} \mathrm{~L}^{-1}$ com obietiva de aumento de $50 \mathrm{X}$. 
Como pode ser observado na FIG. 29, a mudança na composição do eletrólito não influencia significativamente no grau de cobertura da camada anódica, assegurando a proteção ao alumínio.

A TAB. 12 lista as espessuras e microdurezas medidas em cada filme, mostrando que o filme preparado no eletrólito misto possui microdureza inferior, o que estaria indicando maior porosidade o que favoreceria a implantação metálica.

TABELA 12: Variação da espessura e da microdureza dos filmes com a composição do eletrólito empregado na anodização.

\begin{tabular}{|c|c|c|}
\hline Composição do eletrólito & Espessura $(\boldsymbol{\mu m})$ & Microdureza (Hv) \\
\hline $\mathrm{H}_{2} \mathrm{SO}_{4} 1,7 \mathrm{~mol} \mathrm{~L}^{-1}$ & 38 & 358 \\
\hline $\mathrm{H}_{2} \mathrm{SO}_{4} 1,7 \mathrm{~mol} \mathrm{~L}^{-1} 50 \% \mathrm{v}+\mathrm{H}_{3} \mathrm{PO}_{4} 1,3 \mathrm{~mol} \mathrm{~L}^{-1} 50 \% \mathrm{v}$ & 29,2 & 315 \\
\hline
\end{tabular}

A variação da espessura com a variação da composição eletrolítica, não foi significativa a ponto de alterar o grau de cobertura do filme sobre o alumínio (FIG. 29).

\subsection{Influência da anodização e da composição do eletrólito de anodização na resistência à corrosão do alumínio}

A EIE é uma técnica utilizada por eletroquímicos para obter diferentes informações sobre a amostra analisada em meio eletroquímico. Nesse trabalho será dado enfoque à interpretação dos diagramas de EIE quanto à resistência à corrosão do alumínio anodizado antes e após as modificações.

Nos diagramas de Nyquist, quanto maior o diâmetro do semicírculo obtido, maior a resistência da amostra analisada à passagem da corrente, portanto, maior a resistência à corrosão da amostra. Os diagramas de Bode, ângulo de fase e módulo de Z são complementares ao diagrama de Nyquist e foram registrados nesse trabalho para facilitar a visualização das diferentes resistências à corrosão das amostras analisadas.

Como já é conhecido, a anodização aumenta a resistência à corrosão do alumínio, este comportamento foi observado em $\mathrm{NaCl} 3,5 \%$ e mostrado nos diagramas de Nyquist e Bode nas FIG. 30, 31 e 32 . 


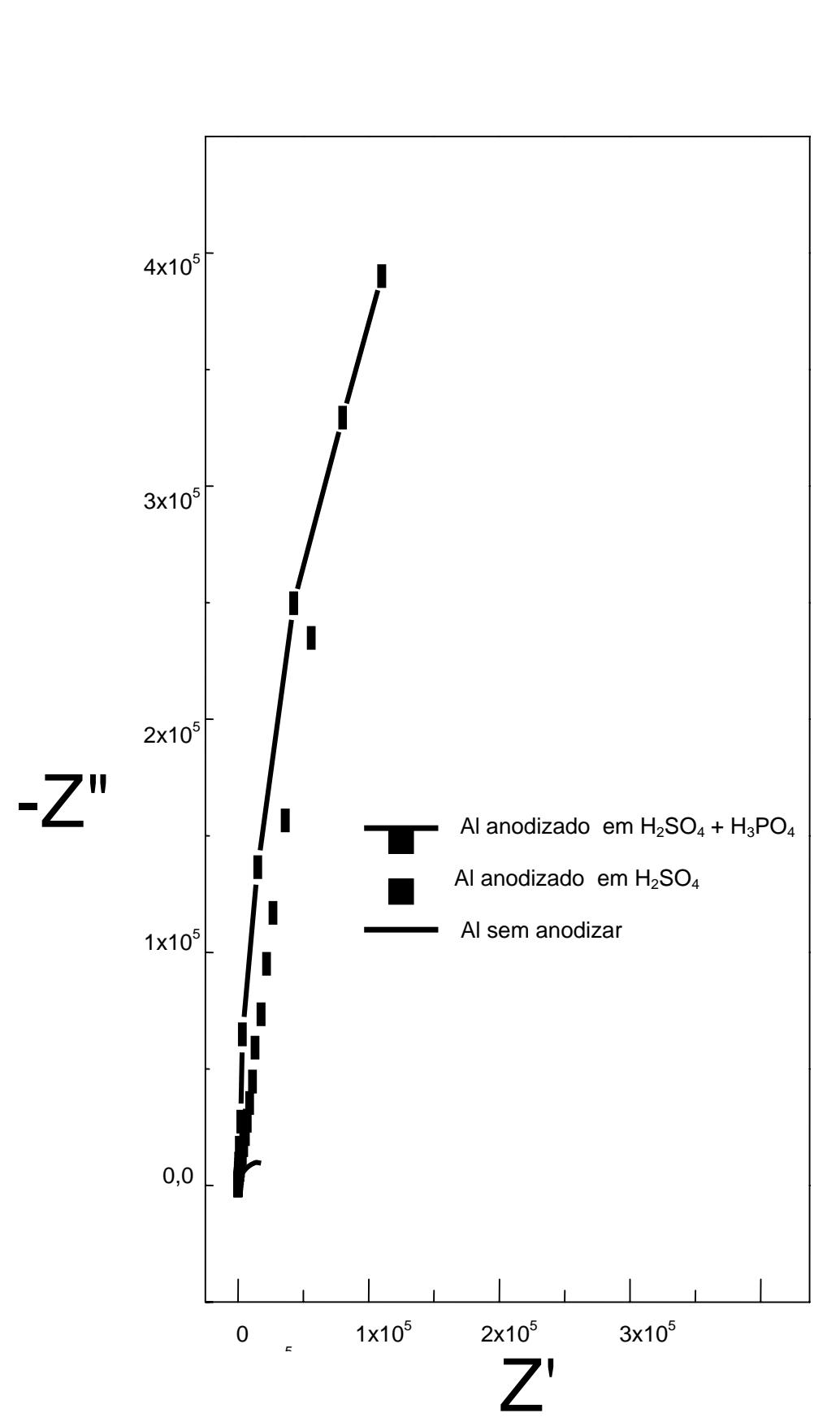

FIGURA 30: Diagrama de Nyquist para o alumínio sem anodizar, alumínio anodizado em $\mathrm{H}_{2} \mathrm{SO}_{4} 1,7 \mathrm{~mol} \mathrm{~L}^{-1} e$ alumínio anodizado em $\mathrm{H}_{3} \mathrm{PO}_{4} 0,65 \mathrm{M}+\mathrm{H}_{2} \mathrm{SO}_{4} 0,85 \mathrm{M}$, ambos por 40 minutos a $20^{\circ} \mathrm{C}$ por controle do potencial.
$\mathrm{O}_{2} \mathrm{H}_{2} \mathrm{SO}_{4}$ utilizado como eletrólito na anodização é conhecido por formar filmes pouco porosos, isso foi confirmado com os valores de microdureza obtidos nesse trabalho, e mostrados na TAB. 12, porém filmes porosos favorecem a incorporação de materiais, e por essa razão a eletrodeposição de ferro pode ser favorecida no alumínio anodizado em eletrólito $\mathrm{H}_{2} \mathrm{SO}_{4}+\mathrm{H}_{3} \mathrm{PO}_{4}$, para comprovar isso, o teor de ferro obtido após a eletrodeposição nos dois casos foi obtido por fluorescência de raios $\mathrm{X}$ e comparado, isso será mostrado no próximo item.

Os dois eletrólitos estudados proporcionaram aumentos na resistência à corrosão do alumínio muito parecidos. Portanto, foi comprovada a eficiência do eletrólito misto na formação de uma camada protetora ao alumínio. 


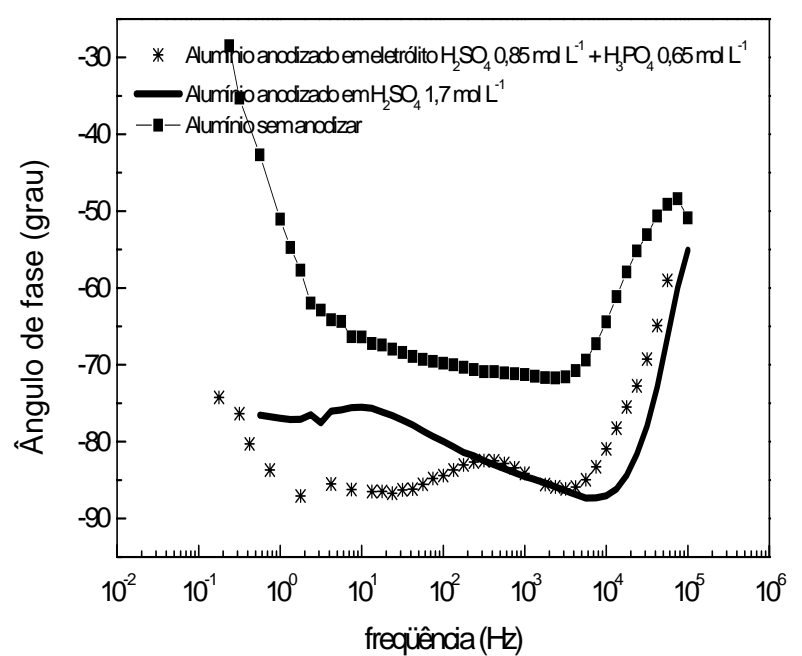

FIGURA 31: Diagrama de Bode ângulo de fase do alumínio sem anodizar, alumínio anodizado em $\mathrm{H}_{2} \mathrm{SO}_{4}$ e em $\mathrm{H}_{2} \mathrm{SO}_{4}+\mathrm{H}_{3} \mathrm{PO}_{4}$.

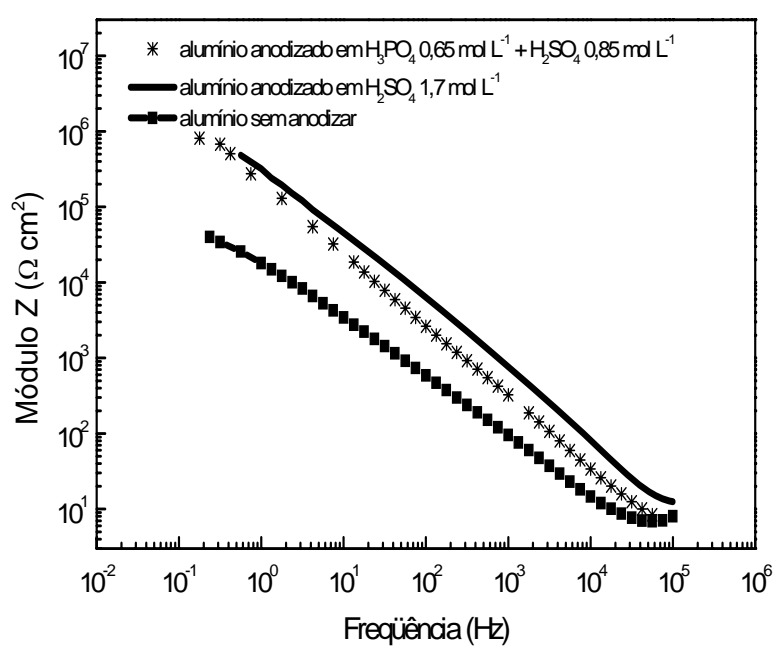

FIGURA 32: Diagrama de Bode módulo Z do alumínio sem anodizar, alumínio anodizado em $\mathrm{H}_{2} \mathrm{SO}_{4}$ e em $\mathrm{H}_{2} \mathrm{SO}_{4}+\mathrm{H}_{3} \mathrm{PO}_{4}$.

\subsection{Eletrodeposição de ferro no alumínio anodizado}

O objetivo do presente trabalho é estudar o efeito da implantação de ferro no alumínio anodizado. Para verificar a eficiência do eletrólito misto no favorecimento da incorporação metálica, o teor de ferro obtido por fluorescência de raios $\mathrm{X}$ após a eletrodeposição foi comparado nas amostras anodizadas sob as melhores condições de anodização encontradas na primeira parte desse estudo variando a composição do eletrólito de anodização. Os valores obtidos são mostrados na TAB. 13.

TABELA 13: Composição por FRX dos principais elementos do óxido anódico de filmes formados por anodização por controle do potencial por CC, $t=40 \mathrm{~min} ., T=20^{\circ} \mathrm{C}, \quad E=23 \mathrm{~V}$ após eletrodeposição galvanostática de ferro em eletrólito $\mathrm{Fe}\left(\mathrm{SO}_{4}\right)_{2}\left(\mathrm{NH}_{4}\right)_{2} \cdot 6 \mathrm{H}_{2} \mathrm{O} 0,31 \mathrm{~mol} \mathrm{~L}^{-1}+\mathrm{C}_{6} \mathrm{H}_{8} \mathrm{O}_{6} 0,06 \mathrm{~mol} \mathrm{~L} \mathrm{~L}^{-1}+\mathrm{H}_{3} \mathrm{BO}_{3}$ $0,65 \mathrm{~mol} \mathrm{~L}^{-1}$ por CC durante $40 \mathrm{~s}, i=33 \mathrm{~mA} . \mathrm{cm}^{-2}$.

\begin{tabular}{|c|c|c|c|c|}
\hline Eletrólito na anodização & \multicolumn{4}{|c|}{ Teor \% } \\
\hline & $\mathrm{Al}$ & $\mathrm{S}$ & $\mathrm{Fe}$ & $\mathrm{O}+$ outros \\
\hline $\mathrm{H}_{2} \mathrm{SO}_{4} 1,7 \mathrm{~mol} \mathrm{~L}^{-1}$ & 37,614 & 03,236 & 00,000 & 59,150 \\
\hline $\mathrm{H}_{2} \mathrm{SO}_{4} 0,85 \mathrm{~mol} \mathrm{~L}^{-1}+\mathrm{H}_{3} \mathrm{PO}_{3} 0,65 \mathrm{~mol} \mathrm{~L}^{-1}$ & 41,434 & 02,706 & 00,288 & 55,573 \\
\hline
\end{tabular}


Com os valores da TAB. 13, pode-se inferir que o eletrólito misto formou um filme que favoreceu a incorporação de ferro no interior dos seus poros. A partir desta conclusão, todos os estudos foram feitos sob essa condição de anodização.

O óxido anódico de alumínio formado em meio de ácido fosfórico é bastante conhecido por ser poroso [100], seus poros possuem diâmetro de cerca de $50 \mathrm{~nm}$, podendo variar conforme as demais condições de anodização, tem formato colunar e vão desde a superfície do óxido até atingir o substrato. Como já foi comentado, a concentração e a composição do eletrólito influenciam nas características do filme de óxido anódico. No que se refere à incorporação iônica, no alumínio anodizado em ácido sulfúrico, há a presença de enxofre no filme. Patermarakis e Moussoutzanis [101] estudaram a influência do eletrólito $\mathrm{H}_{2} \mathrm{SO}_{4}$ e da densidade de corrente aplicada na anodização sobre o mecanismo de crescimento dos filmes de $\mathrm{Al}_{2} \mathrm{O}_{3}$. Com o auxílio de vários métodos de caracterização, eles estabeleceram que o mecanismo de crescimento da camada anódica depende fortemente dos parâmetros ensaiados, desde o início da anodização, na própria camada de barreira já acontece a incorporação de sais de sulfato, como o $\mathrm{Al}_{2}\left(\mathrm{SO}_{4}\right)_{3}$, de acordo com a reação 36 :

$$
2 \mathrm{Al}_{(\mathrm{s})}+3 \mathrm{H}_{2} \mathrm{SO}_{4(\mathrm{aq})} \rightarrow \mathrm{Al}_{2}\left(\mathrm{SO}_{4}\right)_{3(\mathrm{aq})}+3 \mathrm{H}_{2(\mathrm{~g})}
$$

e, na parede dos poros, a dissolução dos óxidos hidratados, conforme a reação 37:

$$
\mathrm{Al}_{2} \mathrm{O}_{3} \cdot \mathrm{nH}_{2} \mathrm{O}_{(\mathrm{s})}+3 \mathrm{H}_{2} \mathrm{SO}_{4(\mathrm{aq})} \rightarrow \mathrm{Al}_{2}\left(\mathrm{SO}_{4}\right)_{3(\mathrm{aq})}+(\mathrm{n}+3) \mathrm{H}_{2} \mathrm{O}_{(\mathrm{l})}
$$

Em estudo posterior, o grupo de Patermarakis [102] estudou sobre a natureza coloidal do $\mathrm{Al}_{2}\left(\mathrm{SO}_{4}\right)_{3}$ formado nas paredes dos poros e na superfície do $\mathrm{Al}_{2} \mathrm{O}_{3}$ e da sua influência sobre a cinética e o mecanismo de formação da camada anódica, favorecendo um crescimento não uniforme da camada anódica e a formação dessas partículas coloidais no interior dos poros do óxido anódico, preenchendo os poros. Este comportamento pode afetar a incorporação metálica no filme ou uma possível etapa de selagem, isso explicaria porque não houve incorporação de ferro no filme anódico crescido em solução de $\mathrm{H}_{2} \mathrm{SO}_{4}$, onde a concentração de sulfato é maior que no eletrólito misto. Além disso, filmes anódicos crescidos em meio de ácido sulfúrico são conhecidos por formar filmes pouco porosos $[103,104]$ diferentemente dos filmes formados em meio de ácido fosfórico, que são conhecidamente porosos [105,106]. Essas informações estão de acordo com as microdurezas dos 
filmes medidas nesse trabalho, que indicaram que os filmes formados $\mathrm{em}_{2} \mathrm{SO}_{4}$ tem microdurezas superiores aos formados em $\mathrm{H}_{3} \mathrm{PO}_{4}$.
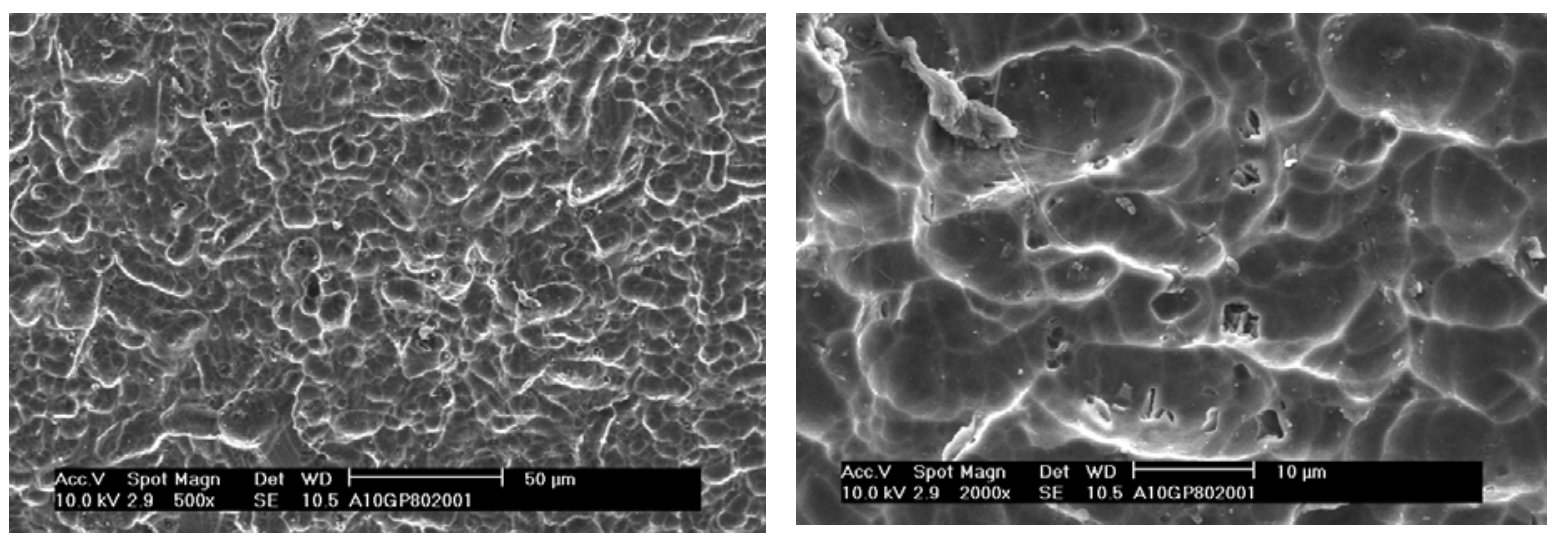

FIGURA 33: Micrografias obtidas por microscópio eletrônico de varredura da superfície do alumínio anodizado por controle do potencial em eletrólito $\mathrm{H}_{2} \mathrm{SO}_{4} 1,7 \mathrm{~mol} \mathrm{~L}^{-1}, T=20^{\circ} \mathrm{C}$, por 40 minutos, corrente contínua, freqüência $200 \mathrm{~Hz}$, com dois aumentos distintos.

Na FIG. 33 é mostrada uma micrografia obtida por MEV onde pode ser observada a morfologia da superfície do óxido anódico em escala micrométrica, nessa resolução é possível observar microcrateras superficiais, porém essas não correspondem aos poros citados no parágrafo anterior, nos quais é depositado o ferro, eles podem ser observados nas micrografias de alta resolução do corte transversal do óxido anódico (FIG. 34 e 35) nas quais se confirma que as dimensões dos nanoporos são muito inferiores que as dimensões das microcrateras observadas na FIG. 33.

Nas FIG. 34 e 35 são mostradas micrografias obtida por MEV (Cambridge Steroscan 240 com sistema de análise de imagem Kontron KS-300 do laboratório de microscopia da Escola Politécnica de Metalurgia-USP) de microfraturas superficiais do óxido anódico em escala nanométrica, nessas imagens é possível visualizar os poros do óxido desde a superfície até o seu perfil (formato colunar). Os poros possuem diâmetro de cerca de 70-100 nm (FIG. 34) e estão distribuídos homogeneamente em toda extensão do óxido. 


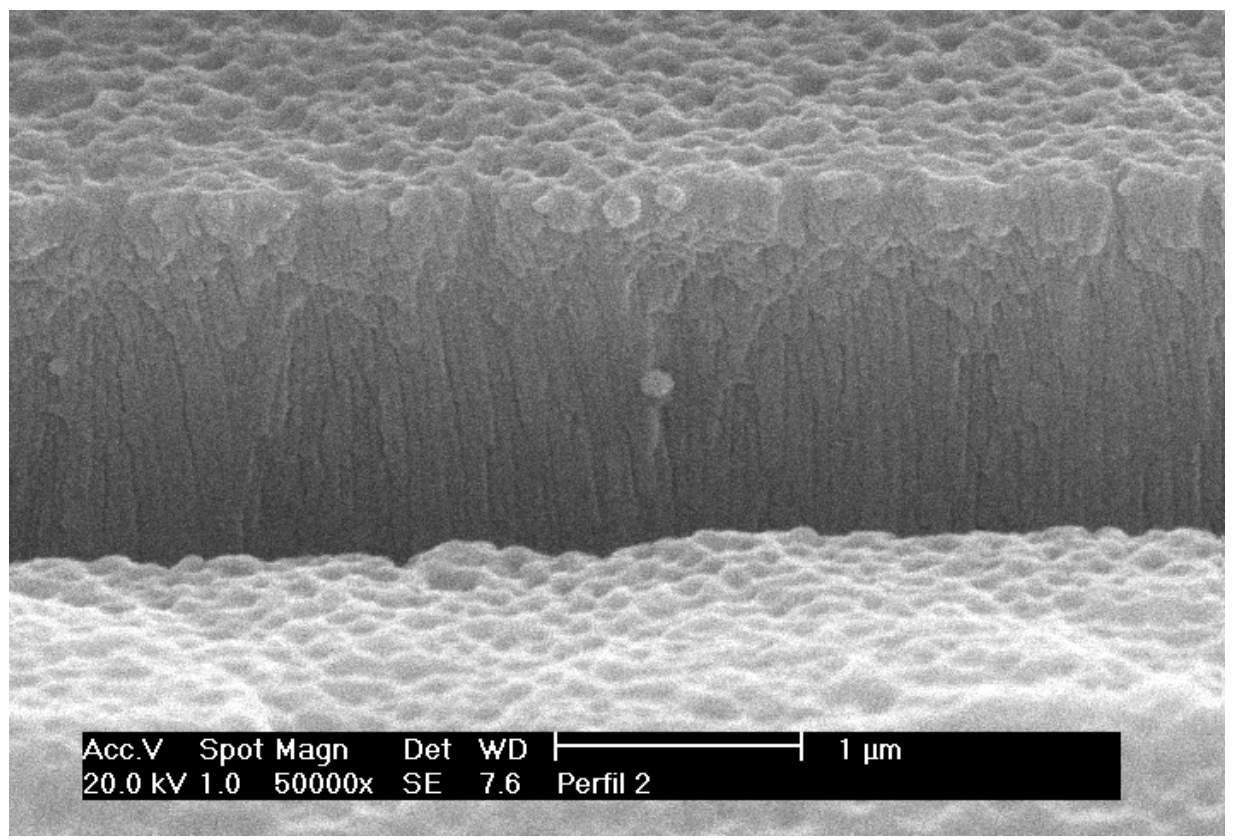

FIGURA 34: Micrografia obtida por MEV de alta resolução de uma pequena fratura superficial do óxido anódico preparado por anodização com eletrólito misto sob as mesmas condições da FIG. 33.

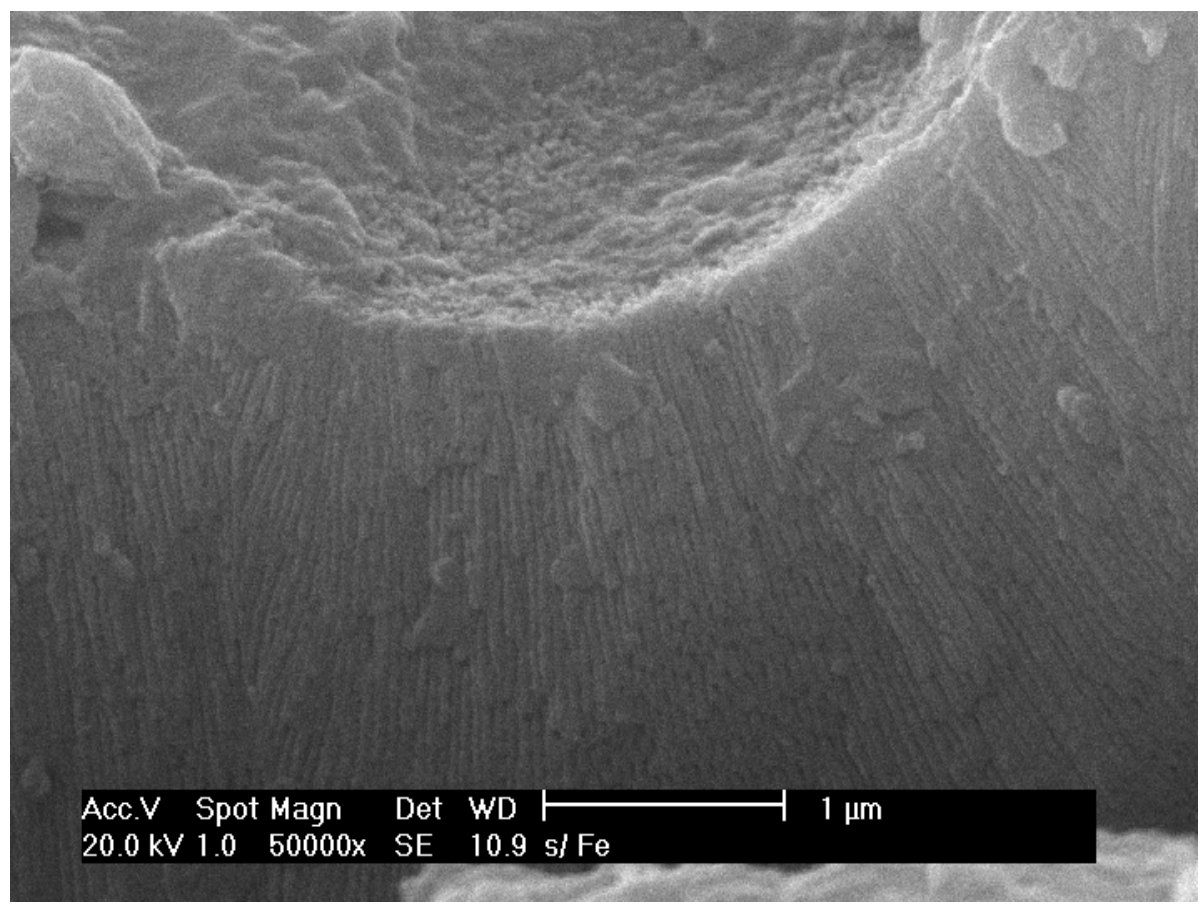

FIGURA 35: Micrografia obtida por MEV de alta resolução de uma pequena fratura superficial do óxido anódico preparado por anodização sob as mesmas condições da FIG. 33, em destaque os canais que são preenchidos pelo ferro após a sua incorporação por eletrodeposição. 

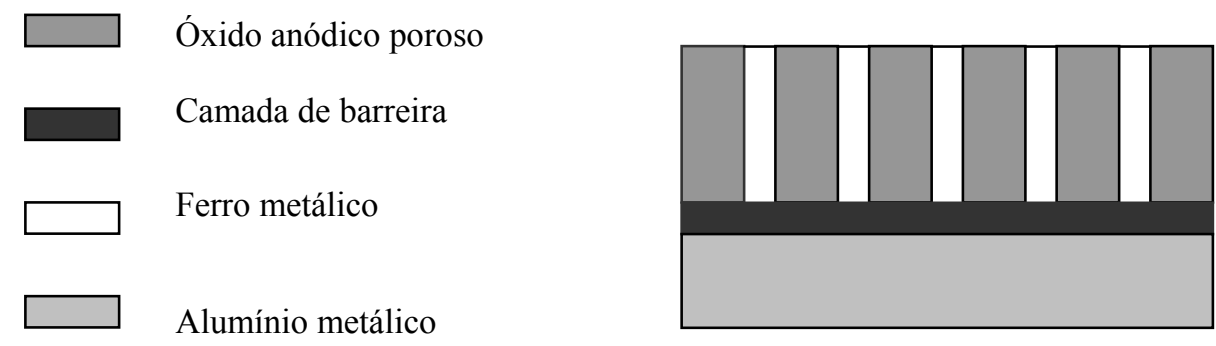

FIGURA 36: Figura esquemática do alumínio anodizado após a incorporação de ferro.

Devido ao fato dos nanoporos do óxido anódico atingirem a superfície do alumínio, é possível implantar outros materiais no interior dos poros não só por métodos químicos (adsorção), mas também por métodos eletroquímicos (eletrodeposição). Neste trabalho estudamos a implantação de ferro no interior dos poros do óxido anódico por eletrodeposição.

A disposição do ferro metálico no óxido anódico é mostrada no esquema da FIG. 36.

Com o objetivo de estudar uma condição de eletrodeposição satisfatória, para assegurar que o ferro eletrodepositado não fique no estado oxidado e que a quantidade de ferro depositada seja suficiente para a modificação da condutividade do alumínio anodizado, e para a fabricação dos nanofios, foi feito um estudo da influência das condições de eletrodeposição, nas características do eletrodepósito, entre as condições estudadas estão: a composição do eletrólito usado na eletrodeposição de ferro; regime de eletrodeposição (por corrente contínua e pulsada) e diferentes tempos de eletrodeposição.

\subsubsection{Efeito da composição do eletrólito usado na eletrodeposição de ferro}

O ácido bórico e o ácido ascórbico são aditivos comumente empregados na eletrodeposição de ferro em diferentes substratos [99, 107]. Existem diversos trabalhos que estudam a função de cada um desses aditivos na eletrodeposição de ferro. A solução de sulfato ferroso também é utilizada para esse tipo de eletrodeposição [99]. No presente trabalho foi estudada uma solução de $\mathrm{Fe}\left(\mathrm{SO}_{4}\right)_{2}\left(\mathrm{NH}_{4}\right)_{2} \cdot 6 \mathrm{H}_{2} \mathrm{O} 0,31 \mathrm{~mol} \mathrm{~L}^{-1}$ e os aditivos são estudados nas seguintes concentrações $\mathrm{C}_{6} \mathrm{H}_{8} \mathrm{O}_{6}$ $0,06 \mathrm{~mol} \mathrm{~L}^{-1}$ e $\mathrm{H}_{3} \mathrm{BO}_{3} 0,65 \mathrm{~mol} \mathrm{~L}^{-1}$ [58] para a eletrodeposição de ferro no alumínio anodizado.

Como foi observado nos cronopotenciogramas obtidos durante a eletrodeposição de ferro (FIG. 37), os aditivos aumentam a eficiência do processo (indicado pelo aumento do potencial de deposição que está relacionado com o aumento da concentração de espécies eletroativas próximas 
ao eletrodo, de acordo com a equação de Nernst), essa melhora foi mais efetiva quando se utilizou o ácido bórico sozinho, isso pode ser explicado considerando que o ácido bórico ao se adsorver na superfície do eletrodo estaria retardando a formação do FeOOH nos sítios ativos da superfície do substrato conforme citado na literatura [107-110], melhorando a eficiência do processo. Porém, já é bastante conhecido que o ácido ascórbico retarda a oxidação do ferro em solução, e isso pode ser observado pela cor da solução que continua verde mesmo após dias, observado neste trabalho e de acordo com o trabalho de Jensen e et al. [111].

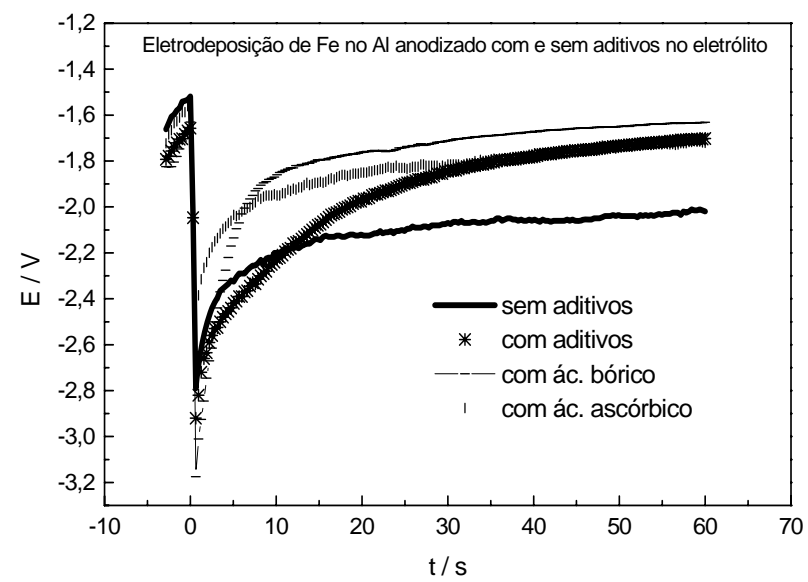

FIGURA 37: Cronopotenciogramas obtidos durante a eletrodeposição de ferro no alumínio anodizado em solução de $\mathrm{FeSO}_{4}\left(\mathrm{NH}_{4}\right) \cdot 6 \mathrm{H}_{2} \mathrm{O}$ com e sem os aditivos $\mathrm{C}_{6} \mathrm{H}_{8} \mathrm{O}_{6}$ e $\mathrm{H}_{3} \mathrm{BO}_{3}$, mantendo-se uma densidade de corrente constante de $33 \mathrm{~mA}$ $\mathrm{cm}^{-2}$.

$\mathrm{Na}$ ausência de ácido ascórbico, a solução de sulfato ferroso inicialmente verde, com o passar do tempo (após 3 horas) vai se tornando alaranjada até chegar à cor marron (1 dia depois), indicando a precipitação do $\mathrm{FeOOH}$ e diminuindo a concentração de $\mathrm{Fe}^{2+}$ no eletrólito. A diminuição da eficiência do processo é causada porque os íons $\mathrm{Fe}^{2+}$ presentes na solução são instáveis e normalmente se oxidam a $\mathrm{Fe}^{3+}$, neste estágio, uma parte da corrente aplicada durante a eletrodeposição seria usada para a redução dos íos férricos a íons ferrosos de acordo com a equação 38 [111]:

$$
2 \mathrm{Fe}^{3+}+2 \mathrm{e}^{-} \rightarrow 2 \mathrm{Fe}^{2+}
$$

A variação do potencial nos primeiros 30 segundos de eletrodeposição apresentou comportamento distinto quando o eletrólito continha a mistura dos aditivos, isso estaria indicando uma ação sinérgica dos dois aditivos no momento da eletrodeposição (FIG. 37). 
Foram obtidas imagens por MEV com EDS das amostras de aluminio anodizado após a eletrodeposição de ferro com e sem os aditivos (FIG. 38). Os espectros de EDS das regiões mais claras dessas imagens são mostrados na FIG. 39.
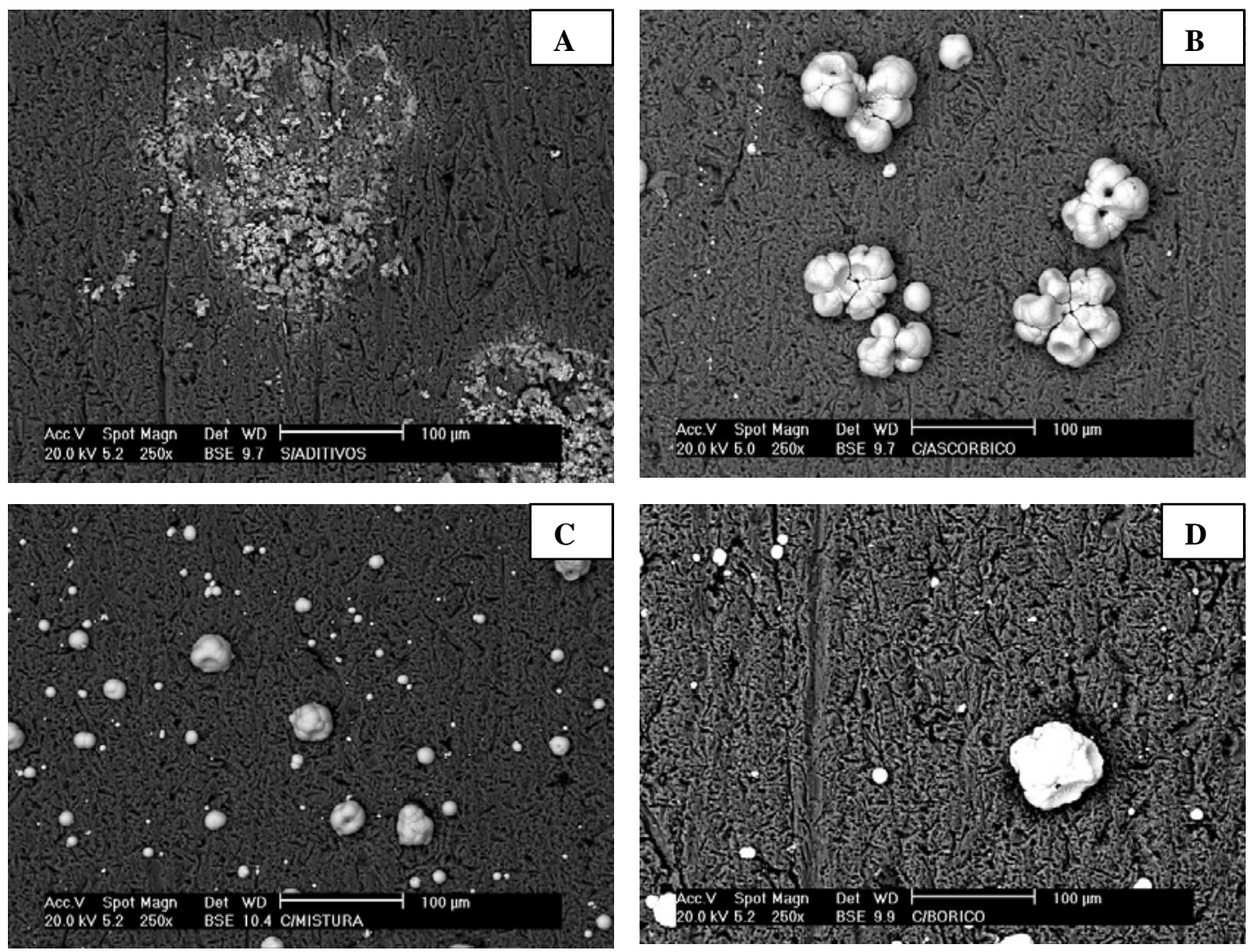

FIGURA 38: Micrografias eletrônicas de varredura da superfície do alumínio anodizado após eletrodeposição de ferro por corrente pulsada por $60 \mathrm{~s}$ com eletrólito $\mathrm{Fe}\left(\mathrm{SO}_{4}\right)_{2}\left(\mathrm{NH}_{4}\right)_{2} \cdot 6 \mathrm{H}_{2} \mathrm{O} 0,31 \mathrm{~mol} \mathrm{~L}^{-1}$ sendo (A) sem os aditivos, (B) com $\mathrm{H}_{3} \mathrm{BO}_{3} 0,65 \mathrm{~mol} \mathrm{~L}^{-1}$,

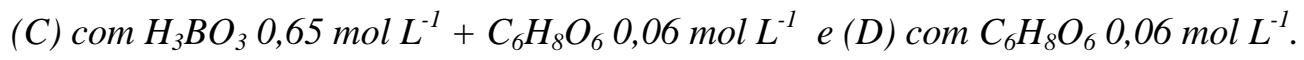

Como pode ser observado na micrografia mostrada na FIG. 38-A, o aspecto da superfície do óxido de alumínio que sofreu eletrodeposição de ferro com eletrólito sem os aditivos é diferente das demais imagens, enquanto que nas demais imagens (FIG. 38-B, 38-C e 38-D) os depósitos de ferro se apresentam em formato nodular, formato conhecido por ser característico dos depósitos de ferro puro, a FIG. 38-A apresenta aspecto diferente, indicando a presença de óxido de ferro no lugar do ferro. 
Todos os espectros obtidos por EDS mostrados na FIG. 39, que são referentes à imagem da FIG. 38, indicam a presença de ferro, alumínio e oxigênio, porém com intensidades diferentes em cada caso. No espectro da eletrodeposição de ferro sem os aditivos (FIG. 39-A), é observado que o pico referente ao oxigênio é mais evidente que nos outros espectros, inclusive é mais evidente que o pico correspondente ao alumínio, isso poderia indicar maior presença de óxido de ferro na região mais clara da imagem do que óxido de alumínio, e estaria de acordo com o observado nas imagens e nos cronopotenciogramas obtidos durante a eletrodeposição (FIG. 37) que nesse caso apresentaram ao longo de toda sua extensão oscilações, indicando alguma alteração no processo, provavelmente a oxidação do ferro na superfície do óxido anódico e a formação de $\mathrm{FeOOH}$, as mesmas curvas construídas com a presença de ácido bórico no eletrólito não apresentaram oscilações. No espectro mostrado na FIG. 38-B, referente à imagem do alumínio anodizado com ferro eletrodepositado em eletrólito com ácido bórico como aditivo, fica evidente a diminuição da intensidade do pico do oxigênio, indicando que o ácido bórico inibe a oxidação do ferro na superfície do substrato, esse dado está de acordo com o que já foi discutido anteriomente.

Outra observação que pode ser feita a partir das micrografias da FIG. 38 é que para o mesmo tempo de deposição, 60 segundos, o ferro após a deposição com a mistura dos aditivos no eletrólito está distribuído mais homogeneamente que nas demais imagens, isso foi observado em toda extensão da amostra analisada.

O aspecto da superfície do óxido observado a olho nu também foi modificado, na superfície do óxido com ferro eletrodepositado sem aditivos são observados pontos amarelados (FIG. 40-B) (indício da provável formação de $\mathrm{FeOOH}$ na superfície), já com aditivos, esses pontos não são visíveis (FIG. 40-A). 

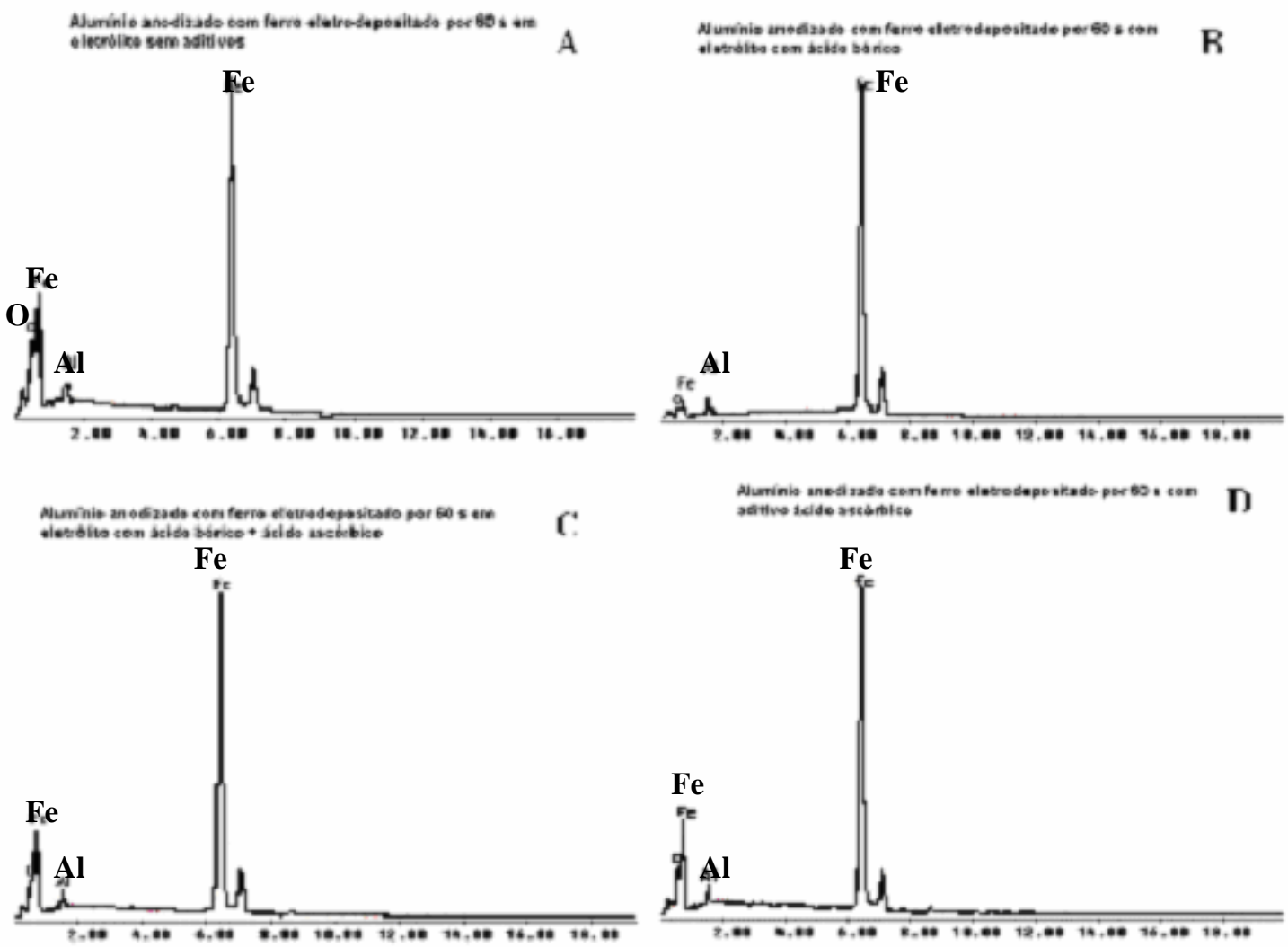

FIGURA 39: Espectros de Energia dispersiva das regiões mais claras das micrografias eletrônicas de varredura da superfície do alumínio anodizado após eletrodeposição de ferro por corrente pulsada por $60 \mathrm{~s}$ com eletrólito $\mathrm{Fe}\left(\mathrm{SO}_{4}\right)_{2}\left(\mathrm{NH}_{4}\right)_{3} \cdot 6 \mathrm{H}_{2} \mathrm{O} 0,31 \mathrm{~mol} \mathrm{~L}^{-1}$ sendo (A) sem os aditivos, (B) com $\mathrm{H}_{3} \mathrm{BO}_{3} 0,65 \mathrm{~mol} \mathrm{~L}^{-1}$, (C) com $\mathrm{H}_{3} \mathrm{BO}_{3} 0,65 \mathrm{~mol} \mathrm{~L}^{-1}+\mathrm{C}_{6} \mathrm{H}_{8} \mathrm{O}_{6} 0,06 \mathrm{~mol} \mathrm{~L} \mathrm{~L}^{-1}$ e (D) com $\mathrm{C}_{6} \mathrm{H}_{8} \mathrm{O}_{6} 0,06 \mathrm{~mol} \mathrm{~L}^{-1}$.

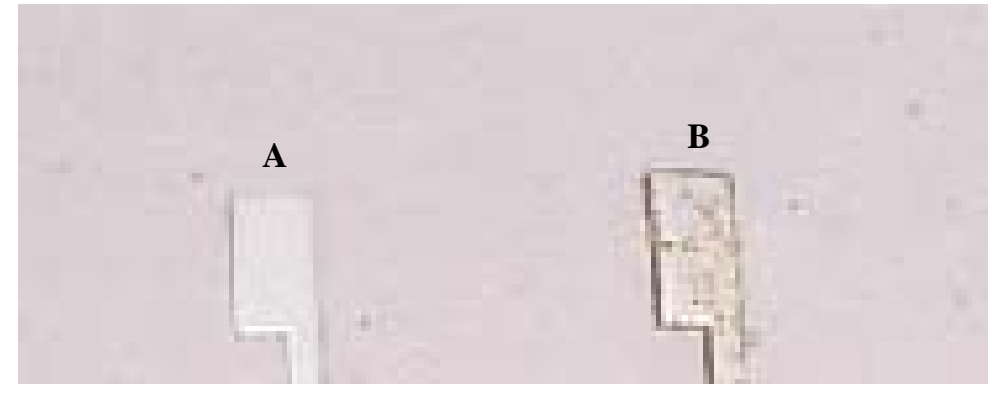

FIGURA 40: Foto de duas amostras anodizadas (A) com ferro eletrodepositado com eletrólito com a mistura dos aditivos e (B) com ferro eletrodepositado com eletrólito sem aditivos.

Durante o processo de eletrodeposição, parte dos íons $\mathrm{Fe}^{2+}$ presentes na solução são eletrodepositados na superfície do substrato, porém é bastante conhecido que o ferro em meio ácido é estável na forma de $\mathrm{Fe}^{3+}$, e devido ao baixo $\mathrm{pH}$ do eletrólito que foi medido $(3,5)$, grande parte dos íons $\mathrm{Fe}^{2+}$ se oxidam a $\mathrm{Fe}^{3+}$ provavelmente na forma de um sólido gelatinoso $\mathrm{FeOOH}$. Parte do $\mathrm{FeOOH}$ formado 
se precipitaria, e outra parte seria adsorvida na superfície do substrato, formando filmes que bloqueiam o sítio ativo na superfície do alumínio anodizado, esta interpretação está de acordo com a literatura [95]. A eletrodeposição de ferro seria retardada pelo gasto dos íons $\mathrm{Fe}^{2+}$ na reação de oxidação na própria solução, causando a falta de íons $\mathrm{Fe}^{2+}$ próximo à interface substrato/solução; e por causa da adsorção preferencial do hidróxido de ferro na superfície do substrato em relação ao ferro metálico, e pelo gasto da corrente na redução dos íons $\mathrm{Fe}^{3+}$ a íons $\mathrm{Fe}^{2+}$ próximo à superfície do eletrodo (equação 39).

O efeito do ácido bórico como aditivo no eletrólito para a eletrodeposição de ferro em outros substratos, já vem sendo estudado por outros pesquisadores [99,107,109-111] que observaram que sua ação está relacionada com o impedimento da oxidação do ferro na superfície do substrato no momento da deposição, isso está de acordo com o observado no presente trabalho (FIG. 38-A). O efeito do ácido ascórbico é de aumentar a vida útil da solução, isso foi observado em nosso trabalho e também está de acordo com a literatura [110], com a inibição da oxidação dos íons $\mathrm{Fe}^{2+}$ em solução a $\mathrm{Fe}^{3+}$, a função do ácido ascórbico seria de prevenir que parte da corrente aplicada durante a eletrodeposição seja usada para a redução dos íos férricos a íons ferrosos (reação 39) aumentando a concentração de íons $\mathrm{Fe}^{2+}$ próximo ao substrato, que são posteriormente reduzidos à forma metálica.

Portanto, de acordo com os resultados obtidos nos cronopotenciogramas, nas imagens de MEV com EDS e nas imagens óticas, a maior eficiência de eletrodeposição foi obtida utilizando-se o eletrólito com a mistura dos aditivos ácido bórico e ácido ascórbico.

$$
\mathrm{Fe}^{3+}+\mathrm{e}^{-} \rightarrow \mathrm{Fe}^{2+}
$$

\subsubsection{Influência do regime de eletrodeposição (por CC e CP) no teor de ferro da camada anódica}

A eletrodeposição por corrente pulsada é conhecida por formar melhores depósitos, mais compactos e com menor quantidade de impurezas [97], por esta razão as eletrodeposições realizadas nas condições citadas no item anterior por corrente contínua (CC) também foram feitas por corrente pulsada (CP), variando-se os ciclos de trabalho (DC). 
Para esse estudo todas as eletrodeposições foram feitas galvanostaticamente em eletrólito $\mathrm{Fe}\left(\mathrm{SO}_{4}\right)_{2}\left(\mathrm{NH}_{4}\right)_{2} \cdot 6 \mathrm{H}_{2} \mathrm{O} 0,31 \mathrm{~mol} \mathrm{~L}{ }^{-1}+\mathrm{C}_{6} \mathrm{H}_{8} \mathrm{O}_{6} 0,06 \mathrm{~mol} \mathrm{~L}^{-1}+\mathrm{H}_{3} \mathrm{BO}_{3} 0,65 \mathrm{~mol} \mathrm{~L}^{-1}$, aplicando-se 33 $\mathrm{mA} \mathrm{cm}^{-2}$ à $\mathrm{T}$ ambiente por corrente contínua e por corrente pulsada. Esta parte do estudo tem como objetivo determinar o melhor tempo de eletrodeposição para a obtenção de um filme com grande quantidade de ferro no interior dos poros da camada anódica.

Existem diversos trabalhos que estudam a eletrodeposição de ferro e suas ligas por corrente pulsada em diferentes substratos $[111,107]$.

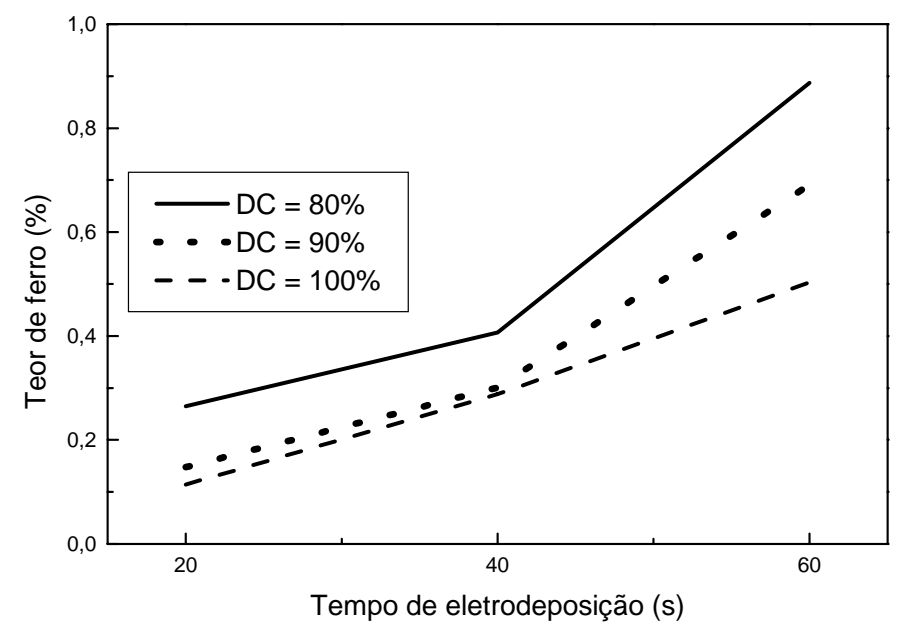

FIGURA 41: Teor de ferro na camada anódica por FRX. Todos os filmes foram anodizados por controle de potencial com eletrólito $\mathrm{H}_{3} \mathrm{PO}_{4}$ 0,65 $\mathrm{M}+\mathrm{H}_{2} \mathrm{SO}_{4} 0,85 \mathrm{M}, t$ $=40$ min., $T=20^{\circ} \mathrm{C}, E=23 \mathrm{~V}$, com ferro eletrodepositado galvanostaticamente em eletrólito $\mathrm{Fe}\left(\mathrm{SO}_{4}\right)_{2}\left(\mathrm{NH}_{4}\right)_{2} \cdot 6 \mathrm{H}_{2} \mathrm{O} 0,31 \mathrm{~mol} \mathrm{~L}^{-1}$ $+\mathrm{C}_{6} \mathrm{H}_{8} \mathrm{O}_{6} 0,06 \mathrm{~mol} \mathrm{~L}^{-1}+\mathrm{H}_{3} \mathrm{BO}_{3} 0,65 \mathrm{~mol} \mathrm{~L}$ ${ }^{1}, i=33 \mathrm{~mA} \mathrm{~cm}^{-2}$ à T ambiente.

$\mathrm{Na}$ maioria desses trabalhos, empregam-se como aditivos, entre outros, o ácido bórico e o ácido ascórbico [99,107,111,112], outros estudam a sacarina [113], ou ainda o $\mathrm{Na}_{2} \mathrm{HPO}_{4}$ e o $\mathrm{K}_{4} \mathrm{P}_{2} \mathrm{O}_{7}$ [114]. No estudo de F. Lallemand et al. [113], foi encontrado que a sacarina se adsorve na superfície e diminui a concentração de ferro na liga eletrodepositada, mas por outro lado ela diminui a corrosão do ferro.

A influência da eletrodeposição por corrente pulsada variando-se os ciclos de trabalho no teor de ferro da camada anódica está mostrada na FIG. 41.

De acordo com os dados mostrados na FIG. 41, eletrodeposições por CP permitem maior quantidade de ferro abrigado no interior dos poros. Assim, para o objetivo deste trabalho a eletrodeposição por CP com DC=80\% foi mais favorável.

Micrografias obtidas por MEV com EDS da superfície do óxido anódico mostraram que em eletrodeposições com tempo superior a 1 minuto, o ferro eletrodepositado preenche os poros e 
começa a ocupar a superfície do óxido (FIG. 42), como este não é o objetivo do trabalho, os tempos de eletrodeposição estudados foram de 20, 40 e 60 s.
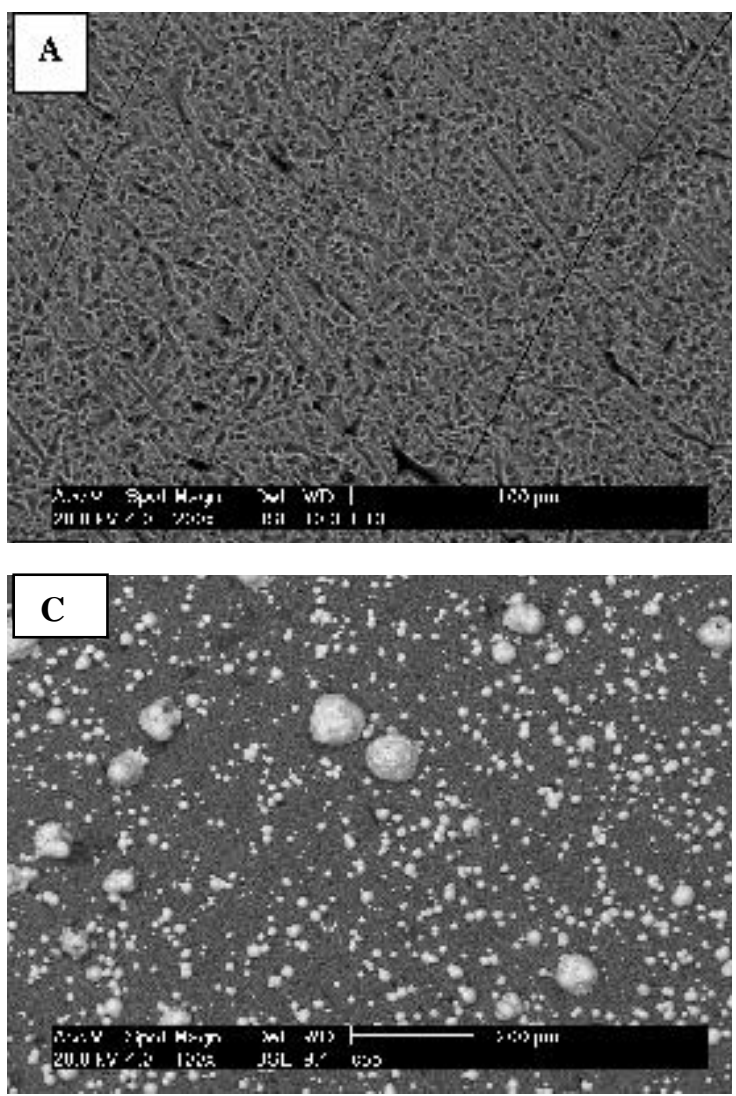

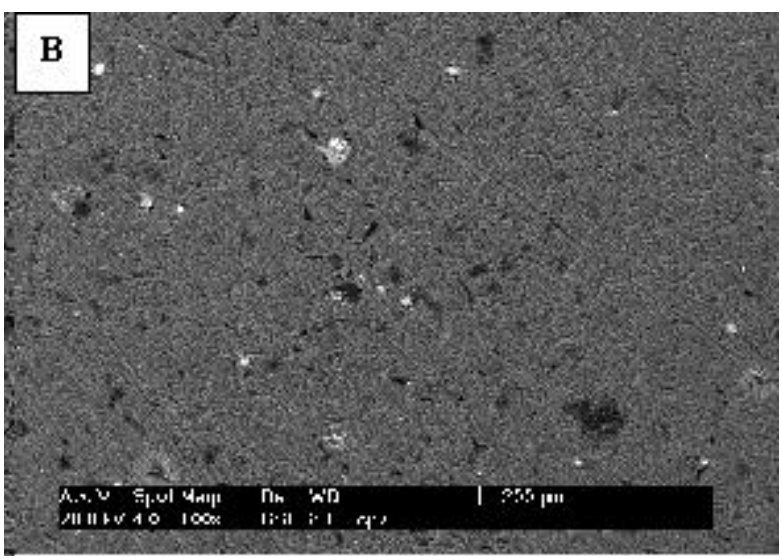

FIGURA 42: Micrografias obtidas por MEV da superfície de amostras anodizadas por controle de potencial em eletrólito misto, E=23 V, T= $20^{\circ} \mathrm{C}, t=40 \mathrm{~min}$, (A) sem eletrodeposição; (B) com ferro eletrodepositado por 40 s em eletrólito $\mathrm{Fe}\left(\mathrm{SO}_{4}\right)_{2}\left(\mathrm{NH}_{4}\right)_{2} \cdot 6 \mathrm{H}_{2} \mathrm{O} 0,31 \mathrm{~mol} \mathrm{~L} \mathrm{~L}^{-1}+$ aditivos, $i=33 \mathrm{mAcm}^{-2}$ e (C) com ferro eletrodepositado por 15 min, nas mesmas condições.

Os pontos brancos observados na FIG. 42-B e 42-C correspondem às partículas de ferro determinadas qualitativamente por EDS (FIG. 43).

Conforme o esperado e obtido por FRX (Fig. 41), quanto maior o tempo de eletrodeposição, maior o teor de ferro na camada anódica. De acordo com esses resultados e com as micrografias eletrônicas, o melhor tempo de eletrodeposição para que o ferro não ocupe a superfície do alumínio anodizado, mas preencha os poros é de $60 \mathrm{~s}$ com ciclo de trabalho de $80 \%$. 


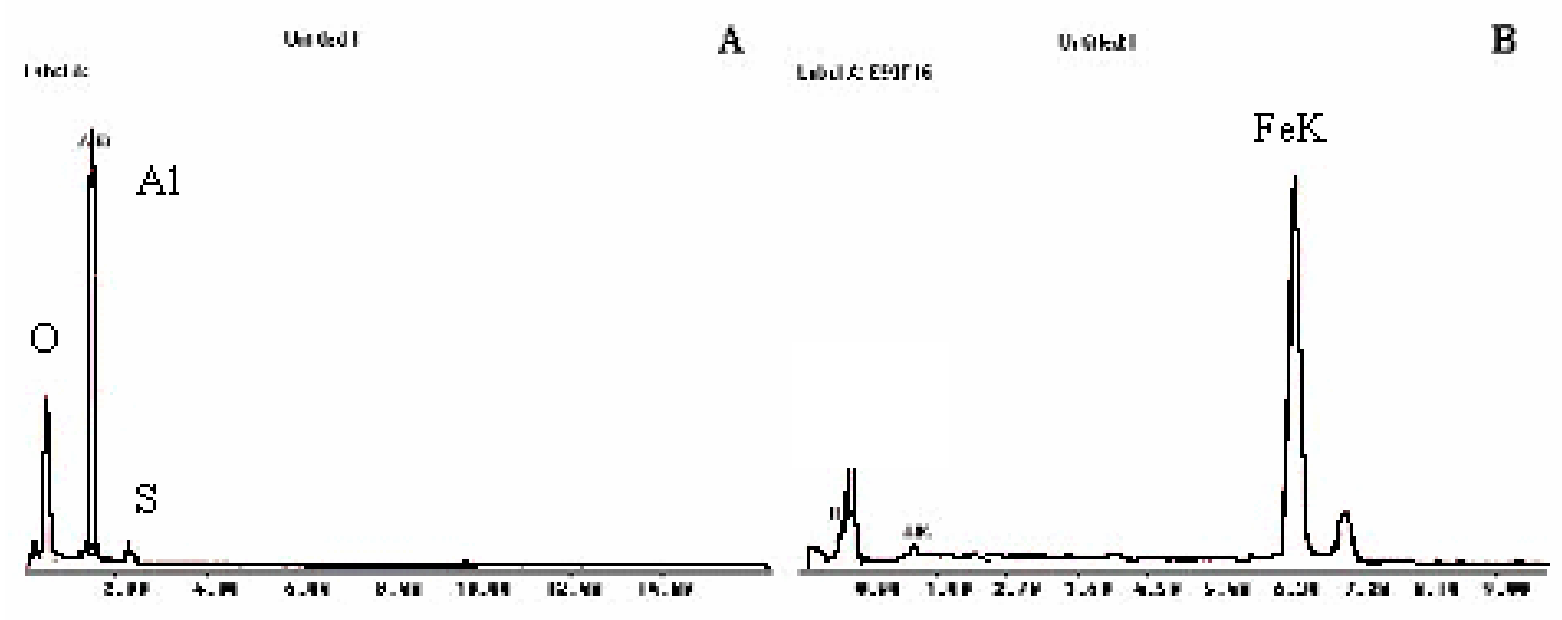

FIGURA 43: Espectros de EDS obtidos das micrografias apresentadas na FIG. 42: (A) de uma região escura; (B) de um ponto branco.

\subsection{Preparação dos nanofios de ferro}

Nesta etapa, já foram escolhidas as melhores condições de anodização e de eletrodeposição para o favorecimento da incorporação de ferro no alumínio anodizado. Assim, nas amostras da liga de Al 6063 anodizadas por controle de potencial por corrente contínua, aplicando-se um potencial final de $23 \mathrm{~V}$, a $20^{\circ} \mathrm{C}$ em eletrólito $\mathrm{H}_{2} \mathrm{SO}_{4} 0,85 \mathrm{~mol} \mathrm{~L}^{-1}+\mathrm{H}_{3} \mathrm{PO}_{4} 0,65 \mathrm{~mol} \mathrm{~L}^{-1}$ durante 40 minutos, foi eletrodepositado o ferro galvanostaticamente por corrente pulsada $\mathrm{DC}=80 \%$, em eletrólito $\mathrm{FeSO}_{4}\left(\mathrm{NH}_{4}\right)_{2} \mathrm{SO}_{4} \cdot \mathrm{H}_{2} \mathrm{O} \quad 0,31 \mathrm{~mol} \mathrm{~L}^{-1}$ com os aditivos $\mathrm{H}_{3} \mathrm{BO}_{4} 0,65 \mathrm{~mol} \mathrm{~L}^{-1}$ e $\mathrm{C}_{6} \mathrm{H}_{8} \mathrm{O}_{6} 0,06 \mathrm{~mol} \mathrm{~L}^{-1}$ a temperatura ambiente por $60 \mathrm{~s}$.

Após a eletrodeposição a amostra foi dissolvida em solução de $\mathrm{NaOH} 2 \mathrm{~mol} \mathrm{~L}^{-1}$. Da solução resultante, os nanofios foram coletados com o auxilio de um imã, utilizando uma fita adesiva que foi usada para revestir o imã que foi aproximado da solução, atraindo os nanofilamentos. A fita adesiva com os nanofios foi observada em um MEV Cambridge Steroscan 240 com sistema de análise de imagem Kontron KS-300 com EDS. Os nanofilamentos observados na FIG. 44 foram caracterizados como sendo de ferro nos espectros mostrados na FIG. 45. Nesse espectro é detectada a presença do alumínio e oxigênio (proveniente do óxido anódico ou do alumínio metálico), sódio (da solução de $\mathrm{NaOH}$ empregada na dissolução do material), ouro (proveniente do recobrimento feito para a observação do MEV) e destacadamente o ferro (dos nanofios). 


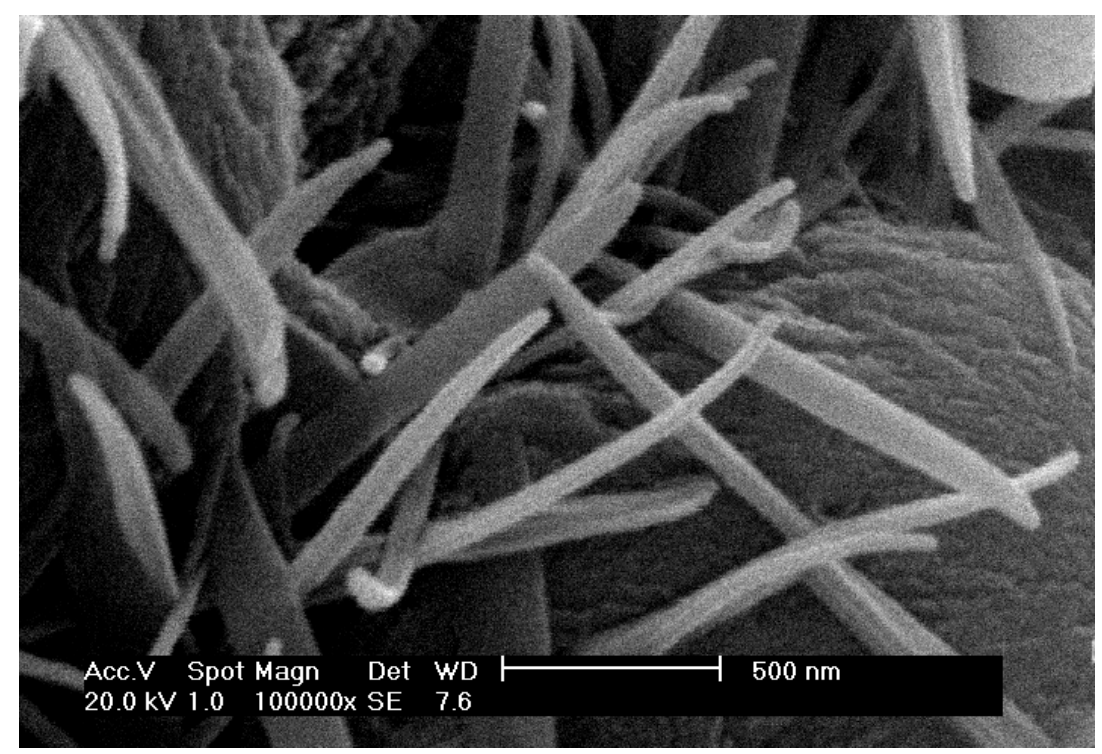

FIGURA 44: Imagem por microscopia eletrônica de varredura dos nanofios de ferro preparados em matriz de óxido anódico.

Nanofilamentos de ferro podem ser empregados como condutores elétricos na fabricação de numerosos tipos de materiais em escala nanométrica como nanochips de computador, ou nanomáquinas.

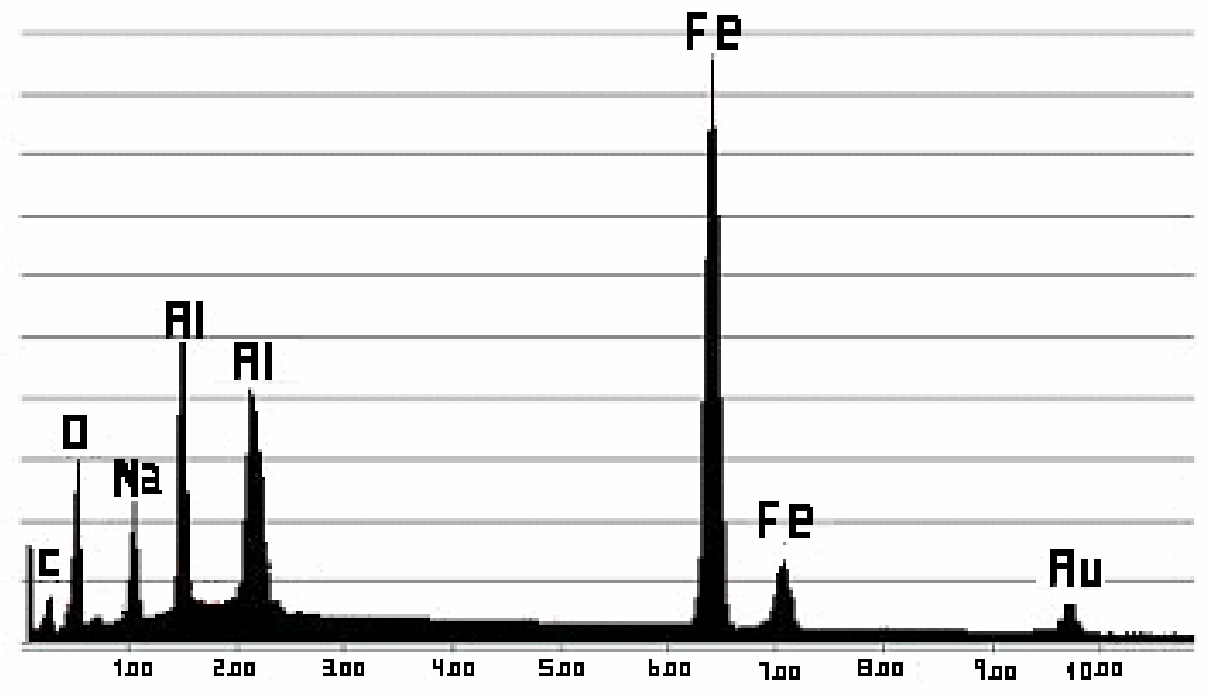

FIGURA 45: Espectro de energia dispersiva de raios X (EDS) da imagem mostrada na FIG. 44. 
Como os poros serviram como matriz para a preparação dos nanofios, as dimensões dos nanofios correspondem às dimensões internas dos poros do óxido anódico, observando-se a imagem da FIG. 44, eles possuem de 70-100 nm de diâmetro, e levando em consideração que eles ocupam os poros desde a sua base até a parte externa, concluímos que o comprimento dos nanofios pode chegar até aproximadamente $25 \mu \mathrm{m}$, que corresponde à espessura da camada porosa.

\subsection{Influência da eletrodeposição de ferro na resistência à corrosão do alumínio anodizado}

A influência do ferro no óxido anódico fica evidente na acentuada diminuição da resistência à corrosão mostrada na FIG. 46. Por esse motivo faz-se necessário um tratamento posterior para manter a integridade do alumínio anodizado uma vez que a resistência à corrosão do alumínio anodizado com o ferro é menor que a resistência à corrosão do alumínio sem anodizar, devido a maior reatividade do ferro no meio.

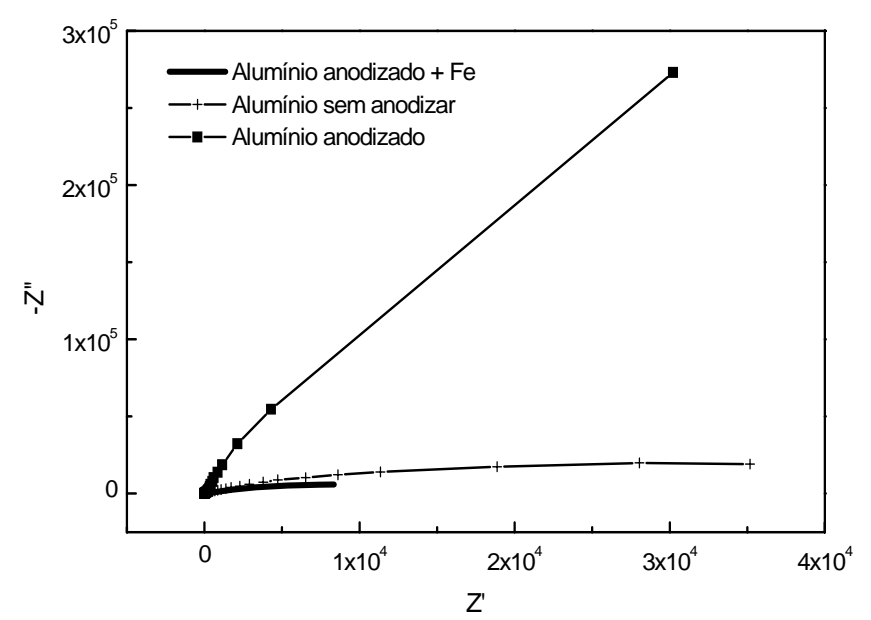

FIGURA 46: Diagrama de Nyquist (20 KHz a 2 $\mathrm{MHz}$ ) do alumínio anodizado sem ferro eletrodepositado e do alumínio anodizado com
A diminuição da resistência à corrosão do alumínio anodizado com o ferro incorporado era esperada devido às características do ferro, que conhecidamente sofre corrosão pela ação do oxigênio e da água (presentes no ar úmido e na solução de $\mathrm{NaCl}$, onde os testes de impedância foram realizados). Estudos mostram que a ação da água, ou ambientes úmidos sobre o ferro pode render três tipos principais de produtos de corrosão, que possuem cores diferentes: o componente principal é o $\mathrm{Fe}_{2} \mathrm{O}_{3} \cdot \mathrm{H}_{2} \mathrm{O}$ (óxido hidróxido ferroso, escrito às vezes como $\mathrm{Fe}(\mathrm{OH})_{3}$, com cor vermelho amarronzado, também pode-se formar o $\mathrm{FeOOH}$, o $\mathrm{Fe}_{3} \mathrm{O}_{4} \cdot \mathrm{H}_{2} \mathrm{O}$ ou o $\mathrm{Fe}_{2} \mathrm{O}_{3}$. FeO. No ar, uma umidade relativa de $50 \%$ fornece a quantidade necessária de água para que o ferro sofra um processo de corrosão $80 \%$ superior a ambiente seco [115]. Se o pH for muito 
baixo, (o pH da solução de $\mathrm{NaCl}$ 3,5\% foi medido, é 6) os íons hidrogênio consumirão os elétrons, formando o gás hidrogênio $\mathrm{H}_{2}$ que se desprende da solução (reação 40):

$$
2 \mathrm{H}_{(\mathrm{aq})}^{+}+2 \mathrm{e}^{-} \rightarrow \mathrm{H}_{2(\mathrm{~g})}
$$

Em ambiente aquoso, ou em ambientes úmidos, os íons de hidrogênio estariam sendo consumidos pelo processo (reação 41). Enquanto o ferro sofreria a corrosão, o pH da solução aumenta. Os íons hidroxila $\left(\mathrm{OH}^{-}\right)$aumentariam na água e reagiriam com os íons de ferro (II) para produzir hidróxidos insolúveis de ferro(II) (reação 41):

$$
\mathrm{Fe}^{2+}{ }_{(\mathrm{aq})}+2 \mathrm{OH}_{(\mathrm{aq})}^{-} \rightarrow \mathrm{Fe}(\mathrm{OH})_{2(\mathrm{~s})}
$$

Os íons de ferro(II) reagiriam também com os íons de oxigênio e de hidrogênio formando como produto os íons de ferro(III) (reação 42):

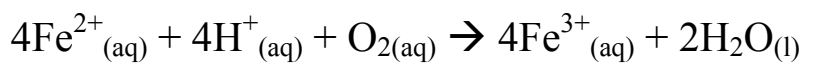

De acordo com esse mecanismo, os íons de ferro(III) reagiriam com as hidroxilas em excesso para produzir os óxidos hidratados de ferro(III) (conhecidos também como hidróxidos de ferro(III))(reação 43):

$$
\mathrm{Fe}^{3+}{ }_{(\mathrm{aq})}+3 \mathrm{OH}_{(\mathrm{aq})}^{-} \rightarrow \mathrm{Fe}(\mathrm{OH})_{3(\mathrm{~s})}
$$

$\mathrm{O} \mathrm{Fe}(\mathrm{OH})_{3}$ poroso poderia lentamente se transformar na forma cristalina $\mathrm{Fe}_{2} \mathrm{O}_{3} \cdot \mathrm{H}_{2} \mathrm{O}$, cujo produto é conhecido por possuir cor vermelho amarronzado [115].

Assim, foi necessário um estudo de um tratamento para aumentar a resistência à corrosão do alumínio anodizado com ferro. $\mathrm{O}$ tratamento estudado foi com $\mathrm{CeCl}_{3}$ em três concentrações diferentes. 


\subsection{Influência do tratamento químico com $\mathrm{CeCl}_{3}$}

O ferro é um metal barato, que possui boa condutividade elétrica e propriedades magnéticas interessantes. Por esse motivo, o ferro é eletrodepositado nos poros do óxido anódico do alumínio a fim de alterar as propriedades elétricas e magnéticas desse material. Porém, o ferro possui baixa resistência à corrosão e daí vem à necessidade de se estudar um tratamento com algum inibidor de corrosão com o objetivo de aumentar a vida útil desse novo material formado. O objetivo desta parte do trabalho é estudar a resistência à corrosão do alumínio anodizado antes e após a eletrodeposição de ferro no interior da camada anódica e após o tratamento para a formação de um filme de óxido de cério utilizando solução de $\mathrm{CeCl}_{3}$, variando-se a concentração dessa solução até a obtenção de uma condição ideal.

\subsubsection{Influência do tratamento com $\mathrm{CeCl}_{3}$ no alumínio anodizado com ferro, quanto à espessura e à microdureza do óxido anódico}

O mecanismo de formação de uma camada protetora de óxido de cério já é bastante conhecido. Resumidamente, há um ataque químico na superfície do substrato gerando um aumento de $\mathrm{pH}$ interfacial, que favorece a formação de um filme de $\mathrm{CeO}_{2}$ e $\mathrm{Ce}(\mathrm{OH})_{3}$ [80] e posterior absorção na superfície. $\mathrm{O} \mathrm{H}_{2} \mathrm{O}_{2}$ é um agente oxidante utilizado para acelerar estas reações, e deve ser usado em baixas concentrações para evitar o ataque excessivo ao substrato.

Os íons $\mathrm{Ce}^{3+}$ são gastos na formação do óxido de cério $[70,88]$ presentes numa concentração adequada de $\mathrm{CeCl}_{3}$, para manter a integridade do substrato de alumínio, e impedir o ataque excessivo do cloreto sobre o alumínio que causa a remoção da camada de óxido.

A ação do $\mathrm{CeCl}_{3}$ de $10^{-3} \mathrm{~mol} \mathrm{~L}^{-1}$ a $8,6 \times 10^{-2} \mathrm{~mol} \mathrm{~L}^{-1}$ foi verificada sobre a espessura e a microdureza do óxido anódico de alumínio. Em baixas concentrações não foi observado um ataque químico superficial sobre o óxido, uma vez que a espessura não foi alterada (FIG. 47-A, 47-B e 47C), entretanto, o tratamento pode ter exercido alguma ação no interior dos poros, fragilizando a microestrutura, isso foi evidenciado na diminuição da microdureza do óxido anódico, medida e mostrada na TAB. 14 após os tratamentos com $\mathrm{CeCl}_{3}$. 


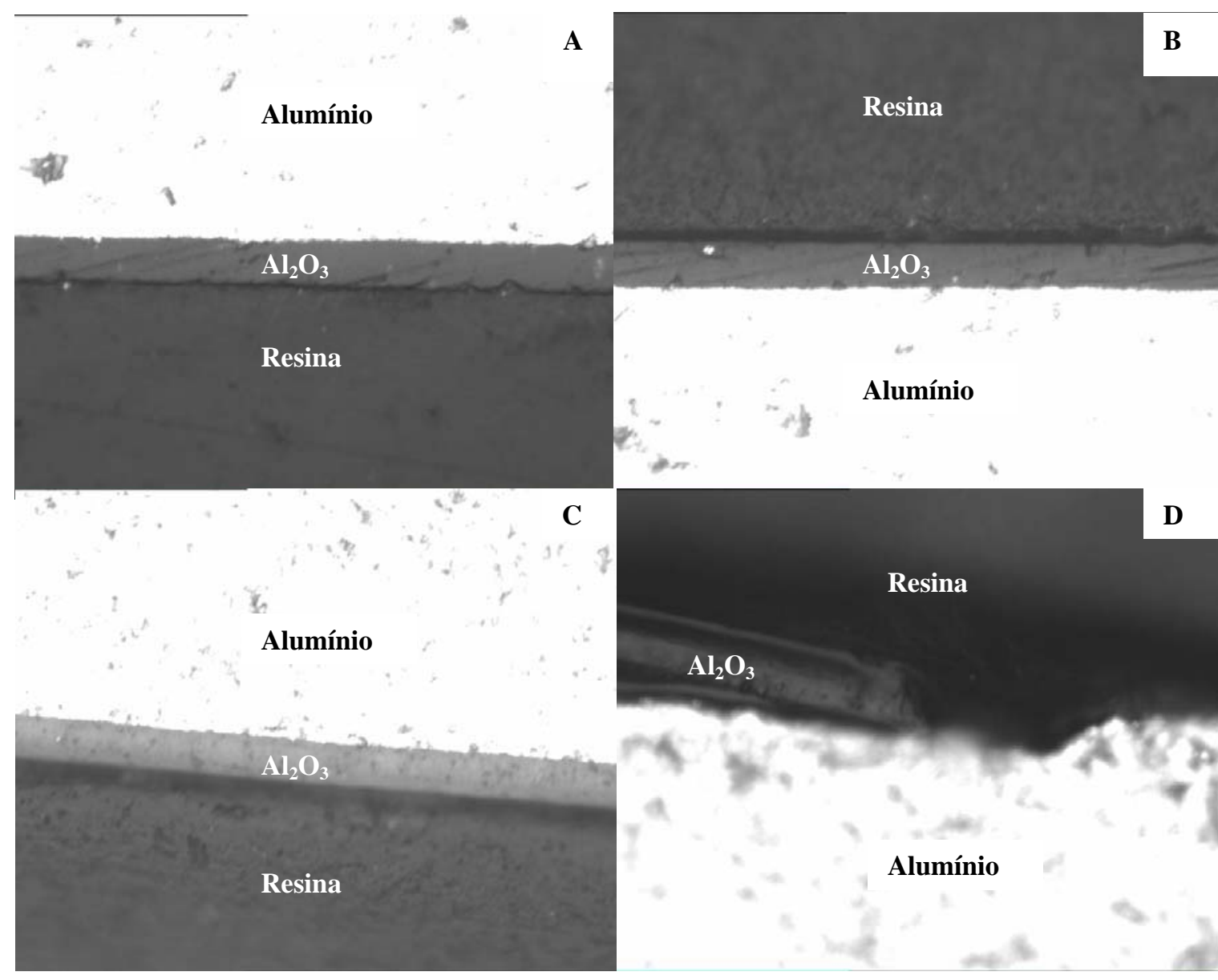

FIGURA 47: Microscopia ótica de um corte transversal do alumínio anodizado com ferro eletrodepositado (A) sem tratamento com cério; (B) após tratamento com $\mathrm{CeCl}_{3} 10^{-3} \mathrm{~mol} \mathrm{~L}^{-1}$; (C) após tratamento com $\mathrm{CeCl}_{3} 5 \times 10^{-3} \mathrm{~mol} \mathrm{~L}^{-1}$ e (D) após tratamento com $\mathrm{CeCl}_{3} 8,6 \times 10^{-2} \mathrm{~mol} \mathrm{~L}^{-1}$.

TABELA 14: Variação da espessura e microdureza do óxido anódico com a concentração de CeCl 3 .

\begin{tabular}{|c|c|c|}
\hline Tipo da amostra & Espessura $(\mu \mathrm{m})$ & Microdureza $(\mathrm{Hv})$ \\
\hline Alumínio anodizado $+\mathrm{Fe}$ & 11,5 & 357 \\
\hline Alumínio anodizado $+\mathrm{Fe}$ tratado com $\mathrm{CeCl}_{3} 10^{-3} \mathrm{M}$ & 11,5 & 188 \\
\hline Alumínio anodizado $+\mathrm{Fe}$ tratado com $\mathrm{CeCl}_{3} 5 \times 10^{-3} \mathrm{M}$ & 11,5 & 140 \\
\hline Alumínio anodizado $+\mathrm{Fe}$ tratado com $\mathrm{CeCl}_{3} 8,6 \times 10^{-2} \mathrm{M}$ & Sem camada & Sem camada \\
\hline
\end{tabular}


Há diversos trabalhos que investigam a ação da baixa concentração do $\mathrm{CeCl}_{3}$ na formação de uma película protetora no alumínio e no alumínio anodizado quanto à corrosão $[70,77,78]$. Em concentrações elevadas fica evidenciado no presente trabalho, que o cloreto causa um ataque muito intenso ao alumínio, isto está de acordo com a literatura [10] e a camada de óxido anódico se desprende quase completamente do substrato (FIG. 47-D).

\subsubsection{Influência do tratamento com $\mathrm{CeCl}_{3}$ no alumínio anodizado com ferro eletrodepositado sobre a resistência à corrosão}

Nas FIG. 48 e 49, verifica-se que o tratamento com $\mathrm{CeCl}_{3} 8,6 \times 10^{-2} \mathrm{~mol} \mathrm{~L}^{-1}$ aparentemente eleva a resistência à corrosão do alumínio anodizado com ferro, mas esse aumento é só aparente, pois a impedância observada está próxima à impedância do alumínio puro, isso acontece porque nesse caso, o ataque do $\mathrm{Cl}^{-}$ao alumínio foi tão intenso, devido a alta concentração de $\mathrm{Cl}^{-}$na solução, que a camada anódica se desprendeu na quase totalidade do substrato (FIG. 47-D), portanto o resultado corresponde à superfície do alumínio sem a camada anódica. Já o tratamento com $\mathrm{CeCl}_{3} 10^{-3} \mathrm{~mol} \mathrm{~L}^{-1}$ melhorou consideravelmente a resistência à corrosão do sistema com ferro, sendo que o aumento da resistência à corrosão foi mais intenso com o tratamento com $\mathrm{CeCl}_{3} 5 \times 10^{-}$ ${ }^{3} \mathrm{~mol} \mathrm{~L}^{-1}$ (FIG. 48 e 49), onde a impedância se igualou àquela do alumínio anodizado sem ferro.

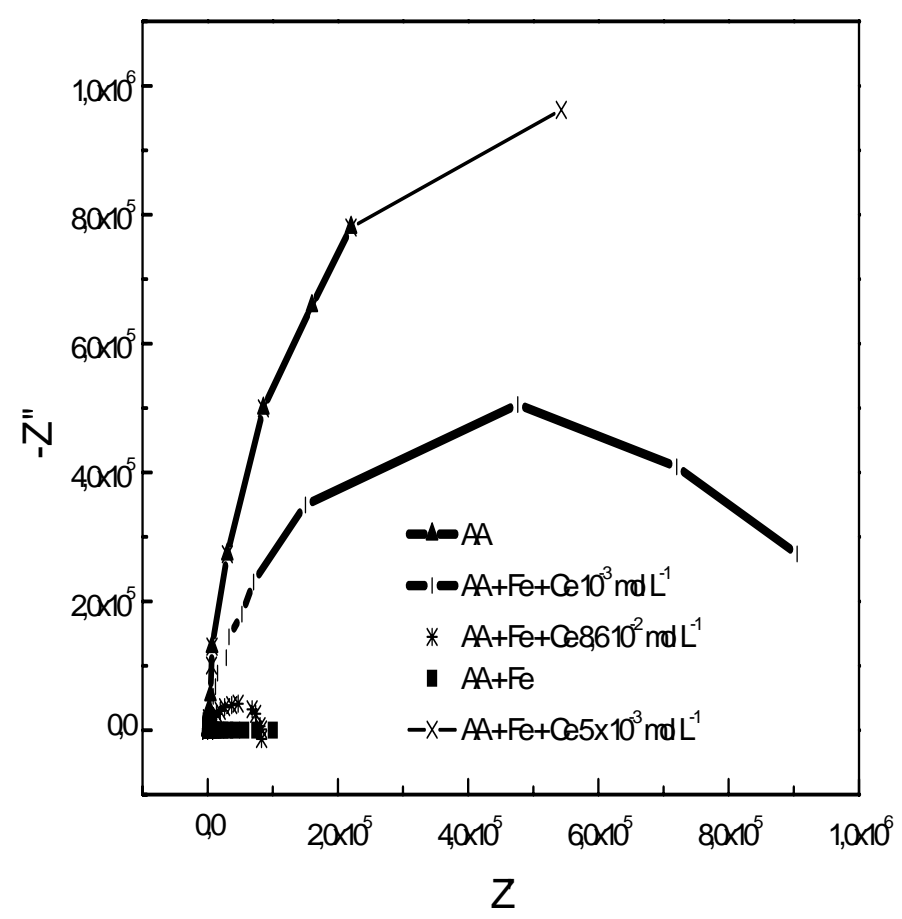

FIGURA 48: Diagrama de Nyquist (20 $\mathrm{KHz}$ a $2 \mathrm{MHz}$ ) do alumínio anodizado $(A A)$, alumínio anodizado com ferro sem tratamento $(\mathrm{AA}+\mathrm{Fe})$, alumínio anodizado com Fe tratado com: $\mathrm{CeCl}_{3} 8,6 \times 10^{-2} \mathrm{M}$, $\mathrm{CeCl}_{3} 5 \times 10^{-3} \mathrm{M}$ e com $\mathrm{CeCl}_{3} 10^{-3} \mathrm{M}$. 

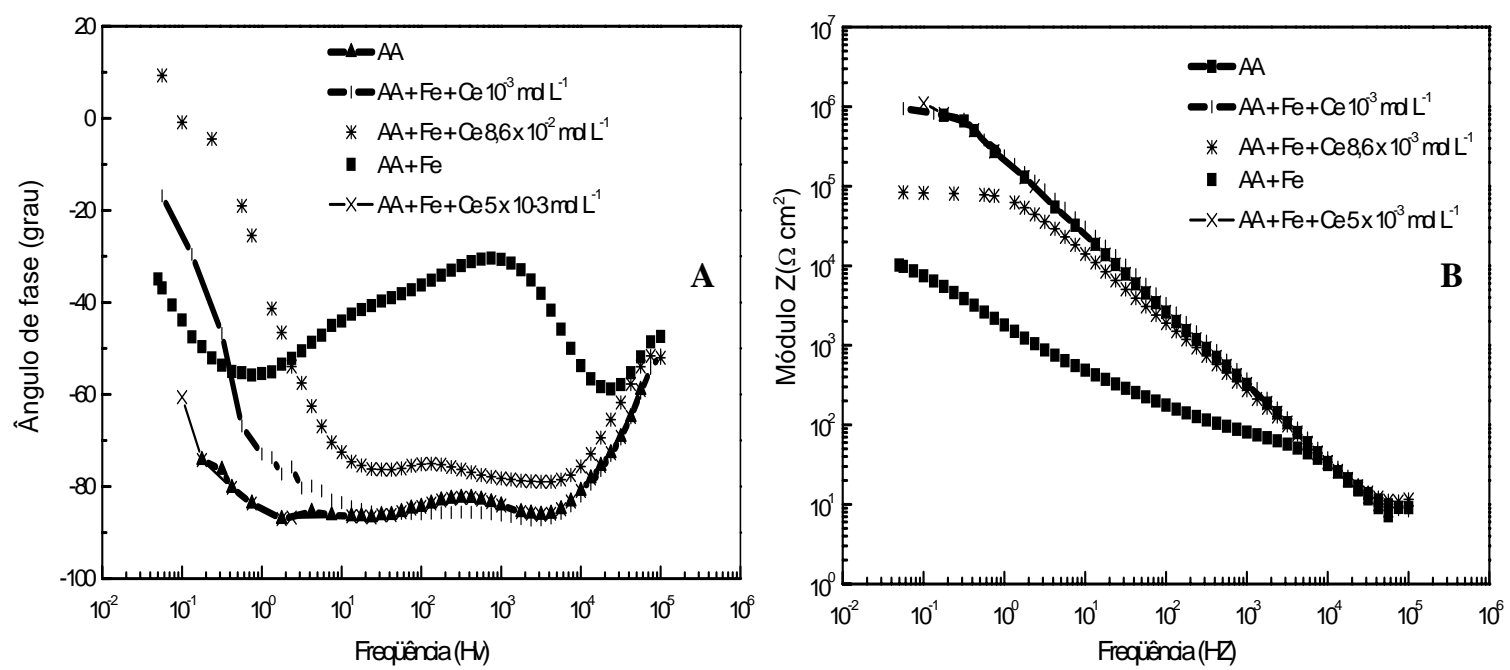

FIGURA 49: Diagramas de Bode (A) Ângulo de fase e (B) Módulo de Z do alumínio anodizado, alumínio anodizado com ferro sem e com os tratamentos com $\mathrm{CeCl}_{3}$ em três concentrações diferentes.

A partir desses dados de impedância eletroquímica, é possível afirmar que o tratamento com $\mathrm{CeCl}_{3} 5 \times 10^{-3} \mathrm{~mol} \mathrm{~L}^{-1}$ proporcionou maior resistência à corrosão ao alumínio anodizado com ferro, porém é preciso avaliar o efeito desse tratamento na condutividade elétrica desse sistema, para isso foram feitas medidas de impedância elétrica pelo método de duas pontas. Os tratamentos com $\mathrm{CeCl}_{3}$ 1 e $5 \times 10^{-3} \mathrm{~mol} \mathrm{~L}^{-1}$ foram eficazes na inibição à corrosão do alumínio anodizado com ferro eletrodepositado e preservaram a integridade da camada, diferente do que acontece quando tratado com $\mathrm{CeCl}_{3} 8,6 \times 10^{-2} \mathrm{~mol} \mathrm{~L}^{-1}$, por isso as análises elétricas serão feitas com os tratamentos nas melhores concentrações de $\mathrm{CeCl}_{3}$, os resultados serão mostrados no próximo item.

\subsubsection{Influência da eletrodeposição de ferro e do tratamento com cloreto de cério nas propriedades elétricas do alumínio anodizado}

O objetivo principal do estudo da implantação de ferro no alumínio anodizado é preparar nanofios de ferro utilizando os poros da camada anódica como matriz, e também modificar as propriedades elétricas do substrato. Por essa razão, após a determinação das melhores condições de formação de um sistema de alumínio anodizado + ferro + óxido de cério, onde a função do filme de 
óxido de cério é aumentar a resistência à corrosão que foi alterada pelo ferro, foram feitas medidas elétricas pela técnica de duas pontas utilizando um impedancímetro $\mathrm{HP} 41922 \mathrm{~A}$ de $5 \mathrm{~Hz} 113 \mathrm{MHz}$, no alumínio anodizado antes e após a eletrodeposição de ferro e com o tratamento com $\mathrm{CeCl}_{3}$ nas concentrações de $\mathrm{CeCl}_{3}$ de $10^{-3} \mathrm{~mol} \mathrm{~L}^{-1}$ e $5 \times 10^{-3} \mathrm{~mol} \mathrm{~L}^{-1}$, a fim de avaliar a influência da eletrodeposição de ferro na resistividade elétrica do alumínio anodizado antes e após os tratamentos.

O aumento da condutividade elétrica do alumínio anodizado com o ferro incorporado era esperado devido à boa condutividade elétrica do ferro $\left(9.9310^{6} \Omega^{-1} \mathrm{~m}^{-1}\right)$. A presença do ferro dobrou a condutividade elétrica do alumínio anodizado.

O ferro está presente no interior dos poros da camada anódica, que conhecidamente possuem formato colunar e estão presentes em toda extensão do óxido, desde a superfície do metal até o exterior dos poros, esses nanofilamentos de ferro funcionariam como conectores elétricos entre o alumínio e a superfície do óxido anódico. Sendo assim, pode-se concluir que quanto maior o teor de ferro no alumínio anodizado, maior a condutividade da camada anódica.

A análise de impedância elétrica por duas ou por quatro pontas, é muito utilizada para medir a resistividade elétrica de materiais em meio natural, sem a ação de um ataque químico ou eletroquímico, como na espectroscopia de impedância eletroquímica. Para a medida da resistividade elétrica do alumínio anodizado no presente trabalho, foi feita uma montagem experimental na qual a amostra anodizada se localizava entre duas placas de platina ligadas ao impedâncímetro, onde era aplicado um potencial de $200 \mathrm{mV}$ e medida a resistência à passagem da corrente elétrica oferecida pela amostra.

Os resultados desta análise estão mostrados na FIG. 50. Devido à alta resistividade do material, não foi possível obter o arco completo diretamente pela análise de impedância, já que o arco se completa a impedâncias muito altas, assim, por esse motivo foi necessário completar as semicircunferências utilizando um compasso, traçando-se duas secantes à circunferência. No ponto de interseção das secantes foi fixada a ponta do compasso e traçada a outra parte do semicírculo, completando o arco, o que permitiu obter os valores de resistividade elétrica e, a partir desses dados, calcular as condutividades das amostras. 


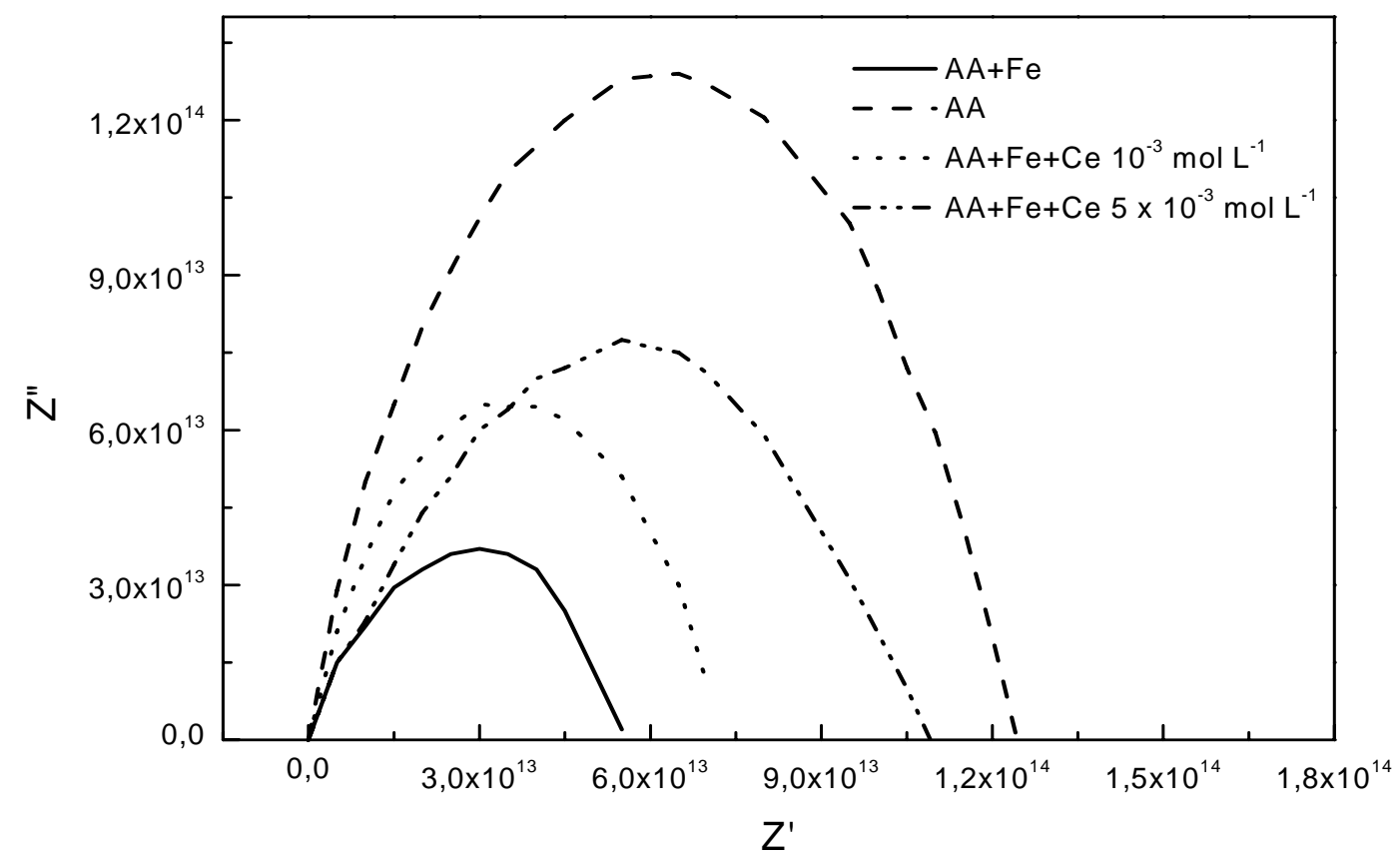

FIGURA 50: Diagrama de impedância elétrica do alumínio anodizado antes e após os tratamentos com ferro e com $\mathrm{CeCl}_{3}$, obtido pela técnica de análise elétrica de duas pontas.

De acordo com o diagrama apresentado na FIG. 50, é possível observar que o ferro diminuiu a impedância do alumínio anodizado mesmo após os tratamentos com cério, sendo que o alumínio anodizado com ferro tratado com $\mathrm{CeCl}_{3} 5 \times 10^{-3} \mathrm{~mol} \mathrm{~L}^{-1}$ apresentou maior resistividade que o tratado com $\mathrm{CeCl}_{3} 10^{-3} \mathrm{~mol} \mathrm{~L}^{-1}$, que foi a melhor condição encontrada no trabalho, já que a resistência à corrosão também foi aumentada com essa concentração de $\mathrm{CeCl}_{3}$.

A resistividade $\rho(\Omega \mathrm{cm})$ é calculada pela equação 44 :

$$
\rho=R(S / L)
$$

onde:

$\mathrm{R}$ é a resistência $(\Omega)$ medida e igual ao diâmetro do semicírculo

$\mathrm{S}\left(\mathrm{cm}^{2}\right)$ é a área da amostra $=1 \mathrm{~cm}^{2}$

$\mathrm{L}(\mathrm{cm})$ é a espessura da amostra $=0,1 \mathrm{~cm}$. 
A condutividade $(C)$ é o inverso da resistividade ( $\rho)$, e foi calculada a partir da equação 45 :

$$
\mathrm{C}=1 / \rho
$$

Os valores de resistência elétrica medidos e de condutividade elétrica calculados são mostrados na TAB. 15.

TABELA 15: Valores de resistência e condutividade elétrica do alumínio anodizado antes e após as modificações.

\begin{tabular}{|c|c|c|}
\hline Amostra & Resistência $(\Omega)$ & Condutividade $\left(\Omega^{-1} \mathrm{~m}^{-1}\right)$ \\
\hline Alumínio anodizado & $1,25 \times 10^{14}$ & $8,0 \times 10^{-16}$ \\
\hline Alumínio anodizado $+\mathrm{Fe}$ & $5,5 \times 10^{13}$ & $1,8 \times 10^{-15}$ \\
\hline Alumínio anodizado $+\mathrm{Fe}+\mathrm{Ce}\left(110^{-3} \mathrm{~mol} \mathrm{~L}^{-1}\right)$ & $7 \times 10^{13}$ & $1,4 \times 10^{-15}$ \\
\hline Alumínio anodizado $+\mathrm{Fe}+\mathrm{Ce}\left(510^{-3} \mathrm{~mol} \mathrm{~L}^{-1}\right)$ & $1,1 \times 10^{14}$ & $9,1 \times 10^{-16}$ \\
\hline
\end{tabular}

A partir dos valores mostrados na TAB. 15 é possível concluir que a incorporação de ferro no alumínio anodizado aumentou sua condutividade elétrica, mesmo após o tratamento com $\mathrm{CeCl}_{3}$ $10^{-3} \mathrm{~mol} \mathrm{~L}^{-1}$.

$\mathrm{O}$ tratamento com $\mathrm{CeCl}_{3} 10^{-3} \mathrm{~mol} \mathrm{~L}^{-1}$ melhorou a resistência à corrosão do alumínio anodizado e conservou o aumento na condutividade elétrica do alumínio anodizado alcançado com a incorporação do ferro.

$\mathrm{O}$ tratamento químico com $\mathrm{CeCl}_{3}$ no alumínio anodizado tem como objetivo formar uma camada conhecidamente muito fina (cerca de 3 a $5 \mathrm{~nm}$ ) de óxido de cério na superfície do óxido anódico. Conforme citado na introdução desse trabalho, existem diversos pesquisadores que investigam a composição deste filme formado sobre diferentes tipos de materiais, e foi encontrada a presença de uma mistura de óxido e hidróxido de cério III e IV. 
A camada de óxido/hidróxido de cério funciona como uma barreira física que dificulta a absorção do eletrólito (ou de moléculas hidratadas presentes no ar) no material tratado diminuindo a ação da corrosão destes no substrato.

Dependendo das condições do tratamento, como concentração de cério na solução, temperatura da solução e duração do tratamento, o filme formado pode ter características diferentes, proporcionando maior ou menor grau de cobertura ao substrato.

No presente estudo, o filme de óxido de cério deve ter grau de cobertura tal que aumente a resistência à corrosão do alumínio anodizado com o ferro, sem que diminua significativamente a impedância elétrica deste novo compósito formado. Essa condição foi obtida satisfatoriamente no tratamento químico em solução de $\mathrm{CeCl}_{3} 10^{-3} \mathrm{~mol} \mathrm{~L}^{-1}$. Já que o tratamento com $\mathrm{CeCl}_{3} 5 \times 10^{-3} \mathrm{~mol}$ $\mathrm{L}^{-1}$ foi eficaz na inibição da corrosão, mas também diminui a condutividade elétrica do alumínio anodizado com o ferro incorporado. 


\section{CONCLUSÕES}

Foi obtido um filme anódico com boas condições protetoras ao alumínio e que favoreceu a incorporação de ferro em anodizações por controle do potencial a $20^{\circ} \mathrm{C}$ em eletrólito $\mathrm{H}_{2} \mathrm{SO}_{4} \quad 0,85$ mol L ${ }^{-1}+\mathrm{H}_{3} \mathrm{PO}_{4} 0,65 \mathrm{~mol} \mathrm{~L}^{-1}$ por 40 minutos, por corrente contínua.

As condições de eletrodeposição de ferro que proporcionaram melhores depósitos e com maior concentração desses no interior dos poros do óxido anódico foram com eletrólito sulfato ferroso amoniacal com a mistura dos aditivos ácido bórico e ácido ascóbico, por corrente pulsada com $\mathrm{DC}=80 \%$ e durante $60 \mathrm{~s}$. O ferro elevou a condutividade elétrica do alumínio anodizado.

$\mathrm{O}$ melhor tratamento com $\mathrm{CeCl}_{3}$ foi com a concentração de $10^{-3} \mathrm{~mol} \mathrm{~L}^{-1}$, pois houve aumento da resistência à corrosão do alumínio anodizado com o ferro e conservação do aumento da condutividade elétrica obtido com a implantação de ferro.

Os nanofios de ferro foram preparados, e esse resultado é de importância tecnológica, por ser uma forma simples e razoavelmente barata para preparar nanofios, não necessitando de equipamentos sofisticados, ou reagentes caros, simplesmente utilizando técnicas eletroquímicas. 


\section{SUGESTÕES PARA TRABALHOS FUTUROS}

Espera-se que esse trabalho seja um precursor para futuros estudos, onde se podem estudar maiores concentrações de ferro no alumínio anodizado a fim de alterar ainda mais sua condutividade, para que ele possa ser empregado como um semicondutor que possui vantagens em relação a outros semicondutores por ser leve e possuir boa resistência à corrosão após tratamento adequado.

Outro aspecto relevante de pesquisa que pode ser desenvolvido é o da modificação das propriedades magnéticas com a incorporação de ferro no alumínio anodizado. 


\section{REFERÊNCIAS BIBLIOGRÁFICAS}

1. DIMOGERONTAKIS, T.; KOMPOTIATIS, L.; KAPLANOGLOU, I. Oxygen evolution during the formation of barrier type anodic film on 2024-T3 aluminium alloy. Corros. Sci., v. 40, n. 11, p. 1939-1951, 1998.

2. CANNEY, S.A.; VOS, M.; KHEIFETS, A.S.; GUO, X.; McCARTHY, I.E.; WEIGOLD, E. Electron momentum spectroscopy studies on the oxidation of aluminium. Surf. Sci., v. 382, n.1/3, p. 241-257, 1997.

3. DELL'OCA, C.J.; FLEMING, P.J. Initial Stages of Oxide Growth and Pore Initiation in the Porous Anodization of Aluminum. J. Electrochem. Soc. v.123, n.10, p.1487, 1978.

4. PATERMARAKIS, G. Transport phenomena inside the pores involved in the kinetics and mechanism of growth of porous anodic $\mathrm{Al}_{2} \mathrm{O}_{3}$ filmes on aluminium. J. Electroanal. Chem., v. 404, n. 1, p. 69-76, 1996.

5. YANG, S.; ZHU, H.; DONGLIANG, Y.; ZHIQIANG, I.; SHAOLONG, T.; YOUWEI, D. Preparation and magnetic property of Fe nanowire array. J. Magnetism and Magnetic Mater., v. 222, n. 1/2, p. 97-100, 2000.

6. YU, X.; YAN, C.; CAO, C. Study on the rare earth sealing procedure of the porous film of anodized Al6061/SiCp, Mat. Chem. and Phys., v. 76, p. 228-235, 2002.

7. DESCAMPS, P.; IKER, J.; WOLF, A. Effects and anodized aluminium surface parameters on the long-therm adhesion of silicone structural glazing sealants. Corros. and Build. Mater., v. 10, n. 7, p. 527, 1996.

8. PALIBRODA, E. Aluminum porous oxide growth - II. On the rate determining step. Electrochimica Acta, vol. 40, No. 8, 1051-1055, 1995.

9. PALIBRODA, E.; LUPSAN, A.; PRUNEANU, S.; SAVOS, M. Aluminium porous oxide growth. On the electric conductivity of the barrier layer. Thin Solid Films, 256, p. 101-105, 1995.

10. WERNICK, S.; PINNER, R. Surface Treatment of aluminium. v.1, 4.ed. Teddington, England.: Robert Drapper Ltda., 1972.

11. SETOH, S.; MITAYA, A. Proc. World Engineering Congress, Tokyo, 1929.

12. RUMMEL, T., Z. Physik, v. 99, p. 518-551, 1936.

13. GÜNTHERSCHULZE, A. Z. Phys. Chem., v.15, p. 95, 1939.

14. MOTT, N.F. Trans Faraday Soc., v. 35, p. 1579, 1939. 
15. MOTT, N.F The teory of the formation of protective oxide films on metal. -III. Trans Faraday Soc., v. 43, p. 429-434, 1957.

16. SCHENK, M. Werkstoff Aluminium und seine anodishe Oxydation. Verlage, Bern A. Francke A.G., 1948.

17. AKIMOV, G.B., TOMASHOV, N. D., TYUKINA, M.N. Zh. Fiz. Chim., v.12, p.9-10, 433, 1942; Light Metals, v. 7, n.78, p. 311, 1944.

18. ANDERSON, S. Mechanism of Electrolytic Oxidation of Aluminum. J. Appl. Phys., v. 15, n. 6, p. 477-480, 1944.

19. CHARLESBY, A. Proc. Phys. Soc,. v.B66, p. 317, 1953.

20. MÜLLER, E. On the passivity of metals. Trans. Faraday Soc., v.27, p. 737-751, 1931.

21. KAWAI, S.; UEDA, E.R. Magnetic properties of anodic oxide coatings on aluminum containing electrodeposited Co and Co-Ni. J. Electrochem. Soc., 122, p. 32-36, 1975.

22. KROTOV, I. V. Zh. Fiz. Khim., v. 28, p. 1550, 1954.

23. SHREIDER, A.V. Metal Science and Heat Treatment, v. 2, n. 10, p. 570-570, 1960.

24. MURPHY, J. F., MICHELSON, C.E. A Theory for the Formation of Anodic Coatings on Aluminium. Conference on Anodising of Aaluminium, Notingham, (1961).

25. KELlER, F.; HUNTER, M.S.; ROBINSON, D.L. Structural features of oxide filmes on aluminum. J. Electrochemical Society, v. 100, n. 9, p. 411-419, 1953.

26. SCHNYDER, B.; KÖTZ. Spectroscopic ellipsometry and XPS studies of anodic aluminum oxide formation in sulfuric acid. J. Electroanal. Chem., v. 339, n. 1/2, p. 167-185, 1992.

27. TAKAHASHI, H.; NAGAYAMA M. Electrochemical behaviour and structure of anodic oxide films forme don aluminium in a neutral borate solution. Electrochimica Acta, v. 23, n. 3, p. 279-286, 1978.

28. MOON, S-M.; PYUN, S-L. The formation and dissolution of anodic oxide films on pure aluminium in alkaline solution. Electrochimica Acta, v. 44, n. 14, p. 2445-2454, 1999.

29. STEVENSON, M.F.J. Anodizing. In: Cotell, C.M., Sprague, J.A., Smidt, F.A.J. Surface Engineering. United States of America: ASM International Handbook Committee, 9a. ed, v. 5, p. 482-493, 1994.

30. BENGOUGH, G. D.; SUTTON, H. Engineer, 122, p. 274-276, 1926.

31. PULLEN, N.D. J. Electrodepos. Tech. Soc., 15, p. 69-78, 1939. 
32. RAUB, E.; NITSCHE, D.; KAWASSE, H.; WEISS, H. Metall, 23, n. 7, p. 667-671, 1969.

33. PRESTON, C.K.; MOSKOVITS, M. Optical haracterization of anodic aluminum oxide films containing electrochemically deposited metal particles, 1. Gold in phosphoric acid anodic aluminum oxide films. J. Phys. Chem., v. 97, p. 8495-8503, 1993.

34. KENDIG, M.; ADDISON, R.; JEANJAQUET, S. Adsorption of Ce (III) on anodized aluminium. Electrochem Solid-Stat Lett., v. 3, p. 266-267, 2000.

35. ZAGIEL, A.; NATISHAN, P.; GILEADI, E. Plationg on anodized aluminum - II. The effect of metal, the anion and the aluminum alloy. Electrochim. Acta, v. 35, n.6, p. 1019-1030, 1990.

36. BOGOYAVLENSKII, A. F. O mekhanizmakh obrazovaniya anodnoi okisnoi plenki na alyuminii: Anodnaya zashchita metallov. Moskow. Dokl. 1-oi mezhvuzovskoi konferentsii . p. 22-34. Mashinostroenie, 1964.

37. NEUFLED, P.; ALI, H.O. The influence of anions on the structure of porous anodic $\mathrm{Al}_{2} \mathrm{O}_{3}$ films grown in alkaline electrolytes. J. Electrochem. Soc., v. 120, p. 479-484, 1973.

38. MASUDA, H.; MIZUNO, T.; BABA, N.; OHMORI, T. Fabrication of Pt microporous electrodes from anodic porous alumina and immobilization of GOD into their micropores. $\boldsymbol{J}$. Eletroanal. Chem., v. 368, n. 1/2, p. 333-336, 1994.

39. GRUBERGER, J.; GILEADI, E. Plating on anodized aluminum - I. The mechanism of charge transfer across the barrier-layer oxide film on 1100 aluminum. Electrochim. Acta, v. 31, n.12, p. 1531-1540, 1986.

40. COLOMBINI, C.; MADEYA, K. Pulse rectifier: anodizing and electroplating wit economic advantages. Metalloberlache, v. 47, n. 9, p. 444-447, 1993.

41. COLONBINI, C. Application of pulse dc power for aluminium anodizing. Alluminio Magazine, n. 9/10, p. 35-37, 1989.

42. COLOMBINI, C. The use of pulse rectifiers for anodizing. Finishing, v.14, n.2, p. 44-46, 1990.

43. NARASIMHAN, V.L.; VINCENT, S.; KANAGARAJ, D. The influence of superimposing varying ratios of pulse current over direct current on hard anodizing of aluminium. International Symposium on Industrial Metal Finishing, Karaikudi, India, 1-5 Fevereiro, 159-161, 1989.

44. YOKOYAMA, K.; KONNO, H.; TAKAHASHI, H.; NAGAYAMA, M. Advantages of pulse anodizing. Plating Surf. Finish., p. 62-65, July, 1982.

45. MEI, Y.F.; HUANG, G.S.; LI, Z.M.; SIU, G.G.; RICKY, K.Y. FU; YANG, Y.M.; WU, X.L., TANG, Z.K., CHU, P.K. Formation of Si-based nano-island array on porous anodic alumina. Acta Materialia, v. 52, p. 5633-5637, 2004. 
46. JAGMINAS, A.; LICHUSINA, S.; KURTINAITIENE, M.; SELSKIS, A. Concentration effect of the solutions for alumina template AC filling by metal arrays. Appl. Surf. Sci., v. 211, n. 1/4, p. 194-202, 2003.

47. SUH, J.S.; LEE, J.S., KIM, H. Linearly joined carbon nanotubes. Synthetic Metals, v. 123, n. 3, p. 381-383, 2001.

48. ROCCO, M.C. Reviews of national research programs in nanoparticle and nanotechnology research. Nanoparticle and nanotechnology research in the U.S.A. J. Aerosol. Sci., v.29, n.5/6, p. 749-760, 1998.

49. TACCONI, N.R.; RAJESHWAR, K. Semiconductor nanostructures in na alumina template matrix: micro- versus macro-scale photoelectrochemical behavior. Electrochim. Acta, v. 47, n. 16, p. 2603-2613, 2002.

50. ZAGIEL, A.; NATISHAN, P.; GILEADI, E. Plating on anodized aluminum-II. The effect of the metal, the anion and the aluminum alloy. Electrochim. Acta, v. 35, n. 6, 1019-1030, 1990.

51. YA. I. Alexandrov. Electrokhimiya v. 12, p. 350, 1976.

52. HABAZAKI, H; ZHOU, X.; SHIMIZU, K.; SKELDON, P.; THOMPSON, G.E.; WOOD, G.C. Incorporation and mobility of zinc íons in anodic alumina films. Thin Solid Films, v. 292, p. 150-155, 1997.

53. PALIBRODA, E. Le mechanisme du developpement de l'oxyde poreux d'aluminium - I. Sur la possibilite du contact direct aluminium-solution electrolytique au cours du processus de formation - transformation de la couche barriere. Electrochim. Acta, v. 28, p. 1185-1190, 1983.

54. MARTIN, C.R.; PARTHASARATHY, R.; MENON, V. Template synthesis of electronically conductive polymers - preparation of thin films. Electrochim. Acta, v.39, n. 8/9, p. 1309-1313, 1994.

55. SEREBRENNIKOVA, P.; VANÝSEK, V.; BIRSS, I. Characterization of porous aluminum oxide films by metal electrodeposition. Electrochim. Acta, v. 42, n. 1, p. 145-151, 1997.

56. VAROL, H.S.; HINSCH, A. $\mathrm{SnO}_{2}$ : $\mathrm{Sb}$ dip coated films on anodized aluminum selective absorber plates. Solar Energy Materials and Solar Cells, v. 40, n. 3, p. 273-283, 1996.

57. BETHENCOURT, M.; BOTANA, F.J.; CALVINO, J.; MARCOS, M.; RODRIGUEZCHACÓN, M.A. Lanthanide compoundss as envirommentally friendly corrosion inhibitors of aluminium alloys a review. Corros. Sci., v. 40, n. 11, p. 1803-1819, 1998.

58. PONTIFEX, G. H.; ZHANG, P.; WANG, Z.; HASLETT, L.; ALMAWLAWI, D.M.; MOSKOVITS, M., STM Imaging of the Surface of Metal Particles Formed in Anodic Oxide Pores, J. Phys. Chem., v. 95, p. 9989-9993, 1991. 
59. UOSAKI, K.; OKAZAKI, K.; KITA, H. Preparative method for fabricating microelectrode ensemble: Electrochemical response of microporous aluminum anodic oxide film modified gold electrode. Anal. Chem., v. 62, p. 652-656, 1990.

60. AOKI, C.S.C.; FREIRE, C.M.A; BALLESTER, M. Pulsed current Ni-P coatings, Iberomat, 1998.

61. PUIPPE, J.C. Pulse plating versus d.c. plating, in: $3^{\text {rd }}$ International Pulse Plating Simposium, 1986, Washington, proc., Washington:AESF, p. 1-14, 1986.

62. PERGER, G. Pulse plating - retrospect's and prospect, Metal Finishing, v. 77, p. 17-19, 1979.

63. OSERO, N.M. An overview of pulse plating, http://dynatronix.com/overview.htm, 1999.

64. FREIRE, C. M. A. ; AOKI, C. S. C. ; BALLESTER, Margarita . Eletrodeposição de Revestimentos de Liga Zn-Ni. In: Interfinish Latino-Americano - EBRATS 1997 - Anais em CD-ROM, 1997, São Paulo. Interfinish Latino-Americano. São Paulo - Brasil, 1997

65. FREIRE, C.M.A., BALLESTE, M. Eletrodeposição por corrente pulsada. Tratamento de Superfície, v. set./out., p. 30-36, 1998.

66. MOUTARLIER, V.; GIGANDET, M.P., PAGETTI, J. Characterisation of pitting corrosion in sealed anodic films formed in sulphuric, sulphuric/molybdate and chromic media, Appl. Surf. Sci., v. 206, n. 1/4, p. 237-249, 2003.

67. ZUO, Y.; ZHAO, P-H.; ZHAO, J-M. The influences of sealing methods on corrosion behavior of anodized aluminum alloys in $\mathrm{NaCl}$ solutions, Surf. Coat. Technol., v. 166, n. 2/3, p. 237$242,2003$.

68. MELO, H.G.; PALOMINO, M.L.E.; CASTRO, J.F.W.; AOKI, I.V. Comparação do comportamento de impedância da liga Al 2024-T3 com camada de conversão de cério e amostras industriais com camada anodizada em solução crômica. In: XIV Simpósio Brasileiro de Eletroquímica e Eletroanalítica, 2004, Teresópolis.

69. HINTON, B.R.W.; ARNT, D.R.; RYAN, N.E. The inhinition of aluminium alloy corrosion by cerous cations. Metals Fórum, v. 7, n. 4, p. 211-217, 1984.

70. MONTEMOR, F.; SIMÕES, A.M.; FERREIRA, M.G.S. Composition and Behaviour of Cerium Films on Galvanised Steel. Progress in Organic Coatings, v. 43, n. 4, p. 274-281, 2001.

71. MONTEMOR, F.; SIMÕES, A.M.; FERREIRA, M.G.S. Composition and corrosion behaviour of galvanised steel treated with rare-earth salts: the effect of the cation. Progress in organic Coatings, v. 44, p. 111-120, 2002.

72. LI, F-B. NEWMAN, R.C., THOMPSON, G.E. In situ atomic force microscopy studies of electrode position mechanism of cerium oxide films: nucleation and growth out of a gel mass precursor. Electrochimica Acta, v. 42, n. 16, p. 2455-2464, 1997. 
73. AZEVEDO, W.M.; CARVALHO, D.D.; KHOURY, H.J.; VASCONCELOS, E.A.; SILVA, E.F. Spectroscopic characteristics of doped nanoporous aluminum oxide. Mat Sci. And Engineering, v. 112, p. 171-174, 2004.

74. YU, X.; YAN, C.; CAO, C. J. Study on the rare earth sealing procedure of the porous film of anodized 2024 aluminum alloy. Mat Sci. Technol., v. 19, n. 1, p. 51-53, 2003.

75. BALASUBRAMANIAN, M.; MELENDRES, C.A.; MANSOUR, A.N. An x-ray absorption study of the local structure of cerium in eletrocchemically deposited thin films. Thin Solid Films, v. 347, n.1/2, p. 178-183, 1999.

76. QIANG-LI, G.; LI, D.; GUO, B.L.; PENG, M.X. The investigation of formation reactions for cerium conversion coatings deposited on porous film $\mathrm{f}$ anodized aluminium under cathodic polarization. Materials Forum, v. 28, p. 1282-1289, 2004.

77. BeTHENCOURT, M.; BOtANA, F.J.; CANO, M.J., MARCOS, M. High protective, environmental friendly and short-time developed conversion coatings for aluminium alloys. Appl. Surf. Sci., v. 189, n. 1/2, p. 162-173, 2002.

78. ARENAS, M.A.; DAMBORENEA, J. J. Growth Mechanisms of Cerium Layers on Galvanised Steel. Electrochimica Acta, v. 48, p. 3693-3698, 2003.

79. PALOMINO, L.E.M.; CASTRO, J.F.W.; AOKI, I.V.; MELO, H.G. Microstructural and electrochemical characterization of environmentally friendly conversion layers on aluminium alloys. J. Braz. Chem. Soc., v.14, n.4, p. 651-659, 2003.

80. RIVERA, B.F.; JOHNSON, B.Y.; O'KEEFE, M.J.; FAHRENHOLTZ, W.G. Deposition and characterization of cerium oxide conversion coatings on aluminum alloy 7075-T6. Surf. Coat. Technol., v. 176, n. 3, p. 349-356, 2004.

81. MANSFELD, F.; PEREZ, F.J. Surface modification of aluminum alloys in molten salts containing $\mathrm{CeCl}_{3}$. Thin Solid Films, v. 270, n. 1/2, p. 417-421, 1995.

82. DAVENPORT, A.J.; ISAACS, H.S.; KENDIG, M.W. X-ray absorption study of cerium in the passive film on aluminum. J. Electrochem. Soc., v. 136, n. 6, p. 1873-1838, 1989.

83. YU, X.; CAO, C. Electrochemical study of the corrosion behavior of Ce sealing on anodized 2024 aluminum alloy, Thin Solid Films, v. 423, n.2, p. 252-256, 2003.

84. YU, X.; LI, G. XPS study of cerium conversion coating on the anodized 2-24 aluminum alloy. J. of Alloys and Compunds, v. 364, n. 1/2, p. 193-198, 2004.

85. CAMPESTRINI, P.; TERRYN, H.; HOVESTAD, A; WIT, J.H.W. Formation of cerium-based conversion coating on AA2024: relationship with the microstructure. Surf. Coat. Tech., v. 176, n. 3 P. 365-81, 2004. 
86. ARNOTT, D.R.; HINTON, B.R.W.; RYAN, N.E.; SEXTON, B.A.; HUGHES, A.R. Auger and XPS studies of cerium corrosion inhibition on 7075 aluminium alloy. Application of Surface Science, v. 22-23, parte 1 p. 236-51, 1985.

87. ALDYKIEWICZ, A.J.; DAVENORT, A.J.; ISAACS, H.S. Studies of the formation of ceriumrich protective films using X-ray absorption near-edge spectroscopy and rotating disk electrode methods. J. Electrochemical Society, v. 143, p. 147-154, 1996.

88. HUGHES, e.; HARDIN, S. D.; WITTEL K. W.; MILLER, P. R. Accelerated cerium based conversion coating. In: SYMPOSIUM SURFACE CONVERSION OF ALUMINIUM AND ALUMINIUM ALLOYS FOR CORROSION PROTECTION, Orlando, 2000. Proceedings of the NACE Meeting Corrosion 2000.

89. HINTON, B.R.W.; WILSON, L. A method of forming a corrosion resistant coating. Int. Cl.4 C23C 22/48. WO 88/06639. September 7, 1988.

90. PUIPPE, J-C; LEAMAN, F. Theory and practice of pulse plating. Orlando, Florida, American Electroplaters and Surface Finishes Society, 1968.

91. ETT, G. Estudo eletroquímico da co-redução de $\mathrm{KBF}_{4}$ e $\mathrm{K}_{2} \mathrm{TiF}_{6}$ em meio de uma mistura eutética de LiF-NaF-KF para a obtenção do diboreto de titânio. 1999. Tese (doutorado) Instituto de Pesquisas Energéticas e Nucleares, São Paulo.

92. PADILHA, A.F.; AMBROZIO, F.F. Técnicas de análise microestrutural. Hemus, São Paulo, 1985.

93. WOLYNEC, S. Técnicas Eletroquímicas em Corrosão. Ed. Universidade de São Paulo, São Paulo, 2003.

94. MACDONALD, J.R. Impedance Spectroscopy: emphazing solid materials and systems. John Wiley, New York, 1987.

95. TERTIAN, R.; CLAISSE, F. Principles of quantitative $\boldsymbol{X}$-ray fluorescence analysis. Heyden, London, 1982.

96. CHIU, R.-L.; CHANG, P.-H.; TUNG, C.-h. The effect of anodizing temperature on anodic oxide formed on pure Al thin films. Thin Solid Films, v. 260, n. 1, p. 47-53, 1995.

97. VILLANOVA, R.L.; DICK, L.F.P. Influência de parâmetros de processo de anodização na morfologia do óxido formado em ligas de alumínio AA 2024-T3. In: XIV SIBEE, Simpósio Brasileiro de Eletroquímica e Eletroanalítica, 2004 - Teresópolis - RJ. CD de resumos do XIV SIBEE, 2004.

98. JUHL, A.D. The structure and properties of the oxide layer formed by different pulse anodizing. Extrufinishing, p. 43-46, december, 1999. 
99. KANAGARAJ, D.; VINCENT, S.; NAGASIMHAN, V.L. Advantages of pulse anodizing of aluminium alloys. International Simposium on Industrial Metal Finishing, Karaikudi, India, 1-5, Fevereiro, p. 163-165, 1989.

100. WU, H.; ZHANG, X.; HERBERT, K.R. Atomic force microscopy study of the initial stages of anodic oxidation of aluminum in phosphoric acid solution. J. Electrochem. Soc., v. 147, n. 6, p. 2126-2132, 2000.

101. PATERMARAKIS, G.; CHANDRINOS, J.; MOUSSOUTZANIS, K. Interface physicochemical processes controlling sulphate anion incorporation in porous anodic alumina and their dependence on the thermodynamic and transport properties of cations. J. Electroanal. Chem., v. 510, n. 1/2, p. 59-66, 2001.

102. PATERMARAKIS, G.; MOUSSOUTZANIS, K. Solid surface and field catalysed interface formation of colloidal $\mathrm{Al}_{2}\left(\mathrm{SO}_{4}\right)_{3}$ during $\mathrm{Al}$ anodizing affecting the kinetics and mechanism of development and structure of porous oxides. J. Solid State Electrochem., v. 6, p. 475-484, 2002.

103. THOMPSON, G.E. Porous anodic alumina: fabrication, characterization and applications. Thin Solid Films, v. 297, n. 1/2, p. 192-201, 1997.

104. VRUBLEVSKY, I.; PARKOUN, V.; SCHRECKENBACH, J. Analysis of porous oxide film growth on aluminum in phosphoric acid using re-anodizing technique. Appl. Surf. Sci., v. 242, n. 3/4, p. 333-338, 2005.

105. SHARMA, A.K.; BHOJRAJ, H.; NARAYANAMURTHY, H.; PATKI, A.V. Hard anodizing behaviou of aluminum alloy DTD 5124 containing varying amounts of impurities under different electrolytic conditions, Plating Surf. Finish., p. 55, July 1998.

106. CHENG, R.B.; HAO, L. Comparative study of the effects of sealing processes on the wear resistance and sealing quality of hard anodic coatings, Metal Finishing, v. 98, n. 5, p. 48-55, 2000.

107. ZECH, N.; LANDOLT, D. The influence of boric acid and sulfate ions on the hydrogen formation in Ni---Fe plating electrolytes. Electrochimica Acta, v. 45, n. 21, p. 3461-3471, 2000 .

108. M. MATLOZ, J. Competitive adsorption effects in the electrodeposition of iron-nickel alloys. J. Electrochem. Soc., v.140, n. 8, p. 2272-2279, 1993.

109. HORKANS, J. Effect of plating parameters on electrodeposited NiFe. J. Electrochem. Soc., v. 128, n. 1, p. 45-49, 1981.

110. KIELING, V. C. Parameters influencing the electrodeposition of Ni-Fe alloys. Surf. Coat. Tech., v. 96, n. 2/3, p. 135-139, 1997. 
111. JENSEN, J.D.; GABE, D. R.; WILCOX, G.D. The practical realisation of zinc-iron CMA coatings. Surf. Coat. Tech., v. 105, n. 3, p. 240-250, 1998.

114. GE, F.Y.; XU, S.K.; YAO, S.B.; SHOU, S.M. Study of the structures of pulse plating Zn-Fe deposits. Surf. Coat. Tech. v. 88, n.1/3, p. 1-4, 1996.

112. TRUDEAU, M.L. Nanocrystalline Fe and Fe-riched Fe-Ni through electrodeposition. Nanostructured Materials, v.12, n.1/4, p. 55-60, 1999.

113. LALLEMAND, F.; RICQ, L.; DESCHASEAUX, E.; VETTOR, L.; BERÇOT, P. Electrodeposition of cobalt-iron alloys in pulsed current from electrolytes containing organic additives. Surf. Coat. Techn., v. 197, n.1, p. 10-17, 2005.

115. MELLOR, J.W. Química Inorgânica Moderna, 2 ed. Porto Alegre, R.S: Globo, 1952. England.: Robert Drapper Ltda., 1972. 


\section{CURRICULUM VITAE}

Nome: Kellie Provazi de Souza

Endereço: Rua Bernardo Teles, 27 - Jd. Raposo Tavares - São Paulo - SP

CEP : 05551-210

Telefones: (11) 3785-5263 e (11) 7168-8166

e-mail: kkppss@zipmail.com.br

Nascimento: 01/10/1975

Educação Universitária

2001 - 2006: $\quad$ Doutorado em Ciências - Tecnologia Nuclear de Materiais

Instituto de Pesquisas Energéticas e Nucleares

Universidade de São Paulo, São Paulo (SP)

Título da Tese: A Influência do Ferro e do Óxido de Cério na Condutividade Elétrica e Resistência à Corrosão do Alumínio Anodizado

1999 - 2001: $\quad$ Mestre em Físico-Química

Instituto de Química

Universidade de São Paulo, São Paulo (SP)

Título da Dissertação: Estudo Espectroeletroquímico do Efeito de

Aditivos Sobre as Reações do Eletrodo de Hidróxido de Níquel

1995 - 1998: $\quad$ Formada em Química Industrial

Escola Superior de Química

Faculdades “Oswaldo Cruz”, São Paulo (SP)

\section{Ensino Médio}

1991 - 1994: $\quad$ Técnico Magistério

CEFAM - Centro de Formação e Aperfeiçoamento de Alunos no Magistério

E. E. P. S. G. São Paulo da Cruz, Osasco (SP) 


\section{Experiência Profissional}

maio 2006 - atual

dezembro 2001 - maio 2006

fevereiro 1999 - junho 2001

maio 1998 - janeiro 1999

julho 1997 - abril 1998

novembro 1995 - fevereiro 1997

\section{Doces Michele Ltda}

Química Responsável - contrato como autônoma

Instituto de Pesquisas Energéticas e Nucleares

Universidade de São Paulo

Doutorado em Ciências

Área: Tecnologia Nuclear de Materiais

Instituto de Química

Universidade de São Paulo

Mestrado em Ciências

Área: Físico-Química

\section{Instituto de Química}

Universidade de São Paulo

Estágio em Iniciação Científica

Título do trabalho: "Preparação e Caracterização de Sais de $C_{60}$ por Intercalação Eletroquímica em Meio Aquoso"

\section{Instituto de Ciências Biomédicas}

Universidade de São Paulo

Função - Técnico de Laboratório

INDENE - Projetos e Sistemas de Segurança Ltda.

Função - Auxiliar de Escritório 


\section{Artigos de Periódicos Internacionais}

PROVAZI, K.; E. J. PESSINE. Incorporation of iron by pulsed and continuous current electrodeposition on anodized aluminum - effect of duration of electrodeposition and electrolyte additives. Surface and Coatings Technology. Em submissão. 2006.

PROVAZI, K.; DALL'ANTONIA, L. H.; GIZ, M. J.; de TORRESI, S. I. C. The effect of Co, $\mathrm{Cd}$ and $\mathrm{Zn}$ as additives of nichekl hydroxide electrode on its opto-Electrochemical behaviour.. Journal of Power Sources, v. 102, p. 224-232, 2001. Referências adicionais: Estados Unidos/Inglês; Meio de divulgação: Impresso; ISSN/ISBN: 03787753.

PROVAZI, K.; MALTA, M.; TORRESI, Roberto M.; de TORRESI, S. I. C. The effect of additives in the stabilization of alpha phase in $\mathrm{Ni}(\mathrm{OH})_{2}$ electrodes. Journal of Electrochemical Society, v. 148, n. 10, p. A1179-A1184, 2001. Referências adicionais: Estados Unidos/Inglês; Meio de divulgação: Impresso; ISSN/ISBN: 00134651.

PROVAZI, K.; CORIO, P.; de TORRESI, S. I. C. Raman Characterization of C60 salts electroformed in aqueous solutions. Electrochemistry Communications, v. 2, n. 8, p. 547-551, 2000. Referências adicionais: Inglaterra/Inglês; Meio de divulgação: Impresso.

\section{Trabalhos de eventos}

PROVAZI, K.; PESSINE, E. J. Preparação de matriz de filme anódico de alumínio para fabricação da nanomateriais, XII Encontro e Exposição Brasileira de Tratamentos de Superfície, 2006, São Paulo, 2006. Referências adicionais: Classificação do evento: Nacional; Brasil/ Português; Meio de divulgação: Digital.

PROVAZI, K.; SATO, I. M.; SALVADOR, V. L. R.; PESSINE, E. J. A implantação de ferro por eletrodeposição no filme de $\mathrm{Al}_{2} \mathrm{O}_{3}$ crescido por anodização, In: XVI Congresso Brasileiro de Engenharia e Ciência dos Materiais, 2004, Porto Alegre, 2004. Referências adicionais: Classificação do evento: Nacional; Brasil/ Português; Meio de divulgação: Digital.

PROVAZI, K.; PESSINE, E. J. A influência de algumas condições experimentais na qualidade do filme de $\mathrm{Al}_{2} \mathrm{O}_{3}$ formado por anodização. In: XIV SIBEE, 2004, Teresópolis, 2004. Referências adicionais: Classificação do evento: Nacional; Brasil/ Português; Meio de divulgação: Digital. 
SOUZA, K. P.; de TORRESI, S. I. C. Efeito de diferentes aditivos na modificação das propriedades ópticas de eletrodos de $\mathrm{Ni}(\mathrm{OH})_{2}$. In: XI SIBEE, 1999, Maragogi, 1999. Referências adicionais: Classificação do evento: Nacional; Brasil/ Português; Meio de divulgação: Impresso.

SOUZA, K. P.; TORRESI, R M ; MALTA, M.; de TORRESI, S. I. C. Estudo por microbalança cristal de quartzo do efeito de aditivos sobre as reações do eletrodo de hidróxido de níquel. In: XII Simposio Brasileiro de eletroquimica e Eletroanalítica, 2001, Gramado, RS, 2001. p. 475-477. Referências adicionais: Classificação do evento: Nacional; Brasil/ Português; Meio de divulgação: Digital.

SOUZA, K. P.; de TORRESI, S. I. C.; CORIO, P. Raman Characterization of C60 salts electroformed in Aqueous media. In: 50 Meeting of the International Society of Electrochemistry, 1999, Pavia, 1999. Referências adicionais: Classificação do evento: Internacional; Itália/ Inglês; Meio de divulgação: Impresso.

\section{Trabalho de eventos - Resumos}

PROVAZI, K.; PESSINE, E. J.A influência de pós-tratamentos na resistência à corrosão do alumínio anodizado. In: LATINCORR 2006, Fortaleza, 2006. Referências adicionais: Classificação do evento: Nacional; Brasil/ Português; Meio de divulgação: Digital.

PROVAZI, K.; PESSINE, E. J. A influência das condições experimentais na qualidade do filme de $\mathrm{Al}_{2} \mathrm{O}_{3}$ formado por anodização. In: 26 Reunião Anual da Sociedade Brasileira de Química, 2003, Poços de Caldas, 2003. Referências adicionais: Classificação do evento: Nacional; Brasil/ Português; Meio de divulgação: Impresso.

PROVAZI, K; de TORRESI, S. I. C. Estudo por espectroscopia Raman do efeito de aditivos sobre as reações do eletrodo de hidróxido de níquel. In: 24 Reunião Anual da Sociedade Brasileira de Química, 2001, Poços de Caldas, 2001. p. EQ034. Referências adicionais: Classificação do evento: Nacional; Brasil/ Português; Meio de divulgação: Impresso.

PROVAZI, K.; GIZ, M. J.; de TORRESI, S. C. Estudo Espectroeletroquímico do Efeito de Aditivos Sobre as Reações do Eletrodo de Hidróxido de Níquel. In: 23 Reunião Anual da Sociedade Brasileira de Química, 2000, Poços de Caldas, 2000. Referências adicionais: Classificação do evento: Nacional; Brasil/ Português; Meio de divulgação: Impresso. 
PROVAZI, K.; TORRESI, R. M. ; MALTA, M.; de TORRESI, S. I. C. Electrochemical and eletrogravimetric study of the effect of additives on nickel hydroxide electrodes. In: 51st ISE Meeting, 2000, Varsovia, 2000. Referências adicionais: Classificação do evento: Internacional; Polônia/ Inglês; Meio de divulgação: Impresso

SOUZA, K. P.; CORIO, P.; de TORRESI, S. I. C. Caracterização espectroeletroquimica de sais de $\mathrm{C}_{60}$ por intercalação eletroquimica em meio aquoso. In: 21 Reuniao Anual da SBQ, 1998, Poços de Caldas, 1998. Referências adicionais: Classificação do evento: Nacional; Brasil/ Português; Meio de divulgação: Impresso

\section{Outras Participações em Congressos e Workshops}

Participação como congressista no EBRATS 2003 - XI Encontro e Exposição Brasileira de Tratamentos de Superfície organizado pela Associação Brasileira de Tratamentos de Superfície, realizado no período de 12 a 15 de maio de 2003 no ITM Expo, São Paulo - Brasil.

Participação no $1^{\mathrm{o}}$ Mini-Workshop de Baterias Primárias e Secundárias Modernas Instituto de Química /USP - São Carlos - SP, 31 de março de 2000.

\section{Cursos Extracurriculares}

\section{USP - Universidade de São Paulo}

CIC / USP / IBECC

Centro Interdisciplinar de Ciências

"Curso de Apoio à Formação Científica ao Aluno do Magistério"

Duração: 24 horas

\section{Faculdades Oswaldo Cruz}

Participação como estudante-expositor no projeto "O Meio Ambiente de São Paulo de Todos Nós"

Período: 02 a 05 de junho de 1997 


\section{USP - Universidade de São Paulo}

"Reduzindo o Volume de Substâncias Descartáveis em Laboratório"

Prof. Dr. Peter Wilhelm Tiedemann

QFL - IQUSP

Duração: 4 horas

\section{Mini-curso ministrado na $23^{\mathrm{a}}$ Reunião Anual da Sociedade Brasileira de Química}

"Corrosão Metálica: Potencialidades e Aplicações de Técnicas Eletroquímicas e Nãoeletroquímicas"

Duração: 6 horas

Experiência em análises químicas, físicas e eletroquímicas, e operação de equipamentos

- Espectroscopia Raman

- Espectrometria de Absorção Atômica

- Espectroscopia de Impedância Eletroquímica

- Espectrofotometria

- Microscopia Ótica com Analisador de Imagem

- Microscopia Eletrônica de Varredura

- Microscopia de Força Atômica

- Tratamento Metalográfico

- Potenciostato/Galvanostato

- Retificador de Corrente Contínua e Corrente Pulsada

- Microdurômetro

- Microbalança à Cristal de Quartzo

\section{Idiomas}

- INGLÊS Boa leitura e escrita de artigos técnicos

- ESPANHOL Boa leitura 


\section{Informática}

Conhecimento como usuário:

- Windows

- Processador de Texto: Microsoft Word

- Programa de Cálculo: Excel

- Internet

- Outlook

- Programa de cálculos e gráficos: Microsoft Origin

- Programas de análise eletroquímica: Echem, CorrWare, Zplot

\section{Bolsas de Estudo}

Bolsa de Mestrado com dedicação exclusiva no período vigente da bolsa, pela Fundação de Amparo à Pesquisa do Estado de São Paulo (FAPESP), 1999 - 2001.

Bolsa de Doutorado com dedicação exclusiva no período vigente da bolsa, pela Coordenação de Aperfeiçoamento de Pessoal de Nível Superior (CAPES), 2001 - 2005. 